\title{
A Multi-Criteria Decision Support System for the Selection of Low-Cost Green Building Materials and Components
}

\author{
Junli Yang, Ibuchim Cyril B. Ogunkah* \\ Department of Construction, School of Architecture and the Built Environment, University of Westminster, London, UK. \\ *Corresponding author: cyrilguchi@ymail.com
}

Received September $18^{\text {th }}, 2013$; revised October $25^{\text {th }}, 2013$; accepted November $4^{\text {th }}, 2013$

Copyright (C) 2013 Junli Yang, Ibuchim Cyril B. Ogunkah. This is an open access article distributed under the Creative Commons Attribution License, which permits unrestricted use, distribution, and reproduction in any medium, provided the original work is properly cited. In accordance of the Creative Commons Attribution License all Copyrights (C) 2013 are reserved for SCIRP and the owner of the intellectual property Junli Yang, Ibuchim Cyril B. Ogunkah. All Copyright (C 2013 are guarded by law and by SCIRP as a guardian.

\begin{abstract}
The necessity of having an effective computer-aided decision support system in the housing construction industry is rapidly growing alongside the demand for green buildings and green building products. Identifying and defining financially viable low-cost green building materials and components, just like selecting them, is a crucial exercise in subjectivity. With so many variables to consider, the task of evaluating such products can be complex and discouraging. Moreover, the existing mode for selecting and managing, often very large information associated with their impacts constrains decision-makers to perform a trade-off analysis that does not necessarily guarantee the most environmentally preferable material. This paper introduces the development of a multi-criteria decision support system (DSS) aimed at improving the understanding of the principles of best practices associated with the impacts of low-cost green building materials and components. The DSS presented in this paper is to provide designers with useful and explicit information that will aid informed decision-making in their choice of materials for low-cost green residential housing projects. The prototype MSDSS is developed using macro-in-excel, which is a fairly recent database management technique used for integrating data from multiple, often very large databases and other information sources. This model consists of a database to store different types of low-cost green materials with their corresponding attributes and performance characteristics. The DSS design is illustrated with particular emphasis on the development of the material selection data schema, and application of the Analytical Hierarchy Process (AHP) concept to a material selection problem. Details of the MSDSS model are also discussed including workflow of the data evaluation process. The prototype model has been developed with inputs elicited from domain experts and extensive literature review, and refined with feedback obtained from selected expert builder and developer companies. This paper further demonstrates the application of the prototype MSDSS for selecting the most appropriate low-cost green building material from among a list of several available options, and finally concludes the study with the associated potential benefits of the model to research and practice.
\end{abstract}

Keywords: Analytical Hierarchy Process (AHP); Decision Support System (DSS); Low-Cost Green Building Materials; Decision Analysis; Material Selection Factors

\section{Introduction}

As the green building movement begins to sweep through the housing construction industry, the application of cost effective and energy efficient building materials has become necessary in today's demanding economic market $[1,2]$. Recent discussions on the need to lower the growing demand for conventional sources of energy have highlighted the value of using low-cost green building materials and components, given their lower cost and energy requirements [3,4]. Evidence from previous studies has proven that implementing such products in construction has the potential to not only reduce health and environmental effects, but to also bring savings from energy, maintenance, and operational costs [5-9]. Yet, research has consistently shown that the patronage for such materials in housing construction is still at a very low level in comparison to many other conventional building materials $[8,9]$. Recent studies $[10,11]$ 
argue that several attempts to adopt low-cost green building materials for housing design projects have generally been viewed as challenging, given that most designers are vaguely informed about the full life-cycle impacts of such products. They note that information relating to the impacts of such building materials in the housing construction sector appears to be less available, as evidence $[11,12]$ indicates that only a small proportion of design and building professionals seem to have sufficient knowledge that could allow effective decisionmaking. Ashraf [11] and Zhou et al. [12,13] suggest that maximizing their potential use in the housing industry requires seamless access to appropriate informed information and full understanding of the various options available, so as to inform decision trade-offs at the design stage.

Despite the availability of accurate and reliable data, Seyfang [14] and Malanca [15] however, noted that most designers are found to make decisions regarding the selection of such materials on the basis of their past experience. They observed that inexperienced designers generally engage the traditional mode of selection, by relying on subjective individual perceptions of values and priorities in the material selection process, which rather than facilitate or drive their design ideas, appear to do the opposite thereby limiting creativity and sometimes resulting in considerable frustration $[16,17]$.

Trusty [18-21] \& Woolley [22] further disclosed that existing databases on such materials and their formats are not designed to efficiently and directly provide such information to decision makers. They note that the available data on such materials are normally in the read-only format, and are stored in various operational databases that are not easily accessible to decision makers in usable forms and formats. As a result, decision-making failures during the planning and design stage(s) of low-cost green housing projects hinder their use in terms of their industrial capacity utilisation in the housing industry.

While several studies $[14,15,20]$ have emphasized the relative importance of information access in aiding well-considered and justifiable material choices during the early stages of the design process, Wastiels et al. [16] argue that the existing material selection method focuses mainly on limited aspects of such materials, in terms of their properties and factors that influence the decisionmaking process. Quinones [17] asserted that some lowcost green building materials, for example, contain high embodied energy that leads to ecological toxicity and fossil fuel depletion impacts during their manufacturing phase. She argued that ignoring the relevant factors or properties of any of such materials during the crucial material selection phase could reduce the effective life of that product to less than half of its normal effective life span.
Moreover, Seyfang [14] and Trusty [18-22] argue that choosing the right materials for a particular project can be a very complex decision-making task, given that the selection process is influenced and determined by numerous preconditions, decisions and considerations. They suggested the idea of a decision support system (DSS) as a useful aid in making quick and critical decisions during crucial material selection process. They stressed that the considered approach to encourage the wider scale use of low-cost green building materials in mainstream housing should enable design professionals to have easy access to adequate information on the available options, hence, making the selection results more reasonable and bringing more standardization to the material selection decision-making process at the design stage. They went on advising that whatever method is employed must be such that it allows comparison of not only the cost or technical performance of such materials, but also able to take into account several decision-making criteria, so as to derive conclusive and valid evidence of the differing impacts of various material alternatives.

While there seem to be no compelling evidence of technical research on a holistic approach used by design professionals for the evaluation and selection of building materials, previous material assessment models such as the Leadership in Energy and Environmental Design (LEED) and Building Research Establishment Environmental Assessment Methods (BREEAM), have shown great promise for guiding evaluations of material predictor performance [23]. The findings of the main research study yet, criticised and noted the flawed existing support systems for being partially objective and fraught with problems of fairness [24]. The study revealed that existing methods are found wanting in that they are culturally implicit, and that such methods or tools treat the sustainability [of the] wider built environment as simply a matter of energy and mass flows with little or no regard to the socio-economic, technical, emotive and political dimensions of sustainability [24]. It further revealed that individual country teams establish scoring weights subjectively when evaluating building products, which often pose problems when applied to other regions [25,26]. The analysis of the study however, showed little evidence to justify the assumption that there are tools of demonstrable reliability for designers to assess the sustainability and suitability of such materials or products or their applicability and utility for their potential use in the design of low-cost green housing projects. Hence, a more reliable method is needed to aid design and building professionals in the selection of such building materials and components for low-cost green residential housing projects.

Consequently, to promote more informed decisionmaking in the selection of low-cost green materials both 
individually and as assembled building components, a Decision Support System (DSS) is presented in this paper as an aid to design and building professionals. The objective of this study is to support decision-makers in selecting low-cost green building products that are environmentally, socio-culturally, technically and economically balanced through a proposed conceptual system. The model is to facilitate the integration of more sustainable materials into future designs by helping designers quantify how they compare to materials already permitted under existing codes, using the concept of the Analytical Hierarchy Process (AHP). The AHP approach is designed to be practical, as it combines environmental, technical, socio-cultural and economic performance into a single performance value that is easily interpreted.

In the following sections, the reviews of existing technological approaches are summarised and the main findings and themes to emerge from the literature review and the fieldwork seminars and interviews are reported. Then a step-by-step methodology is presented to illustrate the different stages of the DSS model development. Finally, the application of the prototype DSS for selecting appropriate floor material for a residential project in the London Borough of Sutton is demonstrated. The final section concludes the study and suggests areas for further research.

\section{Technology in Material Selection: Review}

For the past ten years, proven and commercialized technologies have been developed to promote environmental awareness amongst built environment professionals $[18,22,23]$. Empirical research validates that various studies on building material selection support systems have developed in size and specification within the last ten years [24-26]. Castro-Lacouture et al. [26] note that the application of green building support/assessment tools has been widely accepted as an effective and useful way of promoting green housing construction in the housing construction industry. Keysar and Pearce [27] and Bayer et al. [28] however, argue that the contexts in which building environmental assessment methods now operate, and the roles that they are increasingly playing, are qualitatively different than earlier expectations. They note that material assessment tools are now classified based on the type of analysis they perform, such as product, assembly, or whole building analysis, or classified as region-specific tools, either considered based on the life-cycle phases they cover, or on the required skills necessary to operate the tool.

While there is clearly an urgent need for new technologies to optimise the use of low-cost green building materials, it is also true that there are many technologies or systems already in use [25-28]. The first real attempt to establish a comprehensive means of simultaneously assessing a broad range of environmental considerations in building materials was the Building Research Establishment Environmental Assessment Method (BREEAM) [28]. The BREEAM tool assesses the environmental impacts of over 150 various materials and components most commonly used in home construction. The tool takes environmental issues into account, then adds measurements and user-defined weighting to arrive at environmental impacts, measured as "Eco-points" for each building material being assessed. Twelve different environmental impacts are individually scored, together with an overall summary rating, which enables users to select materials and components according to overall environmental performance over the life of the building. This scientifically accepted program however, focuses only on the environmental performance of products rather than environmental, social and financial considerations going hand in hand as parts of the material evaluation and selection process.

With emphasis on the Leadership in Energy and Environmental Design tool (LEED), Keysar and Pearce [27] conducted a detailed evaluative study comparing the effectiveness of five different relative importance indices for selecting appropriate material selection tools such as: relative advantage; compatibility; complexity; trialability; and observability, with the goal of improving the sustainability of materials for capital projects. Here, materials such as; regionally manufactured materials, materials with recycled content, rapidly renewable materials, salvaged materials, and sustainably forested wood products are selected based on credit scores. Analyses of their study however, revealed that the LEED model for example specifically requires an energy model, a task often handled by a specialist within a design firm or outsourced to a third party specializing in energy modeling.

Due to the inflexibility inherent in the application of first generation tools, and since they tend to require greater technical expertise to implement, many different tools of the second generation group have also been launched to address these limitations. Among this category is the ATHENA estimator. This has been one of the most popularly used material data-analytic models that analyses over 1200 building material and assembly combinations [28]. It allows the users to look at the life cycle environmental effects of a complete structure or of individual assemblies and to experiment with alternative designs and different material mixes to arrive at the best scenario. Bayer et al. [28] noted that the major drawbacks to this tool are the fixed assembly dimensions, software cost, the cost and required skills to use it, the limited options of designing high-performance assemblies, and the overall incomplete assessment of whole buildings environmental impacts [28-30].

With the identified setback associated with ATHENA 
estimator, The National Institute Standards and Technology (NIST) developed the Building for Environmental and Economic Sustainability (BEES $\left.{ }^{\circledR}\right)$ 4.0. This model provides a cradle-to-grave product-to-product comparison of over 230 building products based on manufacturer and supply company information [28-30]. The impact categories are weighed, normalized, and merged into a final environmental performance score, to generate a single measure of desirability for product alternatives by combining qualitative and quantitative data. The BEES 4.0 model is however, not capable of providing data for a full LCA of a complete building product, as it only produces data for a limited amount of building materials and evaluative factors [28-31]. These singleattribute claims ignore the possibility that other life-cycle stages or environmental impacts can yield offsetting impacts. Other limitations include; limited product options, limited use for local/regional impact materials and devaluating weighing process [17].

Trusty [18-21] argued that these sets of first and second-generation tools less often consider any of the MultiCriteria Decision Methods available to solve MCDM problems, adding that some systems do not even consider Life Cycle Cost (LCC) and other performance criteria simultaneously or completely. Moreover, he claimed that the existing performance requirements/criteria approach used in such tools tend to rely on immeasurable characteristics in demonstrating the extent of sustainability in a product, which makes them over-burdensome to implement and communicate.

Since the highlighted material assessment tools were developed primarily to be used in different countries, and the data sources used by each tool differed, further efforts have been undertaken to develop knowledge-based or expert DSS for assistance in material selection. For instance, Rahman et al. [32,33] developed an integrated knowledge-based cost model for optimizing the selection of materials and technology for residential housing design using Technique of ranking Preferences by Similarity to the Ideal Solution (TOPSIS). The system is developed to assist architects, design teams, quantity surveyors and self house builders to make decisions for the design from early stage to detailed design stage by ranking the performance and cost criteria of technologies and materials. Loh et al. [34] however, criticised the tool for providing partial assistance in the material selection process of the whole building design as it only considers the cost of roofing materials. They argue that material selection process depends on a number of other factors such as the location, zoning and environmental regulations, demographic characteristics, etc. that are not considered in their system. They note that the TOPSIS approach adopted does not only lack the ability to eliminate bias in the selection process but also unable to allow fairer trade-off process.

Loh et al. [34] emphasise that strategic selection of sustainable materials and building design prior to the building construction is crucial to increasing building life cycle energy performance. They argue that stakeholders involved in the early design process often have conflicting priorities for both building design and construction materials. They developed an environmentally focused decision support system in the form of an Environmental Assessment Trade-off Tool (EATT), which supports the development of the ideal building design and materials combination that meets stakeholders' requirements. It is designed to assist users select the most appropriate material among a set of candidate materials based on the analytical hierarchy process (AHP) concept of decisionmaking, since AHP technique has the robust ability to handle the complexities of real world problems, and to deal formally with judgment error, which is distinctive of the AHP method. The system rank orders a set of preselected, technically feasible materials using different decision factors with and without tangible values, such as a clients favour over a particular building design, publicity potential of the building design, life cycle cost, capital cost and energy performance of different materials and building layouts. Zhou et al. [12] argued that the approach adopted by Loh et al. [34] lacked in robustness as it does not take into account the full-life cycle impacts of newly-accepted building products, and did not specify the sort of materials under studied.

Zhou et al. [12] developed a decision support multiobjective optimization model for sustainable material selection. The material selection tools and material data sheets provide extensive information that includes factors such as cost, mechanical properties, process performance and environmental impact throughout the life cycle based on expert knowledge. Wastiels et al. [16], confirmed that the tool, however, lack the considerations or descriptions to evaluate the intangible aspects of building materials, which are important to architects. They also criticised the selection methodology for being highly restrictive to a limited range of factors and incompatible with other stakeholders.

Ashby and Johnson (2002) introduce "aesthetic attributes" in the material properties list for product designers when describing material aspects such as the transparency, warmth, or softness. Within the discipline of architecture, however, the intangible qualities of materials are not described and mapped within the current design models. No selection framework was provided to support the implementation of a system.

Wastiels et al. [16], proposes a qualitative and quantitative framework to support informed decisions based on physical aspects' and "sensorial aspects" of building materials, but without the tools integration and computerisa- 
tion as done by Zhou et al. [12]. In the presented framework, no pronouncement is made upon how sustainable considerations from these different categories could influence each other, and what MCDM approach could possibly be used if developed.

A similar study by Ding [35], developed a comprehensive assessment decision support system that measures the environmental characteristics of a building product using a common and verifiable set of criteria and targets for building owners and designers to achieve higher environmental standards. Upon analysis it was found that the assessment for her study focused heavily on environmental issues rather than the broader social, cultural, technical and economic aspects of sustainable green construction.

Keysar \& Pearce [27] cited extensive research literature describing how material selection tools facilitate the innovation diffusion process and radical decision-making transformation. They however, note that most of the examined models make choices that result in "fabricated assemblies of standardized performance attributes", implying that they do not choose for materials but rather for 'material systems'.

Hopfe et al. [36] conducted a study that assessed the features and capabilities of six software tools to screen the limits and opportunities for using BPS tools during early design phases. The tools classification was based on six criteria namely the capabilities, geometric modeling, defaulting, calculation process, limitation and optimization. However, the authors did not report what methodology was used to compile these criteria.

A cost modeling system for roofing material selection was further proposed in Perera and Fernando [37]. Several factors were identified and considered in the selection process. Results demonstrated large inconsistency in the evaluation process. No particular reference was made to the selection methodology.

Other influencing reviews within the scope of this study include Mohamed and Celik [38] who proposed a computerised framework that is responsible for materials selection and cost estimating for residential buildings where users are able to choose their preferred one from list of materials without evaluation and synthesis of multiple design criteria and client requirements. No mention was made about the MCDM technique used for evaluating the list of materials selected and their respective quantities.

Mahmoud et al. [39] suggested a method for the selection of finishing materials that covered floors, walls and ceilings and integrates cost analysis at the appropriate decision points, but without the selection information requirements or methodology as proposed in this study.

Lam et al. [40] carried out a survey on the usage of performance-based building simulation tools. His study examined the relative impacts and limitations of knowledge-base tools in decision-making. Murray argues that while there is a natural tendency for design and building professionals to focus on the scientific and technological aspects of green and sustainable construction, their approach does not necessarily maximise the positive contributions professionals have to offer if tools are designed to replace professional judgment in the choice of materials. Murray suggests that this is because tools cannot address the intrinsic motivations people need if they are to embrace the positive changes sustainability requires. He continues that limiting the assembly of buildings to the specification of systems would impede the discovery of design opportunities inherent in materials themselves. Similar patterns of consistency, and lack thereof, have also been obtained [for detailed reviews see 17,24-27,31].

By highlighting the different green building material assessment tools, it can be deduced that existing tools are dispersed and based on individual initiatives without a unified consensus based framework [41,42]. It is apparent that each tool has its own unique application. While each tool could be called an LCA tool, there was little consistency in the methodologies used from one tool to another. In addition, while one tool considered the building as a system, other tools considered primarily the product's individual attributes rather than how that specific product performed within the building system [42]. A key question therefore, is whether current assessment methods that were conceived and created to specifically evaluate the environmental merits of conventional building materials can be easily transformed to account for a qualitatively different set of materials.

Giorgetti \& Lovell [43] for instance have reported the sub-optimal performance of existing tools. They argued that the subjective values and priorities of the authors of the assessment scheme largely dictate the technical characteristics of the systems, and currently represent the major focus of discussion. They suggest that it is necessary for potential users to analyse the local situation and identify the adaptability of using any tool before applying a universal green building assessment tool to a specific country and region. They warned that some existing tools such as BREEAM, LEED, and even current expert tools might potentially institutionalize a limited definition of environmentally responsible building practice at a time when exploration and innovation should be encouraged in another region.

However, in all the reviewed studies, no efforts to develop a DSS that associates with the corresponding attributes and performance characteristics of low-cost green building materials and components, starting from the broad list of available options in the database to the final selection of the most appropriate material, were found in the existing literature $[43,44]$. 
The findings of the review have shown that each of the indices applied in developed regions to deal with issues associated with the impacts and performance of low-cost green building materials in other regions have proven unsatisfactory [44,45]. This finding is premised on the fact that most existing material selection systems have been designed by countries with more developed economies such as the UK, where the scale of social issues and lack of access to resources is simply not as critical as observed in the developing nations $[45,46]$. The setbacks that associates with the tools reviewed in this research thus, highlights the opportunity for developing a Material Selection Decision Support System (MSDSS), to better address the specific needs and attributes specific to the use of low-cost green materials for tool adopters new to green housing.

The following section briefly highlights the aim and objectives of the study. It extensively describes specific methods adopted for each task in Section 3.1.

\section{Research Methodology}

In order to identify the key selection factors or variables that formed the basis for the development of the prototype multi-criteria decision support system (DSS), suitable clusters of research approaches were considered in the research exercise, some of which include: exploratory literature reviews, networking with domain experts and practitioners, series of questionnaire surveys and knowledge-mining interviews [47]. Table 1 provides an overview of the research aim, objectives and the methodology undertaken in four major stages.

\subsection{Research Design}

To provide a clear theoretical framework for the relatively new area of study, and develop preliminary ideas on issues specific to the research theme within the context of decision-making associated with the impacts of low-cost green building materials and components in housing construction, this study reviewed relevant literature through synthesis and analysis of recently published data, using a range of information collection tools such as; books, and peer-reviewed journals from libraries and internet-based sources. Recognising the limitations of the literature review in terms of examining current research thinking in respect of decision support systems for the selection of low cost green building materials and components, a preliminary research study was undertaken to check and validate prior assumptions in the background and review sections.

In order to build upon knowledge gained from the literature review, and recognising the limitations of the preliminary research survey in terms of examining current research thinking in respect of decision support sys- tems for low cost green building materials and components, a mixed method was adopted for this study. This was followed by in-person interviews to further clarify and elaborate on less detailed and pertinent issues associated with the use low-cost green building materials. The in-depth interviews consisted of 10 participants, who involved a sample of practicing architects, engineers, material specifiers, and a host of building professionals-who influence material choice decisions in the UK housing construction industry. This approach was used to examine the potentials of the proposed MSDSS, (being a tool for the assessment and evaluation of low-cost green materials). It further investigated the effectiveness of design and decision support tools, as well as identified requirements of Life Cycle Assessment (LCA) tools for design decisions at the various stages of the design process.

Consequently, a quantitative questionnaire was developed as the result of the analysis of the results from the interviews. In order to elicit the "most important" factors, a questionnaire survey was conducted among the executives of some selected builder/developer firms. They were asked to rank order from a list of factors (compiled from existing literature on the topic and after initial consultation with some of the executives) based on their judgment and experience. The executives were also asked to indicate desired features they would like to have in a DSS for low-cost green material selection. Since the respondents were widely dispersed, and because it was anticipated that building professionals would be more likely to reply and cooperate with a less time-consuming research method, giving the constraints of time, wider coverage, and budget, it was therefore, decided that a questionnaire sent and returned by email would be the most convenient way of collecting the required data. The inclusion of qualitative open-ended questions provided respondents a chance to express their views more freely.

The target groups of respondents were also taken from a database or directory of building professionals provided by the UK, China, Canada, South Africa, Brazil and US Green Building Councils (GBCs). The selection approach followed the random sampling technique to avoid bias and uneven sample sizes amongst different professional groups, and ensure uniformity, consistency and quality of data. To facilitate the response rate, snowball sampling was also adopted, where the approached respondents were asked to distribute the questionnaire to their colleagues and partners within the field [47].

The selection of South Africa and Brazil for the analysis was due largely to their great similarities in social, economic, and geopolitical terms, and likewise their developed counterparts. In a similar vein, the choice of building experts within the selected countries was as a result of their expertise and advancement in the use and 
Table 1. Basic summary of the research methods.

\begin{tabular}{|c|c|c|c|}
\hline \multirow[t]{2}{*}{ AIM } & \multicolumn{3}{|c|}{$\begin{array}{l}\text { To develop a decision support system (DSS) that will provide designers with useful and explicit information associated } \\
\text { with low-cost green building materials and components, to aid informed decision-making in their choice of materials for } \\
\text { low-cost green residential housing projects. }\end{array}$} \\
\hline & Objectives & Tasks & Method \\
\hline \multirow{2}{*}{ 1: REVIEW } & $\begin{array}{l}\text { 1.Examine current views on themes } \\
\text { related to decision-making associated with } \\
\text { the use of low cost green materials in the } \\
\text { housing industry, to identify new ideas \& } \\
\text { issues arising from the study }\end{array}$ & $\begin{array}{l}\text { Step 1. Reviewed relevant literature through synthesis and } \\
\text { analysis of recently published data, using a range of } \\
\text { information collection tools such as; books, peer-reviewed } \\
\text { journals, and articles from libraries and internet base sources }\end{array}$ & $\mathrm{AA}$, \\
\hline & $\begin{array}{l}\text { 2. Review various DSSs currently used at } \\
\text { national and international levels for the } \\
\text { selection of materials to identify } \\
\text { knowledge deficits and the potential } \\
\text { benefits associated with their use }\end{array}$ & $\begin{array}{l}\text { Step 2. Carried out a preliminary research study with leading } \\
\text { researchers who influence the selection of building materials } \\
\text { in the field of housing construction }\end{array}$ & $\begin{array}{l}\mathrm{AA}, \mathrm{QS}, \\
\mathrm{INT}\end{array}$ \\
\hline \multirow{4}{*}{$\begin{array}{l}\text { 2: DATA } \\
\text { COLLECTION } \\
\text { \&SYNTHESIS }\end{array}$} & \multirow{4}{*}{$\begin{array}{l}\text { 3. Conduct surveys and interviews with } \\
\text { building professionals, to identify the } \\
\text { potential factors or variables that influence } \\
\text { the informed selection of low cost green } \\
\text { building materials and components }\end{array}$} & $\begin{array}{l}\text { Step 3. Conducted a pilot study, by deploying a } \\
\text { test-questionnaire to a small sample of researchers who } \\
\text { possess relevant knowledge on issues specific to the use of } \\
\text { low cost green materials using the email addresses taken from } \\
\text { the databases of recognised building construction companies } \\
\text { and research institutions }\end{array}$ & \multirow{4}{*}{$\begin{array}{l}\text { AA, QS, } \\
\text { INT }\end{array}$} \\
\hline & & $\begin{array}{l}\text { Step 4. Conducted the main survey, by administering the } \\
\text { revised questionnaire through email contacts taken from } \\
\text { databases of interested registered building professional groups, } \\
\text { who influence the selection of construction materials from } \\
\text { throughout the construction value chain }\end{array}$ & \\
\hline & & $\begin{array}{l}\text { Step 5. Conducted in-person interviews with interested } \\
\text { building professionals who influence material choice decision } \\
\text { in housing construction using audio recording system to avoid } \\
\text { re-contacting the respondents or falsification of information }\end{array}$ & \\
\hline & & $\begin{array}{l}\text { Step 6. Carried out inspection on available expert systems } \\
\text { most commonly used in building firms in the UK, USA, China } \\
\text { etc. by interviewing experts, with years of experience in the } \\
\text { industry, who have implemented or used such systems and } \\
\text { directly observing how they function when in operation }\end{array}$ & \\
\hline \multirow[t]{4}{*}{ 3: DATA ANALYSIS } & $\begin{array}{l}\text { 4. Evaluate and establish the weighted } \\
\text { importance of the key factors or variables } \\
\text { that will help to determine the relative } \\
\text { impacts of the different choices of } \\
\text { building materials and components }\end{array}$ & $\begin{array}{l}\text { Step 7. Analysed the information and report gathered from the } \\
\text { survey exercise(s) using a suite of statistical analytical } \\
\text { programs, and various quantitative data analytical techniques }\end{array}$ & $\begin{array}{l}\mathrm{AA}, \mathrm{QS} \\
\mathrm{M}\end{array}$ \\
\hline & \multirow{2}{*}{$\begin{array}{l}\text { 5. Develop a system to integrate the } \\
\text { necessary information appropriate to the } \\
\text { informed selection of low-cost green } \\
\text { building materials \& components }\end{array}$} & $\begin{array}{l}\text { Step 8. Assembled the key components by synthesising the } \\
\text { relevant databases to be incorporated in developing the } \\
\text { proposed DSS model. }\end{array}$ & \multirow{2}{*}{$\begin{array}{l}\mathrm{AA}, \mathrm{QS}, \\
\mathrm{M}\end{array}$} \\
\hline & & $\begin{array}{l}\text { Step 9. Developed the main structure workflow of the } \\
\text { proposed system by creating links among the various } \\
\text { databases, }\end{array}$ & \\
\hline & \multirow{4}{*}{$\begin{array}{l}\text { 6. Test the functionality of the proposed } \\
\text { approach; and validate the effectiveness } \\
\text { by applying it to a building material } \\
\text { selection problems using a series of case } \\
\text { study residential building projects in the } \\
\text { UK }\end{array}$} & $\begin{array}{l}\text { Step 10. Inputted relevant data to test the internal links to } \\
\text { know what needed to be measured within the system, and } \\
\text { checking the output of the results against easily calculated } \\
\text { values }\end{array}$ & M \\
\hline \multirow[t]{3}{*}{ 4: DEVELOPMENT } & & $\begin{array}{l}\text { Step 11. Conducted experts survey by deploying a sample of } \\
\text { the prototype system via email of those who participated in the } \\
\text { main survey, using feedback questionnaires as a quicker and } \\
\text { cost effective means of assessing respondents' judgments } \\
\text { about the system }\end{array}$ & QS \\
\hline & & $\begin{array}{l}\text { Step 12. Made necessary changes based on the feedback from } \\
\text { the survey }\end{array}$ & M \\
\hline & & $\begin{array}{l}\text { Step 13. Validate the modified prototype system using a series } \\
\text { of completed building projects in the UK, by comparing the } \\
\text { outputs from the algorithms to monitored data from the } \\
\text { completed building }\end{array}$ & $\mathrm{M}, \mathrm{CS}$ \\
\hline
\end{tabular}

KEYS: AA (Archival analysis); INT (Interview); CS (Case study); QS (Questionnaire Survey); M (Modeling). 
development of green building tools (as they have had the most uptakes in both geographical regions and being part of an emerging market).

To receive a reasonably sized sample, 500 surveys were sent out by email, over a two-month period of March and April 2012. Using a progressive approach of data collection, a total of 250 respondents returned the completed survey, representing a response rate of $50 \%$. The response rate was accepted as the normal ranges between $20 \%-30 \%$ were found in most of the construction industry related research [33,34]. Prior to distribution, the questionnaire was pre-tested for comprehensibility by consulting five academics at two universities [47]. A number of changes were suggested and implemented.

Respondents were also invited to post their ideas about current limitations or improvements that should be avoided or integrated in the development of the proposed MSDSS model at the later part of the questionnaire. The questionnaire also examined the adequacy/inadequacy between traditional manual approach of material selection and computer-aided decision support tools. One of the group's participants commented that one of the hallmarks of good science is that a result can be tested independently and proven to be right or wrong in the latter method. The analysis of the questionnaire survey and interviews provided a list of "key" decision-related factors having significant impacts on the process of material selection for residential development as shown in Section 4.1.1.

\subsection{Research Findings}

The results of the study however, revealed the following.

- Many existing decision support systems in the developed countries do not have the appropriate performance threshold for addressing the most relevant issues specific to less developed countries;

- Current DSS models are unable to relate to matters associated with the informed selection of materials that are commonly used for housing projects in countries with rather less-mature markets;

- The lack of informed knowledge by building professionals in terms of the principles, characteristics, and best practices relevant to the use of low-cost green materials at the design stage, has been identified as a common constraint peculiar to their wider-scale use in the housing industry;

- The majority of building professionals still regard cost and environmental factors as conventional project priorities when selecting building materials or components, but rarely consider the implications of social, political, technical, sensorial, legal and cultural factors in their choice of materials; and finally,

- The majority of low-cost green building materials are yet to be certified under the building regulations, standard specifications and codes of practice; and most importantly,

- There are no demonstrable and compelling evidence of technical research on a holistic approach used by design professionals for the evaluation and selection of low cost green building materials and components at the design stage.

The results of the study thus, provided the platform that suggested the need for a system that could aid informed decision-making to improve understanding, and enhance the effectiveness of actions to implement and promote the wider-scale use of low-cost green building materials and components at the core of the construction business process. In light of their feedback and useful suggestions from building experts who partook in the study, the following portions of the DSS model were either readjusted or improved.

- Easy searchable material selection inputs database;

- Ability to add/remove material selection features with ease;

- Ability to make custom reports;

- Ability to easily navigate all components with ease;

- Comprehensive "HELP or USER INSTRUCTIONS" menu explaining what the tool is doing;

- Being able to understand the material selection process through the lens of non experts;

- Ability to perform trade-off analysis to compare different material options;

- Clarity on the algorithms used to perform the simulations; and Real-time results;

- Data input forms to ensure easy and consistent data input; and,

- Having a huge amount of customizability in terms of output.

After the improvement, the system was shown to the same participants, and minor adjustments were made on the basis of second feedback. In the following sections the proposed MSDSS selection methodology is discussed, and a conceptual framework for the decision support system based on the methodology is presented. Subsequently, the MSDSS model is applied to a hypothetical but realistic material selection problem to rank order the candidate materials for selecting the most appropriate one.

\section{System Development}

For this research, AHP was selected for its simplicity and due to the fact that it can be easily implemented using any spreadsheet software application such as the MS Excel, as it possesses a powerful macro language that is essential since a menu driven interface had to be developed. Since the intention of the research was not to develop a commercial software product, Macro-in-Excel 
VBA (MEVBA) was utilized for the following reasons:

- Macro-in-Excel VBA (MEVBA) has the capabilities to perform all necessary calculations and is common enough that most people are familiar with it;

- It has the ability to write scripts that could automatically convert material data from any graphic table format to an appropriate condensed data table (hidden from the user's view) to allow quick and reliable indexing of material data;

- The Macro-in-Excel VBA framework has the code that makes Windows forms work, so any language can use the built-in code in order to create and use standard Windows forms;

- Makes the application easier to maintain; With MEVBA, codes were easily built into the form or report's definition, since the DSS model contained a large number of macros that respond to events on forms and reports; which would have been difficult to maintain using any other application;

- With Macro-in-Excel VBA it was easy to step through a set of records one record at a time and perform an operation on each record;

- Macro-in-Excel VBA helped to supply a standard security mechanism, which was made available to all parts of the MSDSS data application model;

- Enables the developer to create his own functions: The MSDSS contains a series of mathematical model and computational algorithmic procedures that provided a basis for computing the green development index of material alternatives within an integrated decision-support framework or tool(s).

- Ability to mask error messages during the tests run;

- Enables the system to quickly analyze existing data to discover trends so that predictions and forecasts can be made with reasonable accuracy;

- Allows for extensions and expansions: since the components of the framework are modular, meaning that each may be developed independently, and data may be added as it is acquired to supplement the knowledge and databases, macro-in-excel was used to achieve that goal

\subsection{MSDSS Database/Data Warehouse Design}

The data warehouse design constitutes the major portion of the MSDSS development and hence will be explained in detail in this section. The data warehouse design essentially consists of four steps as follows:

Step 1: Identifying the key influential factors that will impact on the choice of materials;

Step 2: Designing the material selection methodology framework and identifying the objectives of each step;

Step 3: Designing the various components of the MSDSS model and defining their features and functions;

Step 4: Defining the workflow selection methodology and analytical procedure of the actual prototype MSDSS model

\subsection{Identifying the Key Influential Factors}

In order to identify the relative importance of the subcategorical factors or variables based on the survey data, ranking analysis was performed. Five important levels were transformed from Relative Index values: Highly Significant Level $(\mathrm{H})(0.8 \leq \mathrm{RI} \leq 1)$, High-Medium Level (H-M) $(0.6 \leq \mathrm{RI}<0.8)$, Medium Level (M) $(0.4 \leq \mathrm{RI}<$ $0.6)$, Medium-Low Level $(\mathrm{M}-\mathrm{L})(0.2 \leq \mathrm{RI}<0.4)$, and Low Level (L) $(0 \leq \mathrm{RI}<0.2)$.

From the results of the analysis, 40 factors were identified under the "Highly significant" level for evaluating low-cost green building materials with an RI value ranging from 0.952 to 0.806 and a total of 15 factors, were recorded to have "High-Medium" importance levels with an RI value ranging from 0.795 to 0.652 . The analysis of the main survey identified a total of 55 key influential factors out of 60 initial factors as important components of the material selection process.

"Life Expectancy" was ranked as the first priority in the technical category with an RI value of 0.952 , and it was also the highest among all factors and was highlighted at "High" importance level. "Resistance to fire" was also rated high in importance among the selection factors. "Maintenance Cost" was ranked third in importance. It was clear from this research that there is a perception of ambiguity surrounding the long-term maintenance of low-cost green building materials. This is not entirely any surprise given that maintenance free buildings are increasingly sought after by clients, anxious to minimise the running costs associated with buildings. "Life-cycle cost" has been, and will continue to be, major concerns for building designers, as well as important traditional performance measure.

Among the top 20 ranking factors, it was observed that only one factor from the environmental category out of the list was ranked high among the selection factors. This again suggests that environmental issues within the context of the developing countries are not strongly considered despite the high environmental awareness exhibited by design and building professionals in developed regions. This finding also corroborates the initial observations of various studies $[14,15]$ repeatedly highlighted in the background and literature studies. They suggest that the problems within the developing regions are characterised by mainly social and economic issues, unlike the developed regions where the scale of social issues and lack of access to basic resources are simply not much of a problem as it is in the developing world.

From Figure 1, a total of 15 factors, consisting of 12 site factors, 1 socio-cultural factor, and 2 sensorial factors, were recorded to have "High-Medium" importance 
levels. Although these 15 variables were in the same importance level category, the "building orientation" factor within the "general/site category" (average RI $=0.652$ ) was considered to be the least important variable compared to the factor "Glossiness" under the "sensorial category" (with an average RI $=0.774$ ), and "material availability" still under the "general/site category" (with an average $\mathrm{RI}=0.795$ ). However, it should be noted that site factor accounted for $75 \%$ in the "High-Medium" importance level. The result is an example of evidence pointing to the trend that environmental and perhaps site issues are no longer considered as the most important factors for material selection in housing projects, especially within the context of the less developed regions.

Some factors in the three categories were ranked relatively higher in the "High-Medium" level. For example, "material availability (GS1)" was rated as first in the general/site subcategory, and ranked as thirty-fifth in the overall ranking with an RI value of 0.795 . An interesting observation from the results is that none of the criteria fell under the medium and other lower importance level. This clearly shows how important the factors are to building designers in evaluating low-cost green building materials. All factors were rated with "High" or "HighMedium" importance levels. However factors such as Compatibility with other materials, Skills availability, and UV resistance fell within the medium-low level. The findings of the analysis asserted that the criteria with medium or low RI does not mean they are not important for selecting materials, but rather created an opportunity to highlight the relative importance of the key criteria from their vantage points. The following shows a framework consisting of the key factors in their order of importance.

\subsection{Designing the MSDSS Selection Methodology}

The diagram shown in Figure 2 demonstrates the conceptual framework of the selection methodology for the decision support system. Table 2 describes a step-bystep procedure of the selection methodology for the material selection decision support system. Section 4.4 presents various components of the MSDSS schema or model.

\subsection{Designing the Features of the MSDSS Model}

The next stage of the model development was to design the various features of the databases containing the logic and showing relationships between the data organized in different modules. Each module contains the physical information and contents needed to aid in the material evaluation and selection process.

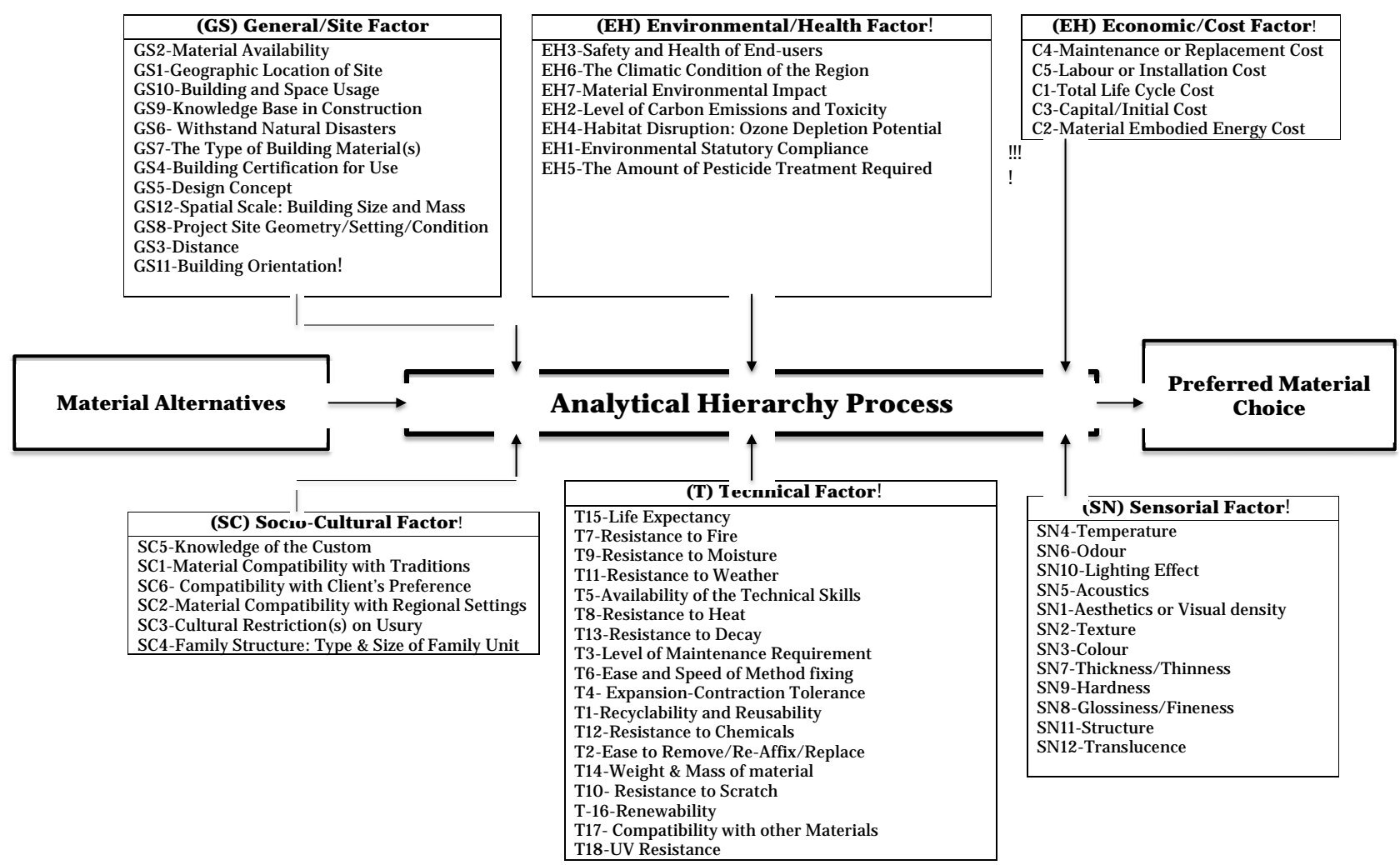

Figure 1. Ranked factors for measuring the impacts of low-cost green building materials. 
Table 2. Description of the selection methodoly.

\begin{tabular}{l} 
OBJECTIVE \\
\hline 1. Define or state overall objective/goal \\
$\begin{array}{l}\text { 2. Identify Set of all Possible Material Alternatives to be } \\
\text { Assessed }\end{array}$
\end{tabular}
Assessed

3. Prune all infeasible alternatives from set

\begin{abstract}
4. Evaluate Remaining Alternatives
\end{abstract}
- Weight Attributes (Decision Factors)

- Calculate Values for Attributes

- Amalgamate Weighted Attributes

- Develop Ranking

5. Review Ranking of Alternatives

6. Select Alternative Based on Ranking

\section{TASK}

The first step of the methodology is to define the main goal of the intended task.

After defining the main goal of the task, the next step is to generate the set of all possible alternatives that are available for selection based on the decision-making parameters. In the material selection process, this comprehensive set of alternatives includes all construction materials and components currently in the database, and the market in context.

The third step is to reduce the complete set of alternatives by eliminating/pruning those alternatives, which are clearly infeasible for the intended application from the database consisting of all materials, based on classifications of materials according to the

Construction Standards Institute (CSI) Divisions, and material heuristics. For example, if the element under consideration is a structural beam, materials such as roofing sheet and glass are automatically pruned from the set of possible alternatives under consideration, since none of these materials fall under the CSI structural divisions. This should result in a subset of alternatives, all of which would be feasible choices for the intended application. The "pruning" approach is used rather than allowing the user to select feasible materials from the whole set because users tend to overlook alternatives which might be unfamiliar to them but are nonetheless feasible.

The fourth step in the methodology is to evaluate the feasible alternatives using the AHP model such that a ranking can be developed according to the relative importance of the material for the intended application.

- First, the decision maker weights each factor or variable according to the relative importance that the decision factor or variable holds for the decision maker. It involves the decision-maker replacing probabilities with user weightings for each factor or variable to supplement, not replace, his judgment.

- Second, values for each of the factors or variables are determined for each material with regard to the manufacturer's information \& details of the material or component contained in the material database, and then, a normalized value between zero and one is calculated for each factor value.

- After weights have been established and values calculated for each attribute against a set of materials or components, the weights and normalized values are multiplied and summed to create an index of preference for that alternative(s).

- Then, a list of alternatives ranked according to the relative importance of the factors or variables is then presented.

When the indices of factors or variables have been calculated for all feasible alternatives, a ranking is developed sorting the alternatives according to each utility value based on the AHP model of decision-making. The alternative with the highest utility value is recommended from the ranked list of potential materials for each design/building element.

The decision maker may then either elect/decide to select the highest ranked alternative, or choose another alternative from the set based on his professional judgment.

The decision maker satisfied with the selection process, then proceeds to the next design/building element.
The conceptual model/framework of the prototype MSDSS tool consists of a number of interconnected modules/features. A logical model illustrating the developed DSS for material selection is shown in Figure 3. Table 3 describes the functions of each component of the MSDSS model.

\subsection{How the System Works}

The following steps explain how the prototype MSDSS model works during the material evaluation process.

Step 1: The load manager provides the user with a list of design elements from the "Design Elements" module, and then prompts the user to select the design element of his/her choice in accordance with the terms and specifications of the Construction Standards Institute (CSI) Divisions;

Step 2: The User then selects the particular design element needed for the intended task from a list of design elements (as broken down by the Construction Standard Institute Division);

Step 3: User then enters values for the relevant parameters to answer prompts about areas and dimensions 


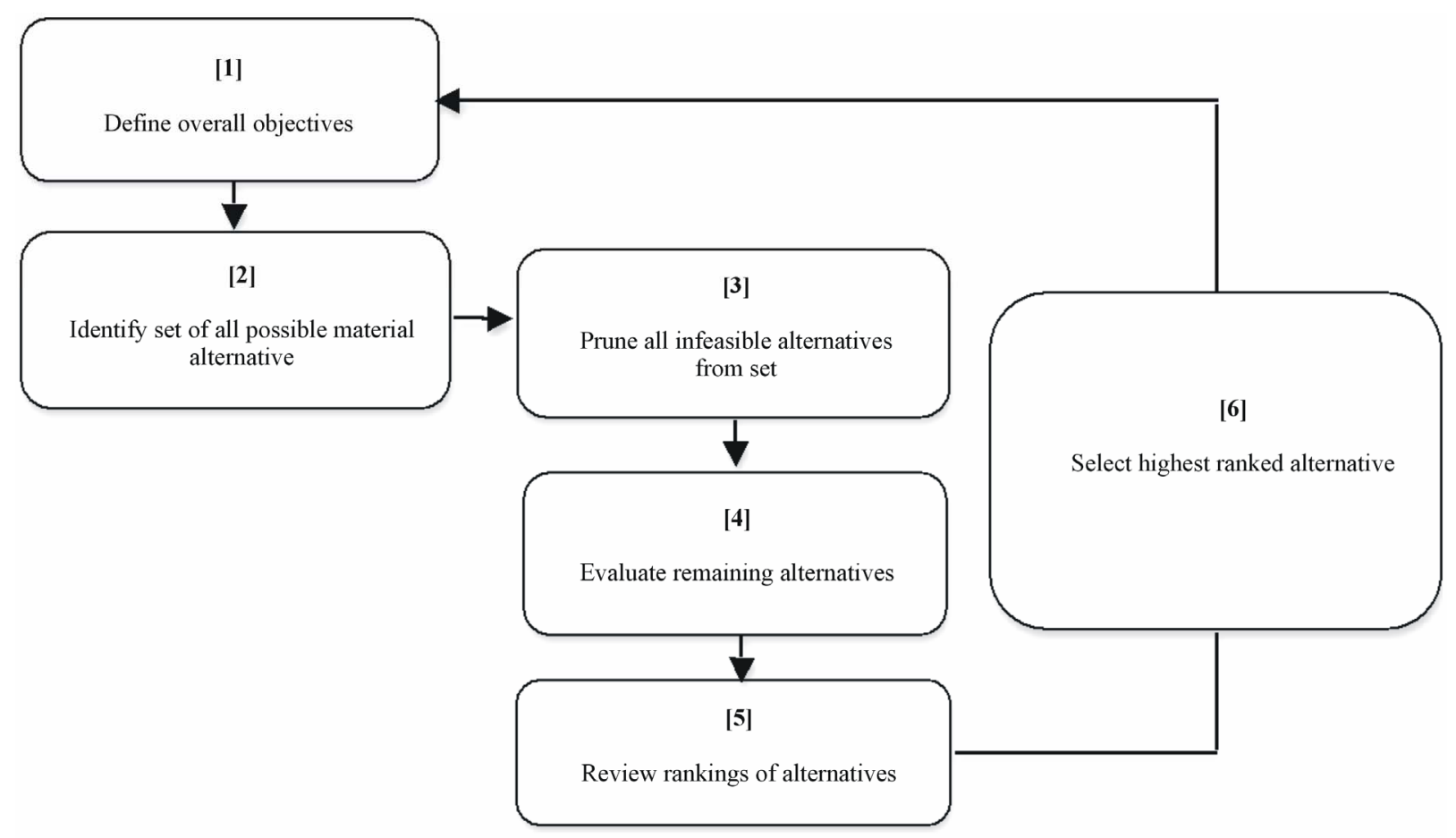

Figure 2. Selection methodology for the MSDSS model.

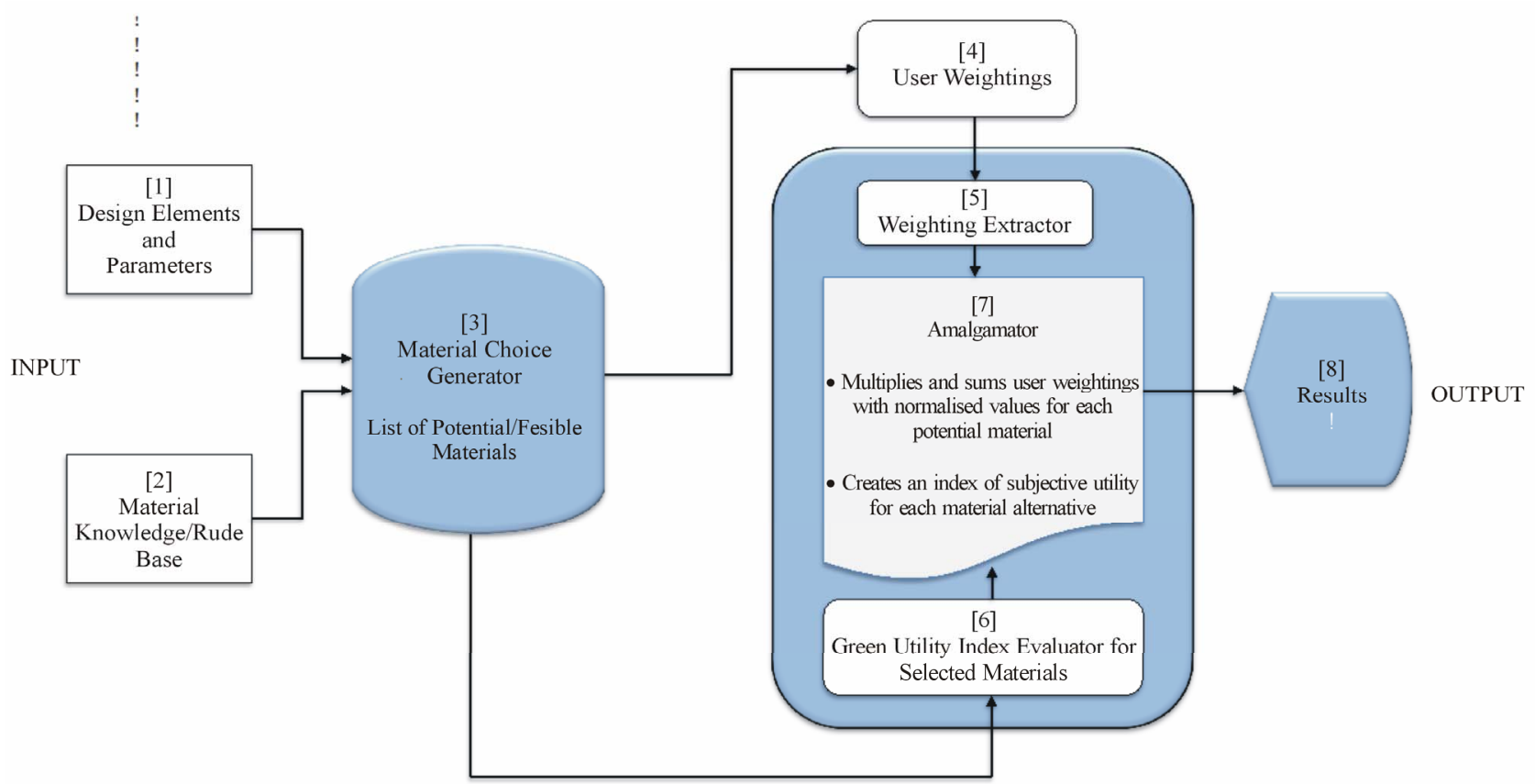

Figure 3. Conceptual framework of the MSDSS model.

of the selected design element, and then sets the threshold values in the material knowledge base

Step 4: The system validates the design parameters and threshold details entered by the user, and then generates the set of all feasible material alternatives that are available for selection, (which includes all categories of construction materials contained in the materials data- base);

Step 5: After a set of feasible material alternatives has been generated for the "particular design element", the system through the "Weighting Score Extractor Module" prompts the user to obtain weightings for the desired parent and sub-factors according to the relative importance that each factor or variable holds over another 
based on the decision maker's preference of value;

Step 6: After weights have been established and values calculated for each factor for a particular material, the weights and normalized values are multiplied and summed to create an index of subjective utility for each alternative;

Step 7: The alternative with the highest utility value is recommended by the system;

Step 8: The user reviews the system's recommended choice for each element in the "Result" module, and then either selects the highest ranked alternative, or chooses another alternative from the set based on professional judgment and/or the system's recommendation.

Step 9: The user may choose to generate a printout report or graphical representation of the list of selected materials and green utility indices if desired.

Step 10: The selection process then proceeds to the next design element.

Figure 4 presents a graphical representation of the system workflow.

An illustrative example of the AHP concept is displayed and explained in following section to demonstrate the selection process by applying the prototype MSDSS model to a hypothetical case study design project.

\section{Application}

The following example illustrates the selection process of floor covering products. It selects the best one among three alternatives. The prototype MSDSS, developed using the AHP technique, was used to select the most appropriate residential building floor material for housing development in the city of London, located in the Sutton County of London. The results demonstrate the capabilities of the MSDSS system in a real-life but hypothetical application scenario. In the following section this process of application is described and discussed.

\subsection{A Hypothetical Study Case}

The next stage of the model development was to design the various features of the databases containing the logic and showing relationships between the data organized in different modules. Each module contains the physical information and contents needed to aid in the material evaluation and selection process. Table 4 summarizes the details for the three options of flooring materials for the proposed residential low-cost green housing project. The description of the three options in Table 4 was based on the standard practices and construction details commonly used in the housing construction industry.

These three (3) floor materials described above will be analysed amongst a host of other material alternatives for the selection of a more sustainable option. In other words, this section will analyse the problem using the MSDSS model, which relies on the use of the AHP mathematical multi-criteria decision-making technique, to identify and decide which material is the most sustainable and suitable flooring material in this case.

To achieve this goal, the MSDSS model was sent to 10

Table 3. Functions of the features of the MSDSS model.

\begin{tabular}{|c|c|}
\hline MSDSS Features & Functions \\
\hline 1. Design Elements and Parameters & $\begin{array}{l}\text { This feature provides users with a range of building design elements and their respective } \\
\text { parameters }\end{array}$ \\
\hline 2. Material Rule Base & $\begin{array}{l}\text { This feature articulates the listing of individual materials in prescribed sequences, gradually } \\
\text { eliminating candidate materials based on their inability to meet stated material selection } \\
\text { heuristics/rules. }\end{array}$ \\
\hline 3. Material Choice Generator & $\begin{array}{l}\text { This feature contains the material/component database, which generates the set of all possible } \\
\text { material alternatives that are available for selection. }\end{array}$ \\
\hline 4. User's Weightings & Sets preferred weighting value for all attributes to compare with. \\
\hline 5. Weighting Extractor & $\begin{array}{l}\text { This feature queries the user to obtain weightings for the factors, based on the user's preference of } \\
\text { value on a scale of } 1-9 .\end{array}$ \\
\hline 6. Material Index Evaluator & $\begin{array}{l}\text { The material index evaluator calculates values of the selected factors or variables for each feasible } \\
\text { material choice. }\end{array}$ \\
\hline 7. Amalgamator & $\begin{array}{l}\text { Here the user's weightings are amalgamated (i.e. multiplied and summed) with the factor values or } \\
\text { weightings for each potential material, resulting in a relative ranking of the feasible materials for } \\
\text { each element. }\end{array}$ \\
\hline 8. Results & $\begin{array}{l}\text { - This component provides the ability to view the processed data, and to generate reports. It allows } \\
\text { the MSDSS model User Interface to communicate with the user; and also connects all the reports } \\
\text { and queries that are generated in the Monitoring databases to the corresponding project files. }\end{array}$ \\
\hline
\end{tabular}




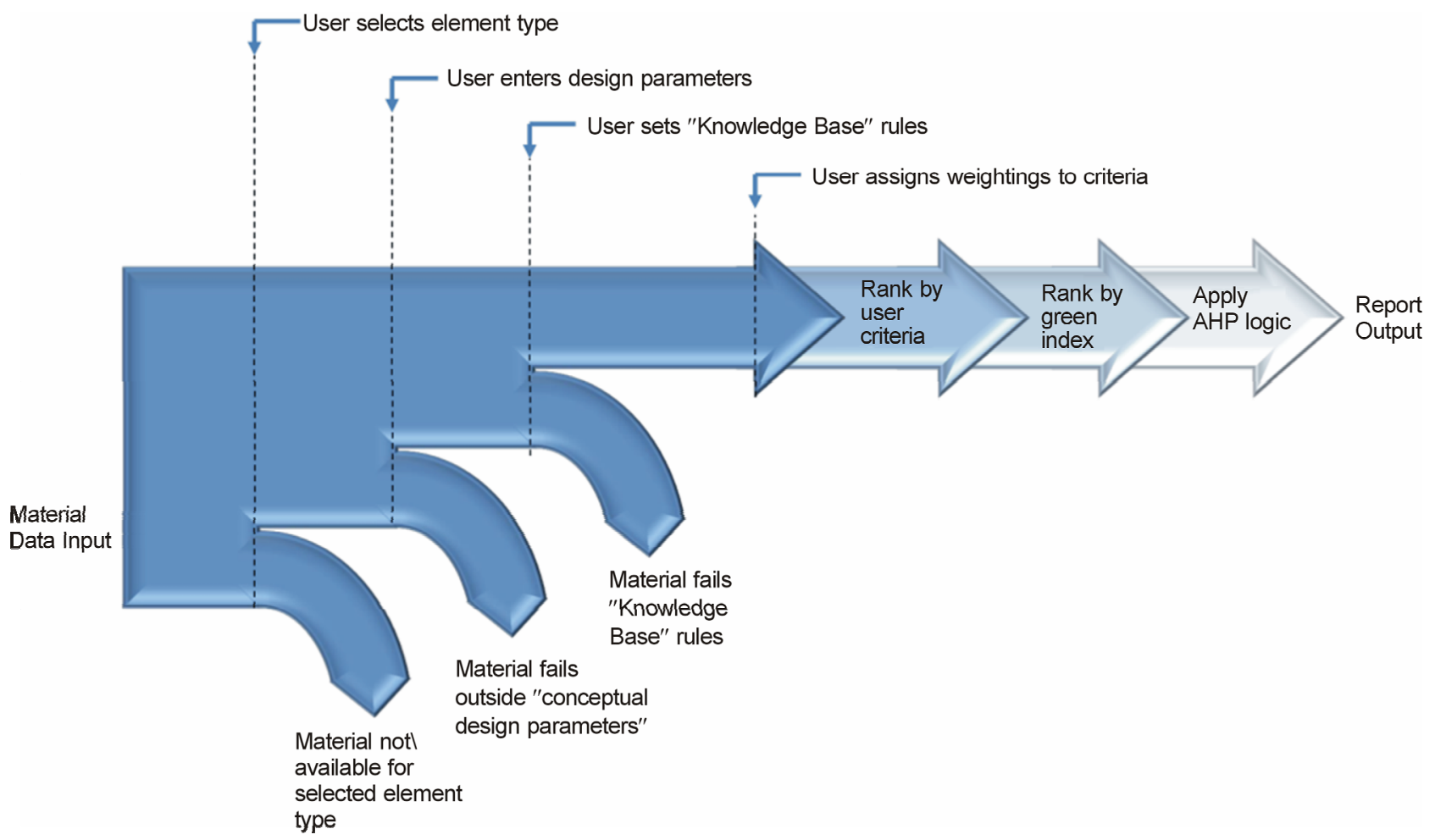

Figure 4. Workflow of the MSDSS model.

Table 4. Summary of the flooring options.

\begin{tabular}{cccc}
\hline Description & Material A & Material B & Material C \\
\hline Design Element Type & Paneled Flooring & Laminated Flooring & Concrete Flooring \\
Building Type & Residential & Residential & Residential \\
& Bamboo XL laminated Split & Reclaimed/Recycled Laminated & Fly Ash Cement concrete \\
Material Type & Paneled Flooring & Wood Flooring and Paneling & Floor Slab \\
Size of Materials & $230 \mathrm{~mm} \times 150 \mathrm{~mm}$ & $50 \mathrm{~mm} \times 6000 \mathrm{~mm}$ & $900 \mathrm{~mm} \times 900 \mathrm{~mm}$ \\
\hline
\end{tabular}

expert evaluators who had the following qualities:

- Considerable amount of knowledge in material analysis based on the AHP concept;

- Used a wide range of green building assessment tools for material selection; and

- Taken part in the previous survey.

The aim of this exercise was to compare their view of the prototype MSDSS model with existing models in terms of their usability, flexibility, and interoperability attributes using the concept of the Analytical Hierarchy Process (AHP).

\subsection{Rationale for Adopting the AHP Concept}

The study adopted the use of the AHP technique to investigate the interrelationships amongst various criteria and low-cost green material alternatives due to the following reasons:

- AHP is a method that is conceptually easy to use, and decisionally robust to handle the complexities of real world problems;

- It does not require the very strong assumption that the stakeholders make absolutely no errors in providing preference information;

- It has the ability to deal formally with judgment error, which is distinctive of the AHP method;

- The AHP method provides the objective mathematics to process the unavoidably subjective preference inherent in real- world evaluations;

- Possesses an inherent capability to handle qualitative and quantitative criteria important for sustainable material selection; and finally,

- Can enable all members of the evaluation team to visualize the problem systematically in terms of parent criteria and sub-criteria.

Figure 5 shows the flowchart of the material selection computational analysis technique based on the concept of the Analytical Hierarchy Process model. The following sections present details of the evaluation exercise. 


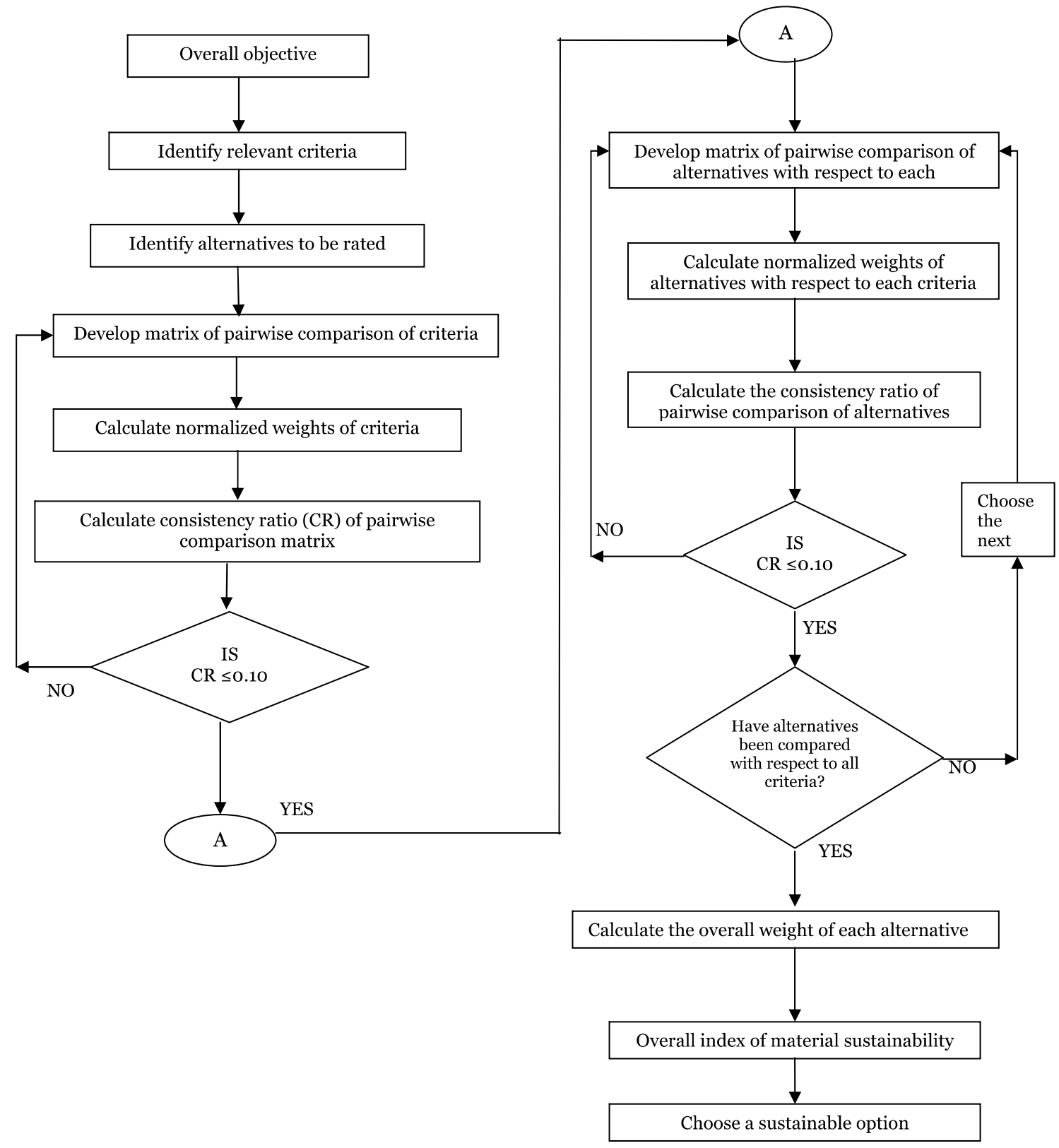

Figure 5. Flowchart of the AHP concept.

\subsection{Applying the AHP Model to the Problem}

According to Reza et al. [48], AHP is a subjective MCDM method that does not necessarily involve or rely on a large sample for its analysis. To better illustrate the procedure of the AHP technique of decision-making, with reference to the case presented in Section 5.1, a complete example of applying AHP to the problem of material selection is provided here based on evaluators' results. Twenty (20) respondents representing various fields of the housing construction industry, and who had fore knowledge of the AHP procedure were selected to participate in the AHP survey.
By evaluating the consistency level of the collected questionnaires, 5 questionnaires out of the 10 received had acceptable consistency and were entered into the system. In order, to avoid arbitrary and inconsistent answers in the data, the mean values of five (5) out of the ten (10) respondents were used to fill out the pair-wise comparison matrices for the parent and sub-factors.

The package included the model, evaluation questionnaire and a cover letter stating the purpose of the research, the validation process and what was expected of them. To conduct the exercise, the study adopted Chua's et al. [49] approach based on a number of suggestions as follows: 
- A document that reminded and explained the overall aim and objectives of the study to the respondents, followed by a step-by-step demonstration of its operation;

- A demo illustrating a practical exercise. This allowed the evaluators the experience of using the system ensued. During the practical assessment session of the demo, evaluators were able to see the controls and get a general overview of the MSDSS interface;

- An illustrative example of the objective and methodology of the AHP technique based on the instructions in the demo, to guide and illustrate to every respondent on how to browse and conduct analysis;

- After the introduction, a feedback questionnaire was forwarded to the evaluators;

- After each evaluation, each evaluator highlighted their experience(s) and provided feedback on the feel of the system, with special attention to the problems that they encountered during the evaluation process;

- Finally, a reflective or post-user questionnaire was completed to obtain feedback;

- Evaluators were asked to answer each statement or question relating to the model in the questionnaire based on their personal view(s);

- They were also asked to assess the importance of the system based on their perception. Evaluators were also asked to add general comments on the system, and provide feedback on the applicability of the prototype system in assisting in specific material selection problems during their experience and other ways of improvement;

- Problems uncovered or areas that proved difficult to understand during the evaluation process were immediately modified so that it did not arise in subsequent sessions, as this procedure followed each evaluation;

- The respondents were instructed of the relevance of observing consistency in their answers whilst using the MSDSS model;

- The questions relating to different aspects were presented in different sections. This helped respondents to focus on one aspect at a time.

The following sections exemplify the process.

\subsection{Decomposition of the Decision Problem}

The evaluation exercise provided users with the opportunity to define the problem. Figure 6 shows the exemplary hierarchy of the problem. The goal is placed at the top of the hierarchy. The hierarchy descends from the more general or parent factors in the second level to subfactors in the third level to the alternatives at the bottom or fourth level as shown in Figure 6). To select a suitable choice among alternatives, the users were instructed to define the decision factors needed for the analysis. In other words, the users determined which alternative could be the best choice to meet the goal considering all the selected decision factors or criteria displayed in Figure 6.

The first step of the methodology (as illustrated in figure 2) was to define the main goal of the intended task, by identifying the design element needed for the analysis, and inputting the relevant dimensional scale for the suggested design element (see Figure 7(a)).

After defining the main goal of the task, the next step was to generate the set of all possible alternatives that were available for selection with reference to the decision-making parameters as shown in Figure 7(b). At this stage the users are prompted or alerted by the MSDSS model to identify a set of feasible floor material alternatives based on a range of material selection heuristics/ knowledge-based rules. The goal is to choose a suitable floor material among options for the project case described in Section 5.1.

\subsection{Pair-Wise Comparison of Parent Factors}

After selecting the design element, and identifying a set of feasible alternatives using the material selection heuristics/knowledge-based rules, the respondents were made to perform pair-wise comparisons following the demo instruction guide of the MSDSS model. This included the analysis of all the combinations of parent factors and sub-factors relationships. The sub-factors were compared according to their relative importance (based on the ratio scale proposed by Saaty [50-55], with respect to the parent element in the adjacent upper level. After performing all pair-wise comparisons by the decisionmakers, the individual judgments were aggregated, basing its analysis on the geometric mean technique as Saaty suggested [52-55].

\subsection{Pair-Wise Analysis of the Parent Factors}

To avoid arbitrary and inconsistent answers in the data obtained from the 10 participants who consented to partaking in the study, the mean values of five (5) out of the ten (10) respondents were used to fill out the pair-wise comparison matrices for both the parent and sub-factors. The pair-wise comparison matrices obtained from 5 respondents were combined using the geometric mean approach at each hierarchy level to obtain the corresponding consensus pair-wise comparison matrices [54-56]. Using the verbal/ratio scale shown in Figure 8, respondents obtained weightings for each parent factor, based on the preference of value(s) on a scale of $1-9$. The MSDSS model then automatically translated each of the matrixes into the corresponding largest eigenvalue problem and was solved to find the normalised and unique priority weights for each factor (as shown in Figure 9). Going by Saaty's [55] rule, the judgment of a respondent 


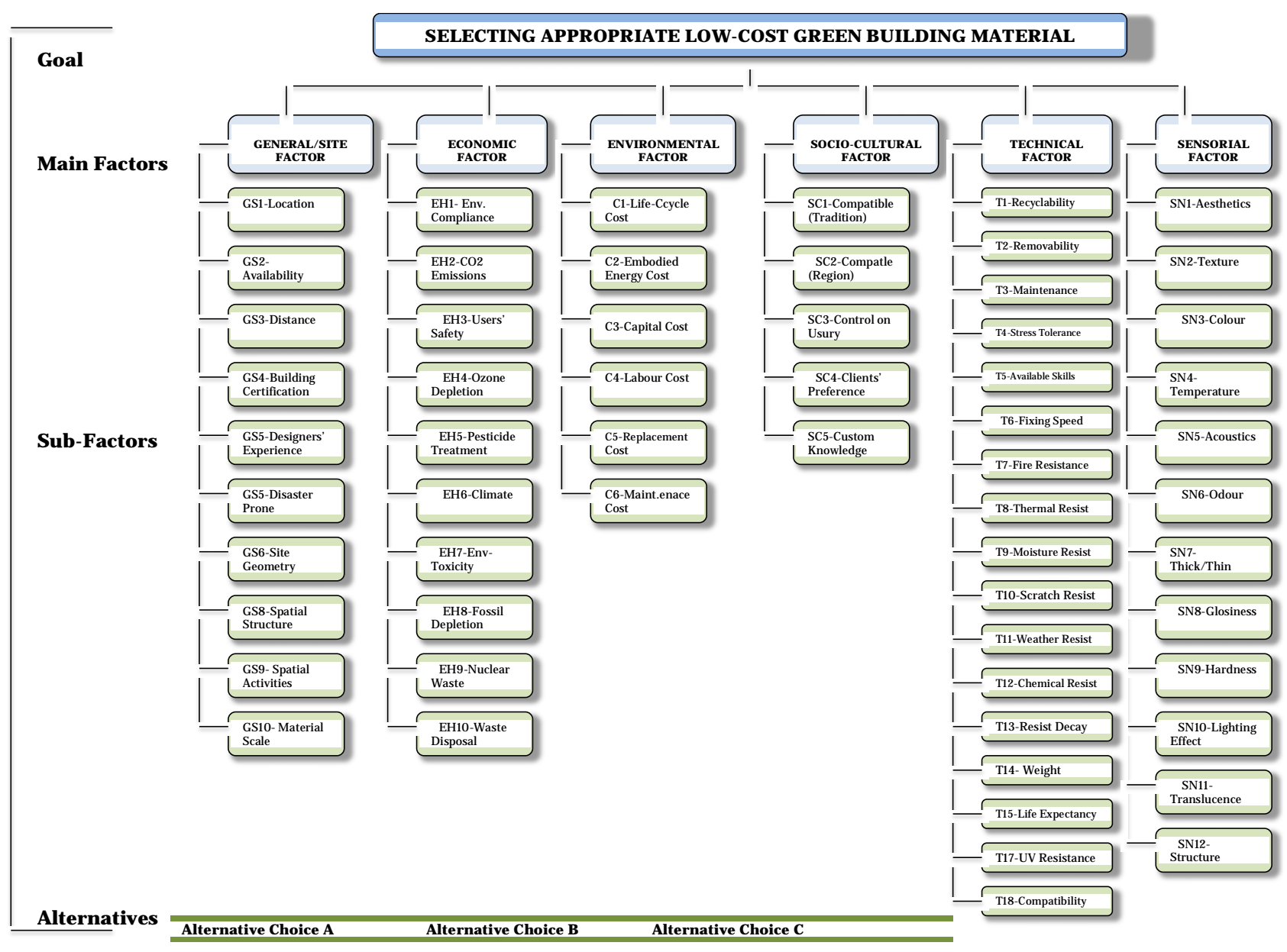

Figure 6. Hierararchy of the material selection phases.

is accepted if the Consistency Ratio $(\mathrm{CR}) \leq 0.10$. In cases were the results of the respondents were not consistent, the participants were alerted or prompted by the model to carefully re-evaluate the factors until consistency was achieved.

Figures 9 and $\mathbf{1 0}$ represent the principal matrix of comparison, which contains the comparison between main/parent factors in relation to the overall objective of the problem (i.e., the selection of a sustainable low-cost green building floor material). From Figure 9, it is possible to observe that factor SC is 3 times more important than factor $\mathrm{EH}$. As a logical consequence, factor $\mathrm{EH}$ is 3 times less important than factor SC. It is also possible to observe that the elements in the principal diagonal are always equal to 1 . In other words, the weight of a criterion in relation to itself, obviously, is always 1 .

From Figure 9, it is also possible to observe that comparing Socio-cultural [SC] and Technical [T] factors, the participants slightly favoured Technical aspects of the products [T], thus arrived at an average value of two (2), derived from the mean calculation of the five respondents. Comparing Socio-cultural [SC] impacts with Sen- sorial [SN], participants somewhat considered Sociocultural [SC] as more relevant in their choice of materials than the emotive or sensorial [SN] aspects of the products, thus arriving at a mean score of 2. Comparing Technical [T] and Sensorial [SN], Technical [T] issues where proven to be more relevant or more slightly favoured than others making it the most dominant factor of the three. Based on their preference values, the system automatically creates a reciprocal matrix on the opposite end as the case may be.

At this stage (as shown in Figure 11), ratio scales are defined for pair-wise comparison of the main or parent factors using the ratio scale of $1-9$. As mentioned earlier, the decision makers obtained values for each parent factor based on their aprioristic knowledge and individual weighting preference. Here, the AHP main criteria matrix is then automatically developed by comparing the relative importance of one parent factor over the other as shown above in Figure 11.

Next, the parent criteria matrices are normalised (by dividing a cell value by the sum of each column) and then checked for consistency using Eigen values as 

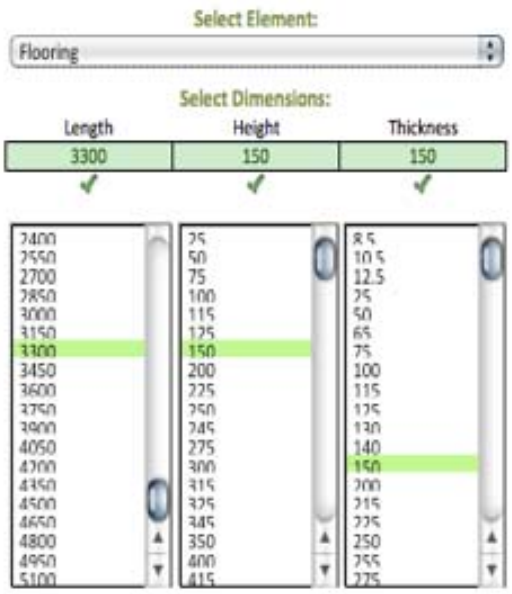

(a)

General/Site
Environment/Health
1) Candidate materials should fall within what
radius of the location or production site?
What is the minimum confsasters Common to the Site?
3) What is the minimum compliance with
Environmental Statutory rules, laws and FsC
principles of the region?
4) What is the maximum level of embodied
CO2 emissions for candidate materials?
Economic/Cost
5) What is the maximum consumption of
embodied energy for candidate materials?
6) What is the maximum capital cost for
candidate materials?
$\quad$ Socio-Cultural
7) What is the minimum compliance with
Indigenous peoples' rights, Tradition,
Regional Setting and Architecture of the region?
$\quad$ Sensorial
8) What is the maximum thermal conductivity of
candidate materials?

(b)

Figure 7. (a) Dimensional scale for the elected design element; (b) Selection rules for the elected design element.

\section{Ratio Scale For Pairwise Comparisons}

\section{Value (W) Definition}

1 Equal Importance of elements

3 Weak Importance of one element over the Other

5 Strong Importance of one element over the other

7 Very Strong Importance of one element over the other

9 Absolute Importance of one element over the other

2,4,6,8 Intermediate values between two adjacent judgements

Figure 8. Ratio scale for pair-wise comparison of factors. 


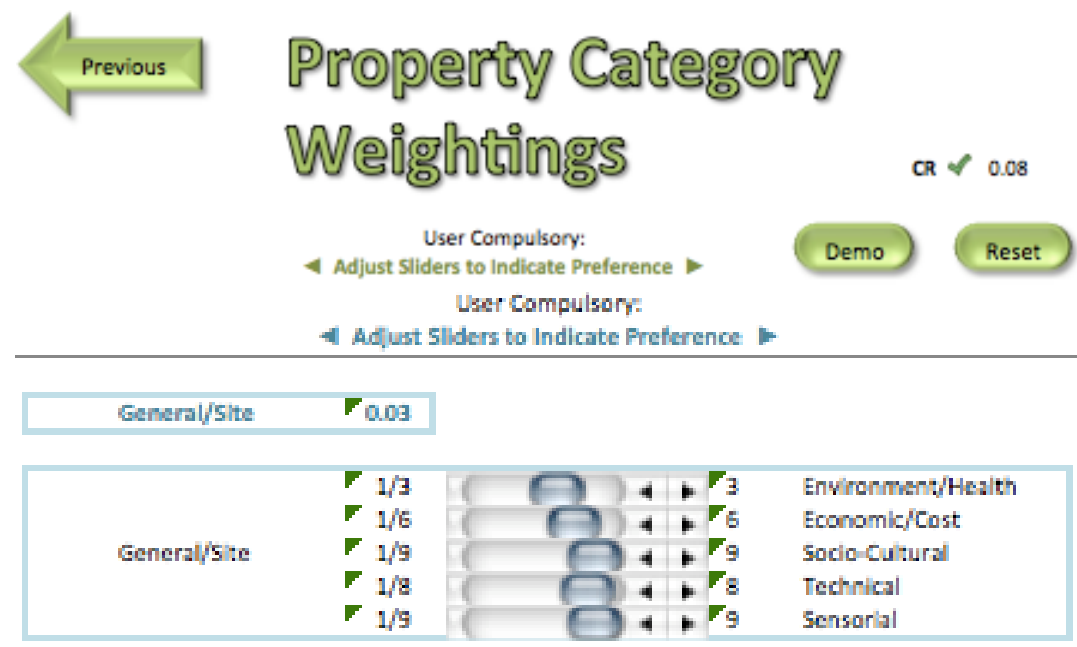

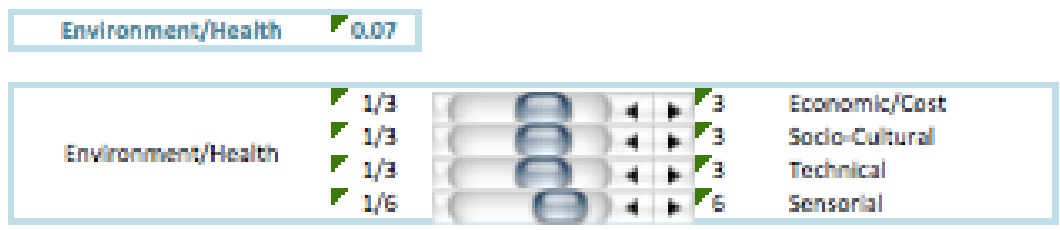

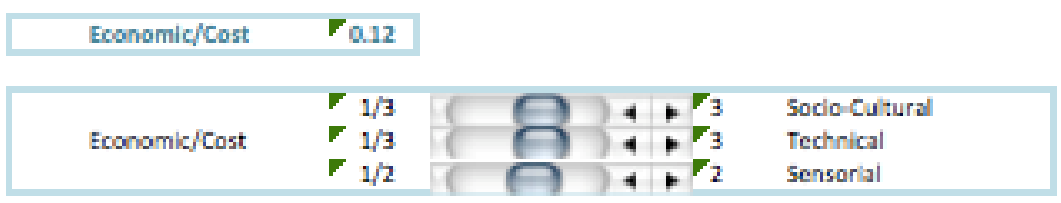

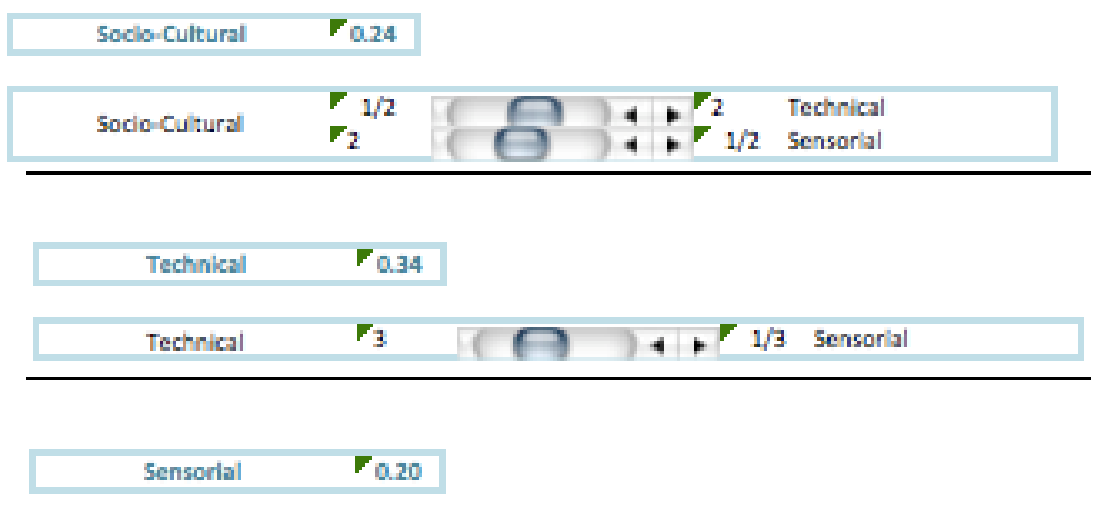

Figure 9. Consensus pair-wise comparison of main factors. 


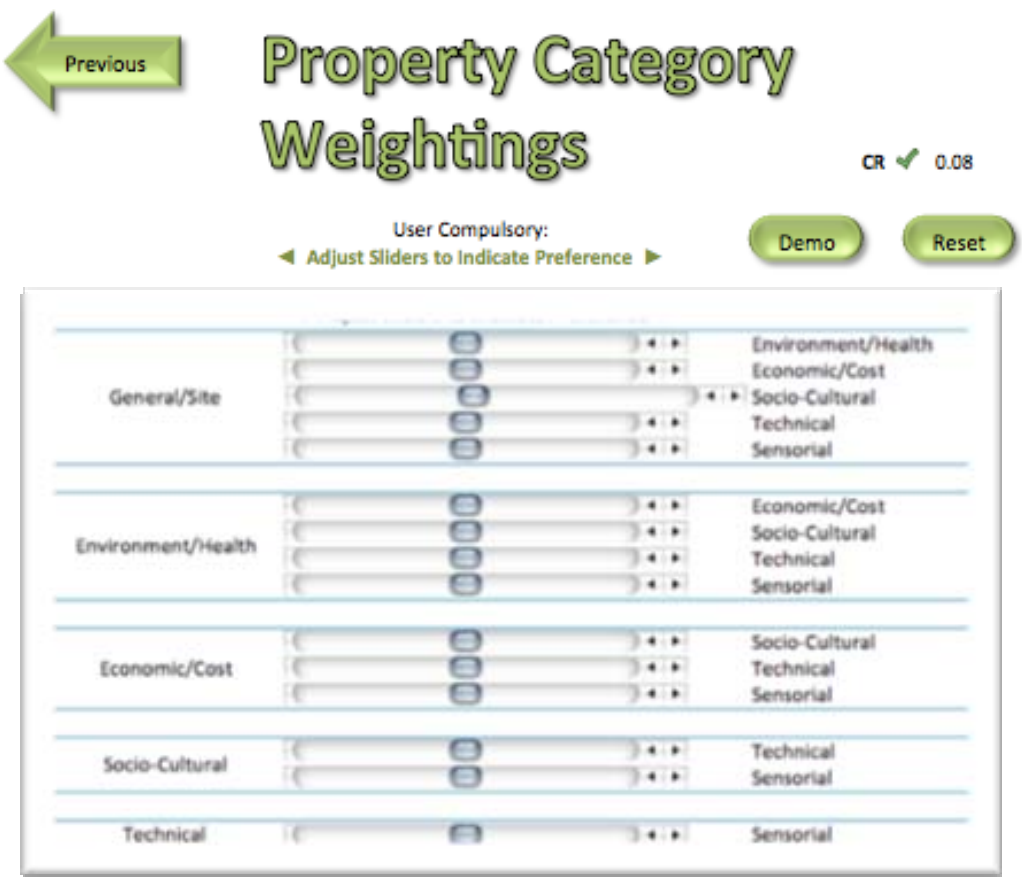

Figure 10. Consensus pair-wise comparison of main factors.

\begin{tabular}{|c|c|c|c|c|c|c|}
\hline & \multicolumn{6}{|c|}{ Weighted Criteria Matrix } \\
\hline & 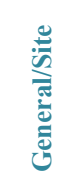 & 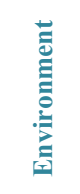 & 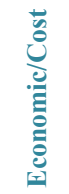 & 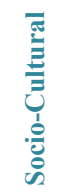 & 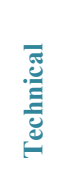 & 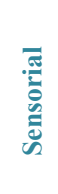 \\
\hline General/Site & 1.00 & 0.33 & 0.17 & 0.11 & 0.13 & 0.11 \\
\hline Environment/Health & 3.00 & 1.00 & 0.33 & 0.33 & 0.33 & 0.17 \\
\hline Economic/Cost & 6.00 & 3.00 & 1.00 & 0.33 & 0.33 & 0.50 \\
\hline Socio-Cultural & 9.00 & 3.00 & 3.00 & 1.00 & 0.50 & 2.00 \\
\hline Technical & 8.00 & 3.00 & 3.00 & 2.00 & 1.00 & 3.00 \\
\hline Sensorial & 9.00 & 6.00 & 2.00 & 0.50 & 0.33 & 1.00 \\
\hline Total & 36.00 & 16.33 & 9.50 & 4.28 & 2.63 & 6.78 \\
\hline
\end{tabular}

Figure 11. Results of pair-wise analysis of parent factors.

shown in Figure 12. A local priority vector score is then generated for the matrix of judgments by normalizing the vector in each column of the matrix (i.e. dividing each entry of the column by the column total) and then averaging over the rows of the resulting matrix [55]. The normalized eigenvector shown in Figure 12 represents the relative importance of each parent criteria.

Based on the calculation in Figure 11, the relative priorities of the parent factors in the final selection of a sustainable floor material were calculated as displayed in Figure 12. The resulting local priority vectors were given as: $(\mathrm{GS}=0.030, \mathrm{EH}=0.070, \mathrm{C}=0.120, \mathrm{SC}=$ $0.240, \mathrm{~T}=0.340$, and $\mathrm{SN}=0.200$ ) as shown in Table 5 .

In order to measure the level of consistency of the matrix for the parent factors, the consistency index (CI) was then calculated at 0.103 (see Figure 11). The random index (RI) was also taken into consideration and values calculated at this stage of the evaluation exercise. According to Saaty (2008), for matrix of order 6, the RI is 1.24 (see Table 6). Given the two values (consisting of both the consistency index $(\mathrm{CI}=0.103)$ and the relative index $(\mathrm{RI}=1.24)$, the $\mathrm{CR}$ was then calculated as: 


\begin{tabular}{|c|c|c|c|c|c|c|c|c|}
\hline & \multicolumn{6}{|c|}{ Normalised Average Criteria Matrix } & \multirow[b]{2}{*}{ Av. } & \multirow[b]{2}{*}{$\lambda_{\operatorname{MAX}}$} \\
\hline & 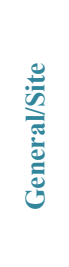 & 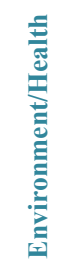 & 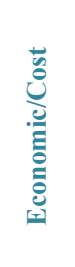 & 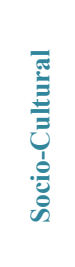 & 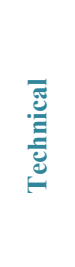 & 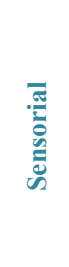 & & \\
\hline General/Site & 0.03 & 0.02 & 0.02 & 0.03 & 0.05 & 0.02 & 0.03 & 0.934297901 \\
\hline Environment/Health & 0.08 & 0.06 & 0.04 & 0.08 & 0.13 & 0.02 & 0.07 & 1.113775203 \\
\hline Economic/Cost & 0.17 & 0.18 & 0.11 & 0.08 & 0.13 & 0.07 & 0.12 & 1.162609985 \\
\hline Socio-Cultural & 0.25 & 0.18 & 0.32 & 0.23 & 0.19 & 0.30 & 0.24 & 1.04719097 \\
\hline Technical & 0.22 & 0.18 & 0.32 & 0.47 & 0.38 & 0.44 & 0.34 & 0.880596922 \\
\hline Sensorial & 0.25 & 0.37 & 0.21 & 0.12 & 0.13 & 0.15 & 0.20 & 1.377336489 \\
\hline \multirow[t]{5}{*}{ Total } & 1.00 & 1.00 & 1.00 & 1.00 & 1.00 & 1.00 & 1.00 & 6.52 \\
\hline & & & & & & & Matrix Size & 6 \\
\hline & & & & & & & RI & 1.24 \\
\hline & & & & & & & CI & 0.103 \\
\hline & & & & & & & CR & 0.083064516 \\
\hline
\end{tabular}

Figure 12. Relative priority scores of the parent factors.

Table 5. Derived priority scores of the parent factors.

\begin{tabular}{cc}
\hline Factor/Criterion & Relative Priority \\
\hline General/Site & 0.030 \\
Environmental/Health & 0.070 \\
Economic/Cost & 0.120 \\
Socio Cultural & 0.240 \\
Technical & 0.340 \\
Sensorial & 0.200 \\
\hline
\end{tabular}

Table 6. Random index values for $1 \leq \mathbf{n} \leq 15$.

$\begin{array}{llllllllllllllll}\mathrm{n} & 1 & 2 & 3 & 4 & 5 & 6 & 7 & 8 & 9 & 10 & 11 & 12 & 13 & 14 & 15\end{array}$

RI $\quad 0 \quad 0 \quad 0.58 \quad 0.91 .121 .241 .321 .411 .451 .491 .511 .541 .551 .571 .58$

$\mathrm{CR}=\mathrm{CI} / \mathrm{RI}=0.103 / 1.24=0.083$ (see Figure 11).

According to the AHP model, a matrix is considered as being consistent when the CR is less than $10 \%$. With a Consistency Ratio (CR) of 0.083 , the matrix was considered consistent since it was less than 0.1 .

\subsection{Pair-Wise Analysis of Sub-Factors}

The results of the next pair-wise comparison matrices amongst the relative sub-factors are shown from Figures 13-24. The same calculations done for the principal matrices of the parent factors were also done for the matri- ces of the sub-factors. The local priority vector and the consistency ratio for each sub-criterion matrix were also computed and displayed on each corresponding table as fully displayed below.

After comparing each sub-factor according to the user's system of value over other sub-factors, the weightings were obtained to establish each priority weightings in the context of the overall goal: selecting the most sustainable low-cost green floor material. The criteria matrices of each sub-factor were then normalised (by dividing a cell value by the sum of each column) and then checked for consistency as shown in Figures 13-24.

\subsection{Determining the Weightings of Sub-Factors}

The next stage of the assessment process was to find the final weightings of both the parent and sub-factors that will be used subsequently to evaluate the material attributes for sustainable building material selection. To determine the final weightings of the selected factors, the priority vectors (1) of the parent factors are multiplied by the corresponding relative priority vectors of each sub-criterion weighting vectors (2) to obtain the (final) weighting (3) as shown in Table 7.

The main/parent factor weighting is derived from users' judgment with respect to a single main criterion. The resultant value of the comparison of each parent factor serves as the priority vector of the main criteria needed for evaluating material attributes. The selected value for 
Table 7. Derived final weightings for G-site factors.

\begin{tabular}{|c|c|c|c|c|c|c|c|c|c|}
\hline \multicolumn{5}{|c|}{$\begin{array}{c}\text { Parent factor/Criteria } \\
\text { Weighting (1) }\end{array}$} & \multicolumn{4}{|c|}{$\begin{array}{l}\text { Sub-Factor/Criteria } \\
\text { Weighting (2) }\end{array}$} & \multirow{2}{*}{$\begin{array}{c}\begin{array}{c}\text { Final } \\
\text { Weighting (3) }\end{array} \\
\text { Total }=1.0000\end{array}$} \\
\hline Criteria & $\begin{array}{l}\text { User } \\
\text { Value }\end{array}$ & Default & $\begin{array}{c}\mathrm{CR} \\
<0.1\end{array}$ & $\begin{array}{l}\text { Selected } \\
\text { Value }\end{array}$ & Sub-Criteria & User Value & $\begin{array}{c}\mathrm{CR} \\
<0.1\end{array}$ & $\begin{array}{l}\text { Selected } \\
\text { Value }\end{array}$ & \\
\hline \multirow[t]{10}{*}{ General/Site } & 0.03 & 0.057 & 0.08 & 0.026 & GS1-Location (Mph) & 0.197 & 0.09 & 0.197 & 0.0051 \\
\hline & & & & & GS2-Material Availability & 0.158 & & 0.158 & 0.0041 \\
\hline & & & & & $\begin{array}{l}\text { GS3-Distance to Market } \\
\qquad(\mathrm{km} / \mathrm{h})\end{array}$ & 0.127 & & 0.127 & 0.0033 \\
\hline & & & & & $\begin{array}{l}\text { GS4-Building Certification } \\
\text { code }\end{array}$ & 0.115 & & 0.115 & 0.0030 \\
\hline & & & & & $\begin{array}{l}\text { GS6-Withstand site natural } \\
\text { disaster }\end{array}$ & 0.083 & & 0.083 & 0.0022 \\
\hline & & & & & $\begin{array}{l}\text { GS8-Conforms to site } \\
\text { geometry }\end{array}$ & 0.114 & & 0.114 & 0.0030 \\
\hline & & & & & $\begin{array}{l}\text { GS9-Conforms to spatial } \\
\text { structure }\end{array}$ & 0.069 & & 0.069 & 0.0018 \\
\hline & & & & & $\begin{array}{l}\text { GS10-Conforms to all spatial } \\
\text { activities }\end{array}$ & 0.053 & & 0.053 & 0.0014 \\
\hline & & & & & $\begin{array}{l}\text { GS11-Conforms to design } \\
\text { geometry }\end{array}$ & 0.044 & & 0.044 & 0.0012 \\
\hline & & & & & $\begin{array}{l}\text { GS12-Mat. Spatial scale/Size } \\
\text { (sq./m) }\end{array}$ & 0.040 & & 0.040 & 0.0010 \\
\hline
\end{tabular}

each parent factor as shown in Table 7 include: GS = $0.026, \mathrm{EH}=0.068, \mathrm{C}=0.122, \mathrm{SC}=0.245, \mathrm{~T}=0.335$ and $\mathrm{SN}=0.203$

The sub-factor weighting is derived from user's judgment with respect to each sub-factor. Some of the selected values that serve as the corresponding relative priority vectors of the general/site variable include: 0.197 , $0.158,0.127,0.115,0.083,0.114,0.069,0.053,0.044$, and 0.040 as shown in Table 7.

Final weighting is derived from multiplying the selected value of the main criteria-weighting or priority vector by the selected value of the sub-factor priority vector. This entry is obtained as follows: $0.026 \times 0.197=$ 0.005122 (as highlighted in Table 7). The same process was applied to the other parent factors of the respective categories. The following steps describe the ways by which the various weighting vectors of each criterion are derived.

\subsection{Pair-Wise Comparison of the Selected Material Alternatives against Each Sub-Factor}

The final step of the exercise was for the respondents to compare each pair of low-cost green material alternatives with respect to each sub-factor. Here the user evaluates the criteria/factors and material alternatives by comparing them through direct rating, to know which factor is more important; how many times; and which material alternative is better in the context of each factor.

The corresponding weightings were based on the im- portance that the evaluators attached to the dominance of each material alternative relative to all other alternatives under each sub-criterion. These matrices were also normalized and checked for consistency as shown in Figures 25-38.

Figures 25-38 present some results of the analyses, which explain the pair-wise matrix priority weightings and normalisation of the various materials with respect to each sub-criterion.

\subsection{Determining the Weightings of Sub-Factors}

The next phase, after analysing the pair-wise matrices of the sub-factors against the various low-cost green floor material alternatives was to normalize the priority weights for each pair-wise comparison judgment matrices. Once the normalised matrices of the floor material alternatives and various sub-factors were obtained, the values derived from the analysis were multiplied and summed to obtain the final composite priority weights of all material alternatives, focusing particularly on the three floor materials used in the fourth level of the AHP model of decision-making shown in Figure 6.

In this case, the final weighting scores (obtained from multiplying the priorities vectors of the parent criteria with that of individual sub-factors), is further multiplied by the priority vector of each material alternative after the pair-wise comparison against each sub-factor (as shown in Figure 38). This resulted in a final composite priority/weighting score of each sub-factor for the three floor material alternatives. 


\begin{tabular}{lccccccccccc}
\hline & Score & GS1 & GS2 & GS3 & GS4 & GS6 & GS8 & GS9 & GS10 & GS11 & GS12 \\
\hline GS1-Location (Mph) & 0.197 & 1.00 & 2.00 & 3.00 & 2.00 & 4.00 & 2.00 & 2.00 & 2.00 & 3.00 & 3.00 \\
GS2-Material Availability & 0.158 & 0.50 & 1.00 & 2.00 & 2.00 & 2.00 & 3.00 & 3.00 & 3.00 & 2.00 & 3.00 \\
GS3-Distance to Market (km/h) & 0.127 & 0.33 & 0.50 & 1.00 & 2.00 & 2.00 & 2.00 & 3.00 & 3.00 & 3.00 & 2.00 \\
GS4-Building Certification code & 0.115 & 0.50 & 0.50 & 0.50 & 1.00 & 2.00 & 2.00 & 3.00 & 2.00 & 4.00 & 2.00 \\
GS6-Withstand site natural disaster & 0.083 & 0.25 & 0.50 & 0.50 & 0.50 & 1.00 & 2.00 & 2.00 & 2.00 & 2.00 & 2.00 \\
GS8-Conforms to site geometry & 0.114 & 0.50 & 0.33 & 0.50 & 0.50 & 0.50 & 1.00 & 3.00 & 7.00 & 3.00 & 4.00 \\
GS9-Conforms to spatial structure & 0.069 & 0.50 & 0.33 & 0.33 & 0.33 & 0.50 & 0.33 & 1.00 & 3.00 & 3.00 & 2.00 \\
GS10-Conforms to all spatial activities & 0.053 & 0.50 & 0.33 & 0.33 & 0.50 & 0.50 & 0.14 & 0.33 & 1.00 & 2.00 & 2.00 \\
GS11-Conforms to design geometry & 0.044 & 0.33 & 0.50 & 0.33 & 0.25 & 0.50 & 0.33 & 0.33 & 0.50 & 1.00 & 2.00 \\
GS12-Mat. Spatial scale/Size (sq./m) & 0.040 & 0.33 & 0.33 & 0.50 & 0.50 & 0.50 & 0.25 & 0.50 & 0.50 & 0.50 & 1.00 \\
CR & 0.09 & & & & & & & & & \\
\hline
\end{tabular}

Figure 13. Pair-wise matrix for general/site factors.

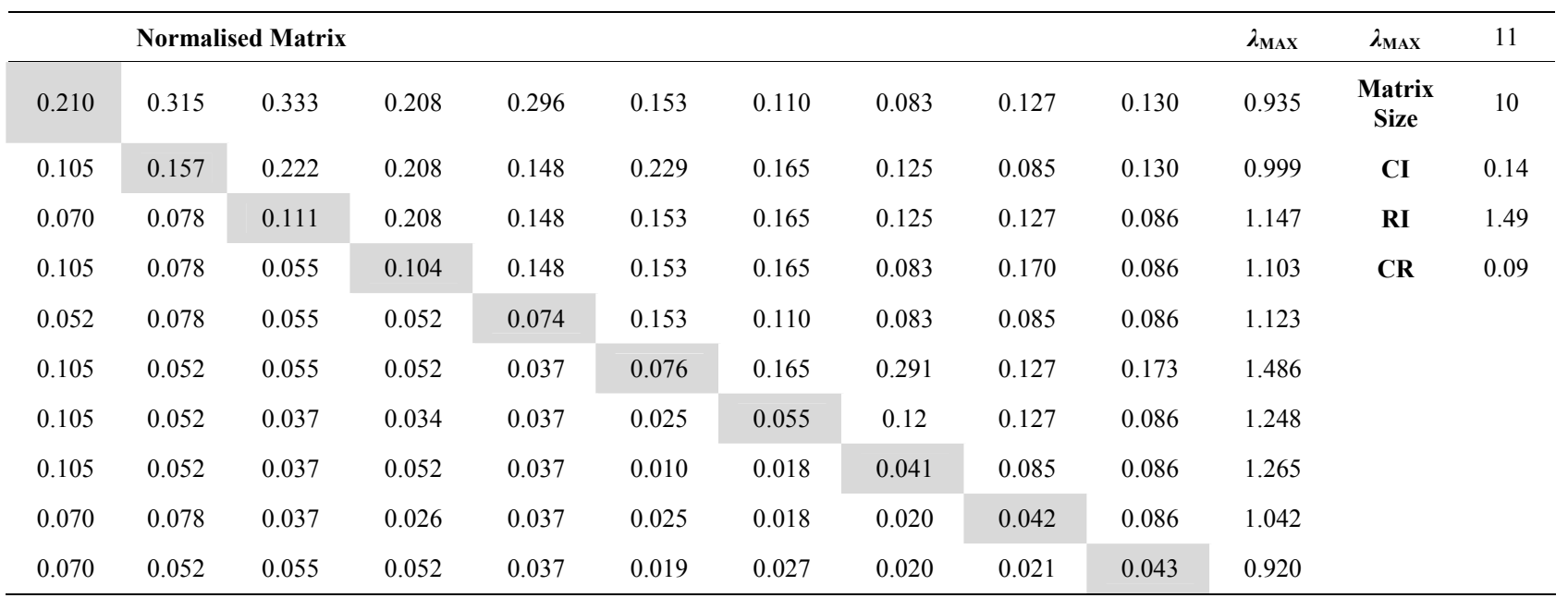

Figure 14. Normalised matrix for general/site factors.

\begin{tabular}{|c|c|c|c|c|c|c|c|c|c|c|c|}
\hline & Score & EH1 & $\mathrm{EH} 2$ & $\mathrm{EH} 3$ & $\mathrm{EH} 4$ & EH5 & EH6 & EH7 & $\mathrm{EH} 8$ & EH9 & EH10 \\
\hline EH1-Env. Statutory Compliance & 0.202 & 1.00 & 4.00 & 3.00 & 2.00 & 2.00 & 3.00 & 3.00 & 2.00 & 2.00 & 2.00 \\
\hline EH2-Embodied $\mathrm{CO}_{2}$ Emission $\left(\mathrm{KgCO}_{2} / \mathrm{m}^{2}\right)$ & 0.124 & 0.25 & 1.00 & 2.00 & 3.00 & 2.00 & 2.00 & 2.00 & 2.00 & 3.00 & 0.50 \\
\hline EH3-Human Toxicity-Users Safety level & 0.113 & 0.33 & 0.50 & 1.00 & 2.00 & 2.00 & 2.00 & 3.00 & 3.00 & 3.00 & 0.50 \\
\hline EH4-Ozone depletion rate & 0.086 & 0.50 & 0.33 & 0.50 & 1.00 & 2.00 & 2.00 & 2.00 & 2.00 & 2.00 & 0.33 \\
\hline EH5-Amt. of Pesticide Treatment $\left(1 / \mathrm{m}^{2}\right)$ & 0.078 & 0.50 & 0.50 & 0.50 & 0.50 & 1.00 & 2.00 & 3.00 & 2.00 & 0.33 & 0.50 \\
\hline EH6-Complies with the Climate of the region & 0.067 & 0.33 & 0.50 & 0.50 & 0.50 & 0.50 & 1.00 & 2.00 & 2.00 & 2.00 & 0.50 \\
\hline EH7-Env. Toxicity (land, water, Animals) & 0.053 & 0.33 & 0.50 & 0.33 & 0.50 & 0.33 & 0.50 & 1.00 & 2.00 & 2.00 & 0.33 \\
\hline EH8-Fossil fuel/Habitat depletion & 0.058 & 0.50 & 0.50 & 0.33 & 0.50 & 0.50 & 0.50 & 0.50 & 1.00 & 4.00 & 0.25 \\
\hline EH9-Nuclear waste rate & 0.057 & 0.50 & 0.33 & 0.33 & 0.50 & 3.00 & 0.50 & 0.50 & 0.25 & 1.00 & 0.33 \\
\hline EH10-Waste Disposal rate & 0.162 & 0.50 & 2.00 & 2.00 & 3.00 & 2.00 & 2.00 & 3.00 & 4.00 & 3.00 & 1.00 \\
\hline CR & 0.10 & & & & & & & & & & \\
\hline
\end{tabular}

Figure 15. Pair-wise matrix for environmental factors. 
A Multi-Criteria Decision Support System for the Selection of Low-Cost Green Building Materials and Components

\begin{tabular}{|c|c|c|c|c|c|c|c|c|c|c|c|c|}
\hline \multicolumn{10}{|c|}{ Normalised Matrix } & \multirow{2}{*}{$\begin{array}{l}\lambda_{\text {MAX }} \\
0.960\end{array}$} & \multirow{2}{*}{$\frac{\lambda_{\mathrm{MAX}}}{\text { Matrix Size }}$} & \multirow{2}{*}{$\begin{array}{l}11 \\
10\end{array}$} \\
\hline 0.210 & 0.393 & 0.285 & 0.148 & 0.130 & 0.193 & 0.15 & 0.098 & 0.089 & 0.32 & & & \\
\hline 0.052 & 0.098 & 0.190 & 0.222 & 0.130 & 0.129 & 0.1 & 0.098 & 0.134 & 0.08 & 1.257 & CI & 0.15 \\
\hline 0.070 & 0.049 & 0.095 & 0.148 & 0.130 & 0.129 & 0.15 & 0.148 & 0.134 & 0.08 & 1.191 & RI & 1.49 \\
\hline 0.105 & 0.032 & 0.047 & 0.074 & 0.130 & 0.129 & 0.1 & 0.098 & 0.089 & 0.05 & 1.162 & CR & 0.10 \\
\hline 0.105 & 0.049 & 0.047 & 0.037 & 0.065 & 0.129 & 0.15 & 0.098 & 0.014 & 0.08 & 1.191 & & \\
\hline 0.070 & 0.049 & 0.047 & 0.037 & 0.032 & 0.064 & 0.1 & 0.098 & 0.089 & 0.08 & 1.038 & & \\
\hline 0.070 & 0.049 & 0.031 & 0.037 & 0.020 & 0.032 & 0.05 & 0.098 & 0.089 & 0.05 & 1.068 & & \\
\hline 0.105 & 0.049 & 0.031 & 0.037 & 0.032 & 0.032 & 0.025 & 0.049 & 0.179 & 0.04 & 1.178 & & \\
\hline 0.105 & 0.032 & 0.031 & 0.037 & 0.195 & 0.032 & 0.025 & 0.012 & 0.044 & 0.05 & 1.273 & & \\
\hline 0.105 & 0.196 & 0.190 & 0.222 & 0.130 & 0.129 & 0.15 & 0.197 & 0.134 & 0.16 & 1.010 & & \\
\hline
\end{tabular}

Figure 16. Normalised matrix for environmental factors.

\begin{tabular}{lccccccc}
\hline & Score & C1 & C2 & C3 & C4 & C5 & C6 \\
\hline C1-Total life-cycle cost (\$) & 0.347 & 1.00 & 2.00 & 2.00 & 3.00 & 5.00 & 9.00 \\
C2-Material embodied energy cost (\$) & 0.247 & 0.50 & 1.00 & 2.00 & 4.00 & 4.00 & 3.00 \\
C3-Material capital cost (\$) & 0.186 & 0.50 & 0.50 & 1.00 & 2.00 & 4.00 & 6.00 \\
C4-Labour/Installation cost (\$sqft) & 0.120 & 0.33 & 0.25 & 0.50 & 1.00 & 3.00 & 5.00 \\
C5-Material replacement cost (\$) & 0.063 & 0.20 & 0.25 & 0.25 & 0.33 & 1.00 & 3.00 \\
C6-Material Maintenance cost (\$) & 0.037 & 0.11 & 0.33 & 0.17 & 0.20 & 0.33 & 1.00 \\
CR & 0.07 & & & & & & \\
\hline
\end{tabular}

Figure 17. Pair-wise matrix for economic/cost factors.

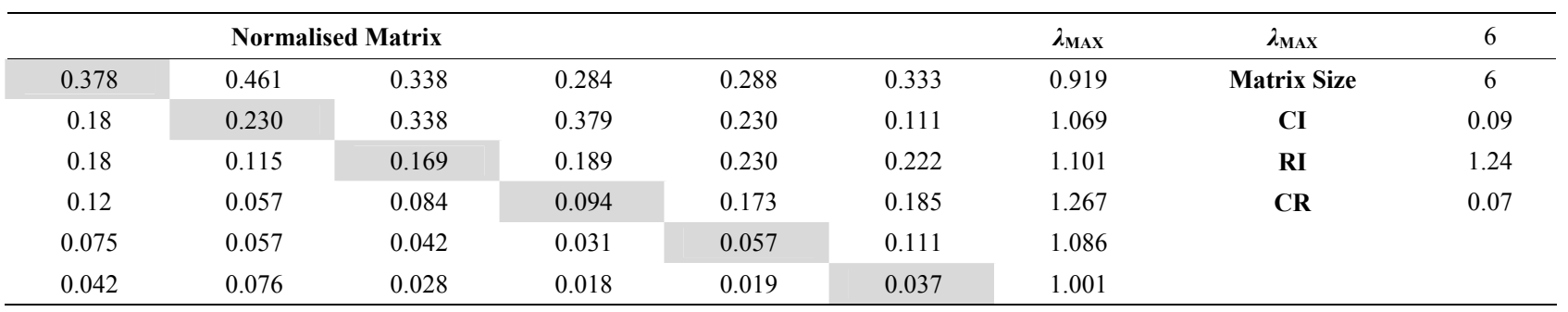

Figure 18. Normalised matrix for economic/cost factors.

\begin{tabular}{lllllll}
\hline & Score & SC1 & SC2 & SC3 & SC4 & SC5 \\
\hline SC1-Material compatibility with traditions & 0.164 & 1.00 & 2.00 & 0.33 & 0.50 & 2.00 \\
SC2-Material compatibility with region & 0.102 & 0.50 & 1.00 & 0.50 & 0.50 & 0.33 \\
SC3-Cultural restriction on usury & 0.362 & 3.00 & 2.00 & 1.00 & 2.00 & 3.00 \\
SC4-Client's preference rating & 0.227 & 2.00 & 2.00 & 0.50 & 1.00 & 2.00 \\
SC5-Conforms to Knowledge of custom & 0.146 & 0.50 & 3.00 & 0.33 & 0.50 & 1.00 \\
CR & 0.08 & & & & & \\
\hline
\end{tabular}

Figure 19. Pair-wise matrix for socio-cultural factors.

\begin{tabular}{|c|c|c|c|c|c|c|c|}
\hline \multicolumn{5}{|c|}{ Normalised Matrix } & $\lambda_{\operatorname{MAX}}$ & $\lambda_{\mathrm{MAX}}$ & 5 \\
\hline 0.142 & 0.2 & 0.125 & 0.111 & 0.24 & 1.147 & Matrix Size & 5 \\
\hline 0.071 & 0.1 & 0.187 & 0.111 & 0.04 & 1.020 & CI & 0.09 \\
\hline 0.428 & 0.2 & 0.375 & 0.444 & 0.36 & 0.964 & RI & 1.12 \\
\hline 0.285 & 0.2 & 0.1875 & 0.222 & 0.24 & 1.022 & CR & 0.08 \\
\hline 0.071 & 0.3 & 0.125 & 0.111 & 0.12 & 1.213 & & \\
\hline
\end{tabular}

Figure 20. Normalised matrix for socio-cultural factors. 


\begin{tabular}{|c|c|c|c|c|c|c|c|c|c|c|c|c|c|c|c|c|c|c|c|}
\hline & Score & $\mathrm{T} 1$ & $\mathrm{~T} 2$ & $\mathrm{~T} 3$ & $\mathrm{~T} 4$ & $\mathrm{~T} 5$ & $\mathrm{~T} 6$ & $\mathrm{~T} 7$ & $\mathrm{~T} 8$ & T9 & $\mathrm{T} 10$ & $\mathrm{~T} 11$ & $\mathrm{~T} 12$ & $\mathrm{~T} 13$ & $\mathrm{~T} 14$ & $\mathrm{~T} 15$ & $\mathrm{~T} 16$ & $\mathrm{~T} 17$ & $\mathrm{~T} 17$ \\
\hline yclable & 0.09 & 1.00 & 2.00 & 2.00 & 3.00 & 0.50 & 2.00 & 2.00 & 0.50 & 0.50 & 2.00 & 3.00 & 2.00 & 2.00 & 2.00 & 3.00 & 0.50 & 0.33 & 0.50 \\
\hline T2-Ease to remove & 0.10 & 0.50 & 1.00 & 0.33 & 0.33 & 0.33 & 3.00 & 2.00 & 3.00 & 0.50 & 2.00 & 3.00 & 2.00 & 2.00 & 3.00 & 2.00 & 3.00 & 2.00 & 2.00 \\
\hline T3- Maintenance level & 0.06 & 0.50 & 3.00 & 1.00 & 1.00 & 1.00 & 1.00 & 1.00 & 1.00 & 1.00 & 1.00 & 1.00 & 1.00 & 1.00 & 1.00 & 1.00 & 1.00 & 1.00 & 1.00 \\
\hline T4-Expansion Tolerance & 0.06 & 0.33 & 3.00 & 1.00 & 1.00 & 1.00 & 1.00 & 1.00 & 1.00 & 1.00 & 1.00 & 1.00 & 1.00 & 1.00 & 1.00 & 1.00 & 1.00 & 1.00 & 1.00 \\
\hline T5-Conforms to skills & 0.06 & 2.00 & 3.00 & 1.00 & 1.00 & 1.00 & 1.00 & 1.00 & 1.00 & 1.00 & 1.00 & 1.00 & 1.00 & 1.00 & 1.00 & 1.00 & 1.00 & 1.00 & 1.00 \\
\hline T6-Ease of fixing & 0.05 & 0.50 & 0.33 & 1.00 & 1.00 & 1.00 & 1.00 & 1.00 & 1.00 & 1.00 & 1.00 & 1.00 & 1.00 & 1.00 & 1.00 & 1.00 & 1.00 & 1.00 & 1.00 \\
\hline T7-Fire resistance & 0.04 & 0.50 & 0.50 & 1.00 & 1.00 & 1.00 & 1.00 & 1.00 & 1.00 & 1.00 & 1.00 & 1.00 & 1.00 & 0.11 & 1.00 & 0.14 & 1.00 & 1.00 & 1.00 \\
\hline T8-Thermal resistance & 0.05 & 2.00 & 0.33 & 1.00 & 1.00 & 1.00 & 1.00 & 1.00 & 1.00 & 1.00 & 1.00 & 1.00 & 1.00 & 1.00 & 1.00 & 1.00 & 0.14 & 1.00 & 1.00 \\
\hline T9-Mo & 0 & 2.00 & 2.00 & 1.00 & 1.00 & 1.00 & 1.00 & 0 & 00 & 1.00 & 00 & 1.00 & 00 & 1.00 & 0 & 00 & 00 & 1.00 & 1.00 \\
\hline T10-Scratch resistance & 0.05 & 0.50 & 0.50 & 1.00 & 1.00 & 1.00 & 1.00 & 1.00 & 1.00 & 1.00 & 1.00 & 1.00 & 1.00 & 1.00 & 1.00 & 1.00 & 1.00 & 1.00 & 1.00 \\
\hline T11-Weather resistance & 0.05 & 0.33 & 0.33 & 1.00 & 1.00 & 1.00 & 1.00 & 1.00 & 1.00 & 1.00 & 1.00 & 1.00 & 1.00 & 1.00 & 1.00 & 1.00 & 1.00 & 1.00 & 1.00 \\
\hline T12-Chemical resistance & 0.05 & 0.50 & 0.50 & 1.00 & 1.00 & 1.00 & 1.00 & 1.00 & 1.00 & 1.00 & 1.00 & 1.00 & 1.00 & 1.00 & 1.00 & 1.00 & 1.00 & 1.00 & 1.00 \\
\hline T13-Resistance to decay & 0.07 & 0.50 & 0.50 & 1.00 & 1.00 & 1.00 & 1.00 & 9.00 & 1.00 & 1.00 & 1.00 & 1.00 & 1.00 & 1.00 & 1.00 & 1.00 & 1.00 & 1.00 & 1.00 \\
\hline T14-Weight of material & 0.05 & 0.50 & 0.33 & 1.00 & 1.00 & 1.00 & 1.00 & 1.00 & 1.00 & 1.00 & 1.00 & 1.00 & 1.00 & 1.00 & 1.00 & 1.00 & 1.00 & 1.00 & 1.00 \\
\hline T15-Life expectancy & 0.07 & 0.33 & 0.50 & 1.00 & 1.00 & 1.00 & 1.00 & 7.00 & 1.00 & 1.00 & 1.00 & 1.00 & 1.00 & 1.00 & 1.00 & 1.00 & 0.25 & 1.00 & 1.00 \\
\hline T16-Biodegradable & 0.08 & 2.00 & 0.33 & 1.00 & 1.00 & 1.00 & 1.00 & 1.00 & 7.00 & 1.00 & 1.00 & 1.00 & 1.00 & 1.00 & 1.00 & 4.00 & 1.00 & 1.00 & 1.00 \\
\hline T17-UV Resistance & 0.06 & 3.00 & 0.50 & 1.00 & 1.00 & 1.00 & 1.00 & 1.00 & 1.00 & 1.00 & 1.00 & 1.00 & 1.00 & 1.00 & 1.00 & 1.00 & 1.00 & 1.00 & 1.00 \\
\hline T18-Compatibility & 0.05 & 0.50 & 1.00 & 1.00 & 1.00 & 1.00 & 1.00 & 1.00 & 1.00 & 1.00 & 1.00 & 1.00 & 1.00 & 1.00 & 1.00 & 1.00 & 1.00 & 1.00 & 1.00 \\
\hline CR & 0.09 & & & & & & & & & & & & & & & & & & \\
\hline
\end{tabular}

Figure 21. Pair-wise matrix for technical factors.

\begin{tabular}{|c|c|c|c|c|c|c|c|c|c|c|c|c|c|c|c|c|c|c|c|c|}
\hline \multicolumn{18}{|c|}{ Normalised Matrix } & \multirow{2}{*}{$\begin{array}{l}\lambda_{\mathrm{MAX}} \\
1.602\end{array}$} & \multirow{2}{*}{$\begin{array}{c}\lambda_{\operatorname{MAX}} \\
\text { Size }\end{array}$} & \multirow{2}{*}{$\begin{array}{l}21 \\
18\end{array}$} \\
\hline 0.05 & 0.11 & 0.11 & 0.17 & 0.02 & 0.11 & 0.11 & 0.02 & 0.02 & 0.11 & 0.17 & 0.11 & 0.11 & 0.11 & 0.17 & 0.02 & 0.01 & 0.02 & & & \\
\hline 0.02 & 0.05 & 0.01 & 0.01 & 0.01 & 0.17 & 0.11 & 0.17 & 0.02 & 0.11 & 0.17 & 0.11 & 0.11 & 0.17 & 0.11 & 0.17 & 0.11 & 0.11 & 1.778 & CI & 0.15 \\
\hline 0.02 & 0.17 & 0.05 & 0.05 & 0.05 & 0.05 & 0.05 & 0.05 & 0.05 & 0.05 & 0.05 & 0.05 & 0.05 & 0.05 & 0.05 & 0.05 & 0.05 & 0.05 & 1.083 & RI & 1.69 \\
\hline 0.01 & 0.17 & 0.05 & 0.05 & 0.05 & 0.05 & 0.05 & 0.05 & 0.05 & 0.05 & 0.05 & 0.05 & 0.05 & 0.05 & 0.05 & 0.05 & 0.05 & 0.05 & 1.074 & CR & 0.09 \\
\hline 0.11 & 0.17 & 0.05 & 0.05 & 0.05 & 0.05 & 0.05 & 0.05 & 0.05 & 0.05 & 0.05 & 0.05 & 0.05 & 0.05 & 0.05 & 0.05 & 0.05 & 0.05 & 1.167 & & \\
\hline 0.02 & 0.01 & 0.05 & 0.05 & 0.05 & 0.05 & 0.05 & 0.05 & 0.05 & 0.05 & 0.05 & 0.05 & 0.05 & 0.05 & 0.05 & 0.05 & 0.05 & 0.05 & 0.935 & & \\
\hline 0.02 & 0.02 & 0.05 & 0.05 & 0.05 & 0.05 & 0.05 & 0.05 & 0.05 & 0.05 & 0.05 & 0.05 & 0.00 & 0.05 & 0.01 & 0.05 & 0.05 & 0.05 & 0.847 & & \\
\hline 0.11 & 0.01 & 0.05 & 0.05 & 0.05 & 0.05 & 0.05 & 0.05 & 0.05 & 0.05 & 0.05 & 0.05 & 0.05 & 0.05 & 0.05 & 0.01 & 0.05 & 0.05 & 0.971 & & \\
\hline 0.11 & 0.11 & 0.05 & 0.05 & 0.05 & 0.05 & 0.05 & 0.05 & 0.05 & 0.05 & 0.05 & 0.05 & 0.05 & 0.05 & 0.05 & 0.05 & 0.05 & 0.05 & 1.111 & & \\
\hline 0.02 & 0.02 & 0.05 & 0.05 & 0.05 & 0.05 & 0.05 & 0.05 & 0.05 & 0.05 & 0.05 & 0.05 & 0.05 & 0.05 & 0.05 & 0.05 & 0.05 & 0.05 & 0.944 & & \\
\hline 0.01 & 0.01 & 0.05 & 0.05 & 0.05 & 0.05 & 0.05 & 0.05 & 0.05 & 0.05 & 0.05 & 0.05 & 0.05 & 0.05 & 0.05 & 0.05 & 0.05 & 0.05 & 0.926 & & \\
\hline 0.02 & 0.02 & 0.05 & 0.05 & 0.05 & 0.05 & 0.05 & 0.05 & 0.05 & 0.05 & 0.05 & 0.05 & 0.05 & 0.05 & 0.05 & 0.05 & 0.05 & 0.05 & 0.944 & & \\
\hline 0.02 & 0.02 & 0.05 & 0.05 & 0.05 & 0.05 & 0.51 & 0.05 & 0.05 & 0.05 & 0.05 & 0.05 & 0.05 & 0.05 & 0.05 & 0.05 & 0.05 & 0.05 & 1.389 & & \\
\hline 0.02 & 0.01 & 0.05 & 0.05 & 0.05 & 0.05 & 0.05 & 0.05 & 0.05 & 0.05 & 0.05 & 0.05 & 0.05 & 0.05 & 0.05 & 0.05 & 0.05 & 0.05 & 0.935 & & \\
\hline 0.01 & 0.02 & 0.05 & 0.05 & 0.05 & 0.05 & 0.4 & 0.05 & 0.05 & 0.05 & 0.05 & 0.05 & 0.05 & 0.05 & 0.05 & 0.01 & 0.05 & 0.05 & 1.227 & & \\
\hline 0.11 & 0.01 & 0.05 & 0.05 & 0.05 & 0.05 & 0.05 & 0.4 & 0.05 & 0.05 & 0.05 & 0.05 & 0.05 & 0.05 & 0.22 & 0.05 & 0.05 & 0.05 & 1.519 & & \\
\hline 0.17 & 0.02 & 0.05 & 0.05 & 0.05 & 0.05 & 0.05 & 0.05 & 0.05 & 0.05 & 0.05 & 0.05 & 0.05 & 0.05 & 0.05 & 0.05 & 0.05 & 0.05 & 1.083 & & \\
\hline 0.02 & 0.05 & 0.05 & 0.05 & 0.05 & 0.05 & 0.05 & 0.05 & 0.05 & 0.05 & 0.05 & 0.05 & 0.05 & 0.05 & 0.05 & 0.05 & 0.05 & 0.05 & 0.972 & & \\
\hline
\end{tabular}

Figure 22. Normalised matrix for technical factors. 


\begin{tabular}{lcccccccccccccc}
\hline & Score & SN1 & SN2 & SN3 & SN4 & SN5 & SN6 & SN7 & SN8 & SN9 & SN10 & SN11 & SN12 & SN13 \\
\hline SN1-Aesthetics & 0.077 & 1.00 & 1 & 1 & 1 & 1 & 1 & 1 & 1 & 1 & 1 & 1 & 1 & 1 \\
SN2-Texture & 0.077 & 1.00 & 1.00 & 1 & 1 & 1 & 1 & 1 & 1 & 1 & 1 & 1 & 1 & 1 \\
SN3-Colour & 0.077 & 1.00 & 1.00 & 1.00 & 1 & 1 & 1 & 1 & 1 & 1 & 1 & 1 & 1 & 1 \\
SN4-Temperature & 0.077 & 1.00 & 1.00 & 1.00 & 1.00 & 1 & 1 & 1 & 1 & 1 & 1 & 1 & 1 & 1 \\
SN5-Acoustics & 0.106 & 1.00 & 1.00 & 1.00 & 1.00 & 1.00 & 2 & 0 & 4 & 0 & 2 & 0 & 2 & 2 \\
SN6-Odour & 0.087 & 1.00 & 1.00 & 1.00 & 1.00 & 0.50 & 1.00 & 2 & 1 & 0 & 2 & 1 & 2 & 2 \\
SN7-Thickness/Thinness & 0.107 & 1.00 & 1.00 & 1.00 & 1.00 & 3.00 & 0.50 & 1.00 & 2 & 2 & 2 & 3 & 0 & 0 \\
SN8-Glossiness/fineness & 0.075 & 1.00 & 1.00 & 1.00 & 1.00 & 0.25 & 2.00 & 0.50 & 1.00 & 1 & 1 & 1 & 1 & 1 \\
SN9-Strength/Hardness & 0.109 & 1.00 & 1.00 & 1.00 & 1.00 & 3.00 & 5.00 & 0.50 & 1.00 & 1.00 & 1 & 1 & 1 & 1 \\
SN10-Lighting effect & 0.068 & 1.00 & 1.00 & 1.00 & 1.00 & 0.50 & 0.50 & 0.50 & 1.00 & 1.00 & 1.00 & 1 & 1 & 1 \\
SN11-Translucence & 0.108 & 1.00 & 1.00 & 1.00 & 1.00 & 6.00 & 2.00 & 0.33 & 1.00 & 1.00 & 1.00 & 1.00 & 1 & 1 \\
SN12-Structure & 0.089 & 1.00 & 1.00 & 1.00 & 1.00 & 0.50 & 0.50 & 4.00 & 1.00 & 1.00 & 1.00 & 1.00 & 1.00 & 1 \\
SN13-Thermal & 0.083 & 1.00 & 1.00 & 1.00 & 1.00 & 0.50 & 0.50 & 3.00 & 1.00 & 1.00 & 1.00 & 1.00 & 1.00 & 1.00 \\
CR & 0.10 & & & & & & & & & & & & \\
\hline
\end{tabular}

Figure 23. Pair-wise matrix for sensorial factors.

\begin{tabular}{|c|c|c|c|c|c|c|c|c|c|c|c|c|c|c|c|}
\hline \multicolumn{4}{|c|}{ Normalised Matrix } & \multirow[b]{2}{*}{0.076} & \multirow[b]{2}{*}{0.076} & \multirow[b]{2}{*}{0.076} & \multirow[b]{2}{*}{0.076} & \multirow[b]{2}{*}{0.076} & \multirow[b]{2}{*}{0.076} & \multirow[b]{2}{*}{0.076} & \multirow[b]{2}{*}{0.076} & \multirow[b]{2}{*}{0.076} & \multirow{2}{*}{$\begin{array}{l}\lambda_{\mathrm{MAX}} \\
1.000\end{array}$} & \multirow{2}{*}{$\begin{array}{c}\lambda_{\operatorname{MAX}} \\
\text { Matrix Size }\end{array}$} & \multirow{2}{*}{$\begin{array}{l}15 \\
13\end{array}$} \\
\hline 0.076 & 0.076 & 0.076 & 0.076 & & & & & & & & & & & & \\
\hline 0.076 & 0.076 & 0.076 & 0.076 & 0.076 & 0.076 & 0.076 & 0.076 & 0.076 & 0.076 & 0.076 & 0.076 & 0.076 & 1.000 & CI & 0.15 \\
\hline 0.076 & 0.076 & 0.076 & 0.076 & 0.076 & 0.076 & 0.076 & 0.076 & 0.076 & 0.076 & 0.076 & 0.076 & 0.076 & 1.000 & RI & 1.5551 \\
\hline 0.076 & 0.076 & 0.076 & 0.076 & 0.076 & 0.076 & 0.076 & 0.076 & 0.076 & 0.076 & 0.076 & 0.076 & 0.076 & 1.000 & CR & 0.10 \\
\hline 0.076 & 0.076 & 0.076 & 0.076 & 0.076 & 0.153 & 0.025 & 0.307 & 0.025 & 0.153 & 0.012 & 0.153 & 0.153 & 1.372 & & \\
\hline 0.076 & 0.076 & 0.076 & 0.076 & 0.038 & 0.076 & 0.153 & 0.038 & 0.015 & 0.153 & 0.038 & 0.153 & 0.153 & 1.131 & & \\
\hline 0.076 & 0.076 & 0.076 & 0.076 & 0.230 & 0.038 & 0.076 & 0.153 & 0.153 & 0.153 & 0.230 & 0.019 & 0.025 & 1.391 & & \\
\hline 0.076 & 0.076 & 0.076 & 0.076 & 0.019 & 0.153 & 0.038 & 0.076 & 0.076 & 0.076 & 0.076 & 0.076 & 0.076 & 0.981 & & \\
\hline 0.076 & 0.076 & 0.076 & 0.076 & 0.230 & 0.384 & 0.038 & 0.076 & 0.076 & 0.076 & 0.076 & 0.076 & 0.076 & 1.423 & & \\
\hline 0.076 & 0.076 & 0.076 & 0.076 & 0.038 & 0.038 & 0.038 & 0.076 & 0.076 & 0.076 & 0.076 & 0.076 & 0.076 & 0.885 & & \\
\hline 0.076 & 0.076 & 0.076 & 0.076 & 0.461 & 0.153 & 0.025 & 0.076 & 0.076 & 0.076 & 0.076 & 0.076 & 0.076 & 1.410 & & \\
\hline 0.076 & 0.076 & 0.076 & 0.076 & 0.038 & 0.038 & 0.307 & 0.076 & 0.076 & 0.076 & 0.076 & 0.076 & 0.076 & 1.154 & & \\
\hline 0.076 & 0.076 & 0.076 & 0.076 & 0.038 & 0.038 & 0.230 & 0.076 & 0.076 & 0.076 & 0.076 & 0.076 & 0.076 & 1.077 & & \\
\hline
\end{tabular}

Figure 24. Normalised matrix for sensorial factors.

Using the priorities determined through these matrices, the weighted overall priority of each candidate material was determined. The amalgamation method yielded a single green utility index of alternative worth, which allowed the material options to be ranked according to their overall priorities. The material with the highest score then becomes the selected candidate material as shown in Figure 38. Looking at Figure 38, it is clear from the results of the analysis that Material option (A) turns out to be the most preferred material among the three material options identified in Table 4, with an overall priority or index score of 0.086 . It is based on the concept of the higher the green utility index value, the better the option. The green utility index as calculated for each of the three material alternatives was $\mathrm{M}(\mathrm{C})=0.086$, $\mathrm{M}(\mathrm{A})=0.072$ and $\mathrm{M}(\mathrm{B})=0.062$ for material options $\mathrm{C}$,
A and B respectively, making Option C (fly-ash cement concrete floor slab) emerge as the best option amongst the other alternatives as shown in Figure 38.

The above example has illustrated the application of the MSDSS in a material selection problem for a proposed 5-bedroom low-cost residential green building project in the London Borough of Sutton. From the illustrated example it can be deduced that the MSDSS model is able to provide rankings in low-cost green building material assessment combining site, economic, technical, social-cultural, sensorial and environmental criteria into a composite index system based on the AHP technique. This model is therefore, based on the presumption that decision makers, given full knowledge of all possible consequences of all possible alternatives and factors, will select the material with the highest-ranking score. 


\begin{tabular}{|c|c|c|c|c|c|c|c|c|c|c|c|c|c|c|c|}
\hline GS1-Location (km) & CSR & $\mathrm{CP}$ & $\mathrm{RL}$ & B.XL & FA & RT & FPH. & SS & RPB & T\&GW & PB & $T \& G$ & $\mathrm{SC}$ & SIT & \\
\hline $\begin{array}{l}\text { Compressed Stabilized } \\
\text { Rammed Earth blocks }\end{array}$ & 1.0 & 2.0 & 2.0 & 4.0 & 2.0 & 5.0 & 8.0 & 8.0 & 4.0 & 4.00 & 4.0 & 4.00 & 7.0 & 2.00 & 4.0 \\
\hline Clay Products-Unfired Bricks & 0.5 & 1.0 & 1.0 & 3.0 & 1.0 & 4.0 & 7.0 & 7.0 & 3.0 & 3.00 & 3.0 & 3.00 & 6.0 & 1.00 & 3.0 \\
\hline $\begin{array}{l}\text { Reclaimed/Recycled laminated } \\
\text { Wood Flooring and Panelling }\end{array}$ & 0.5 & 1.0 & 1.0 & 3.0 & 1.0 & 4.0 & 7.0 & 7.0 & 3.0 & 3.00 & 3.0 & 3.00 & 6.0 & 1.00 & 3.0 \\
\hline $\begin{array}{l}\text { Bamboo XL laminated Split } \\
\text { Paneled Flooring }\end{array}$ & 0.3 & 0.3 & 0.3 & 1.0 & 0.3 & 2.0 & 5.0 & 5.0 & 1.0 & 1.0 & 1.0 & 1.00 & 4.0 & 0.33 & 1.0 \\
\hline $\begin{array}{l}\text { Fly Ash Sand Lime } \\
\text { interlocking Paving } \\
\text { Bricks/Block }\end{array}$ & 0.5 & 1.0 & 1.0 & 3.0 & 1.0 & 4.00 & 7.00 & 7.00 & 3.0 & 3.00 & 3.0 & 3.0 & 6.0 & 1.0 & 3.0 \\
\hline $\begin{array}{l}\text { Recycled timber clad } \\
\text { Aluminium framed window } \\
\text { unit }\end{array}$ & 0.2 & 0.3 & 0.3 & 0.5 & 0.3 & 1.0 & 4.00 & 4.00 & 0.50 & 0.50 & 0.5 & 0.50 & 3.0 & 0.3 & 0.5 \\
\hline $\begin{array}{l}\text { Four panel hardwood door } \\
\text { finished with Alpilignum. }\end{array}$ & 0.1 & 0.1 & 0.1 & 0.2 & 0.1 & 0.3 & 1.0 & 1.0 & 0.2 & 0.2 & 0.2 & 0.2 & 0.5 & 0.1 & 0.2 \\
\hline Stainless Steel Entry Door. & 0.1 & 0.1 & 0.1 & 0.2 & 0.1 & 0.3 & 1.0 & 1.0 & 0.2 & 0.2 & 0.2 & 0.2 & 0.5 & 0.1 & 0.20 \\
\hline $\begin{array}{l}\text { Reprocessed Particleboard } \\
\text { wood chipboard to BS EN } 312 \\
\text { Type P5, }\end{array}$ & 0.3 & 0.3 & 0.3 & 1.0 & 0.3 & 2.0 & 5.0 & 5.0 & 1.0 & 1.00 & 1.0 & 1.00 & 4.0 & 0.3 & 1.00 \\
\hline $\begin{array}{l}\text { Tongue \& grooved Wooddeco } \\
\text { Multiline ceiling tiles to BS EN } \\
\text { 636-2] }\end{array}$ & 0.3 & 0.3 & 0.3 & 1.0 & 0.3 & 2.0 & 5.0 & 5.0 & 1.0 & 1.00 & 1.0 & 1.00 & 4.0 & 0.33 & 1.00 \\
\hline $\begin{array}{l}\text { Plasterboard on } 70 \mathrm{~mm} \text { steel } \\
\text { studs with } 50 \mathrm{~mm} 12.9 \mathrm{~kg} / \mathrm{m}^{3} \\
\text { insulation, }\end{array}$ & 0.3 & 0.3 & 0.3 & 1.0 & 0.3 & 2.0 & 5.0 & 5.0 & 1.0 & 1.00 & 1.0 & 1.00 & 4.00 & 0.33 & 1.00 \\
\hline $\begin{array}{l}\text { Tongue \& Grooved Laminated } \\
\text { Wooden column bolted to steel } \\
\text { plate on concrete base. }\end{array}$ & 0.3 & 0.3 & 0.3 & 1.0 & 0.3 & 2.0 & 5.0 & 5.0 & 1.0 & 1.0 & 1.0 & 1.00 & 4.0 & 0.33 & 1.0 \\
\hline Steel Column UC & 0.1 & 0.2 & 0.2 & 0.3 & 0.2 & 0.33 & 2.00 & 2.00 & 0.3 & 0.25 & 0.3 & 0.3 & 1.0 & 0.17 & 0.3 \\
\hline $\begin{array}{l}\text { Structurally insulated timber } \\
\text { panel system with } \mathrm{OSB} / 3 \text { each } \\
\text { side, roofing underlay } \\
\text { reclaimed clay tiles }\end{array}$ & 0.5 & 1.0 & 1.0 & 3.0 & 1.0 & 4.0 & 7.0 & 7.0 & 3.0 & 3.0 & 3.0 & 3.0 & 6.0 & 1.0 & 3.0 \\
\hline $\begin{array}{l}\text { Structurally insulated natural } \\
\text { slate (temperate EN 636-2) } \\
\text { decking each side] }\end{array}$ & 0.3 & 0.3 & 0.3 & 1.0 & 0.3 & 2.0 & 5.00 & 5.00 & 1.00 & 1.00 & 1.0 & 1.00 & 4.0 & 0.3 & 1.0 \\
\hline Total & 5.1 & 8.7 & 8.7 & 23.2 & 8.7 & 34.8 & 74.0 & 74.0 & 23.2 & 23.2 & 23.2 & 23.2 & 60.0 & 8.7 & 23.2 \\
\hline
\end{tabular}

Figure 25. Pair-wise matrix: location.

\begin{tabular}{ccccccccccccccc}
\hline CS & CP & RL & B.XL & FA & RT & FPH. & SS. & RP, & T\&G] & PB & T\&GW. & SC & SIT & SIS \\
\hline 0.2 & 0.2 & 0.2 & 0.2 & 0.23 & 0.14 & 0.11 & 0.11 & 0.17 & 0.17 & 0.17 & 0.17 & 0.12 & 0.23 & 0.17 \\
0.1 & 0.1 & 0.1 & 0.1 & 0.11 & 0.11 & 0.09 & 0.09 & 0.13 & 0.13 & 0.13 & 0.13 & 0.10 & 0.11 & 0.13 \\
0.1 & 0.1 & 0.1 & 0.1 & 0.11 & 0.11 & 0.09 & 0.09 & 0.13 & 0.13 & 0.13 & 0.13 & 0.10 & 0.11 & 0.13 \\
0.0 & 0.0 & 0.0 & 0.0 & 0.04 & 0.1 & 0.07 & 0.07 & 0.04 & 0.04 & 0.04 & 0.04 & 0.07 & 0.04 & 0.04 \\
0.10 & 0.11 & 0.11 & 0.13 & 0.11 & 0.11 & 0.09 & $9.46 \mathrm{E}-02$ & 0.13 & 0.13 & 0.13 & 0.13 & 0.10 & 0.11 & 0.13 \\
0.0 & 0.0 & 0.03 & 0.02 & 0.03 & 0.03 & 0.05 & 0.05 & 0.02 & 0.02 & 0.02 & 0.02 & 0.05 & 0.03 & 0.02 \\
0.0 & 0.0 & 0.0 & 0.0 & 0.02 & 0.0 & 0.01 & 0.0135134 & 0.01 & 0.01 & 0.01 & 0.01 & 0.01 & 0.02 & 0.01 \\
0.0 & 0.0 & 0.0 & 0.0 & 0.02 & 0.0 & 0.01 & 4 & 0.01 & 0.01 & 0.01 & 0.01 & 0.01 & 0.02 & 0.01 \\
0.0 & 0.0 & 0.0 & 0.0 & 0.04 & 0.1 & 0.07 & 0.067567568 & 0.04 & 0.04 & 0.04 & 0.04 & 0.07 & 0.04 & 0.04 \\
0.0 & 0.0 & 0.0 & 0.0 & 0.0 & 0.1 & 0.1 & 0.067567568 & 0.04 & 0.04 & 0.04 & 0.04 & 0.07 & 0.04 & 0.04 \\
0.05 & 0.04 & 0.04 & 0.0 & 0.04 & 0.1 & 0.1 & 0.067567568 & 0.04 & 0.04 & 0.04 & 0.04 & 0.07 & 0.04 & 0.04 \\
0.0 & 0.0 & 0.0 & 0.0 & 0.0 & 0.1 & 0.1 & 0.067567568 & 0.04 & 0.04 & 0.04 & 0.04 & 0.07 & 0.04 & 0.04 \\
0.0 & 0.0 & 0.0 & 0.0 & 0.0 & 0.0 & 0.0 & 0.027027027 & 0.01 & 0.01 & 0.01 & 0.01 & 0.02 & 0.02 & 0.01 \\
0.1 & 0.1 & 0.1 & 0.1 & 0.1 & 0.1 & 0.1 & 0.094594595 & 0.13 & 0.13 & 0.13 & 0.13 & 0.10 & 0.11 & 0.13 \\
0.0 & 0.0 & 0.0 & 0.0 & 0.04 & 0.1 & 0.07 & 0.067567568 & 0.04 & 0.04 & 0.04 & 0.04 & 0.07 & 0.04 & 0.04 \\
1.00 & 1.00 & 1.00 & 1.00 & 1.00 & 1.00 & 1.00 & 1.00 & 1.00 & 1.00 & 1.00 & 1.00 & 1.00 & 1.00 & 1.00 \\
\hline
\end{tabular}

Figure 26. Normalised matrix: location. 


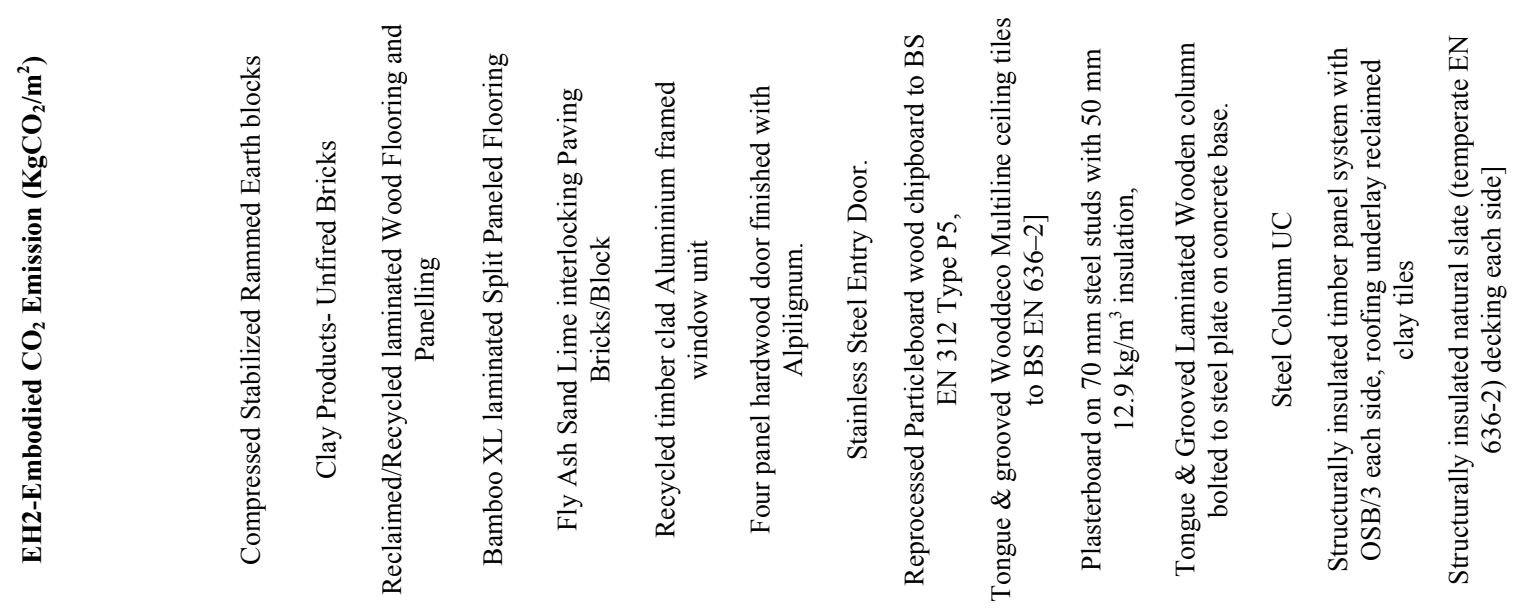

Compressed Stabilized

Rammed Earth blocks

Clay Products-Unfired

Bricks

Reclaimed/Recycled

laminated Wood Flooring

and Panelling

Bamboo XL laminated Split Paneled Flooring

Fly Ash Sand Lime

interlocking Paving

Bricks/Block

Recycled timber clad

Aluminium framed window

unit

Four panel hardwood door finished with Alpilignum.

Stainless Steel Entry Door.

\begin{tabular}{|c|c|c|c|c|c|c|c|c|c|c|c|c|c|c|}
\hline 1.0 & 1.0 & 5.0 & 1.0 & 1.0 & 5.0 & 5.0 & 8.0 & 2.0 & 1.0 & 4.0 & 5.00 & 6.00 & 5.00 & 1.00 \\
\hline 1.0 & 1.0 & 5.0 & 1.0 & 1.0 & 5.0 & 5.0 & 8.0 & 2.0 & 1.0 & 4.0 & 5.0 & 6.0 & 5.0 & 1.0 \\
\hline
\end{tabular}

\begin{tabular}{lll|l|l|l|l|l|l|l|l|l|l|l|l}
0.2 & 0.2 & 1.0 & 0.2 & 0.2 & 1.0 & 1.0 & 4.0 & 0.3 & 0.2 & 0.5 & 1.0 & 2.0 & 1.0 & 0.2
\end{tabular}

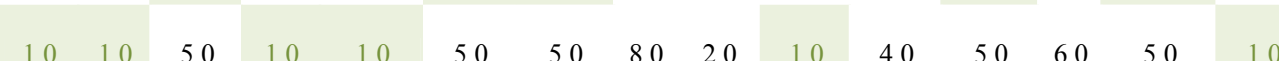

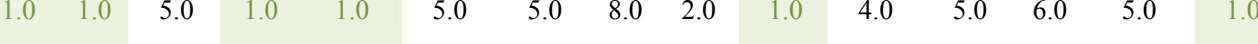

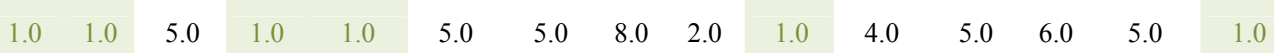

Reprocessed Particleboard

wood chipboard to BS EN 312 Type P5,

Tongue \& grooved

Wooddeco Multiline ceiling tiles to BS EN 636-2]

Plasterboard on $70 \mathrm{~mm}$ steel

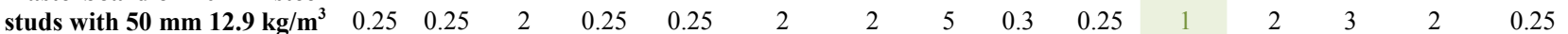
insulation,

Tongue \& Grooved

Laminated Wooden column

bolted to steel plate on

concrete base.

Steel Column UC

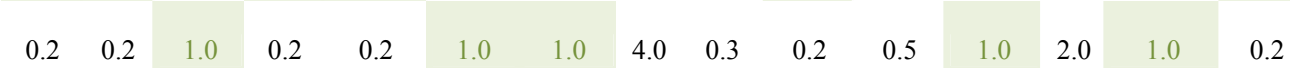

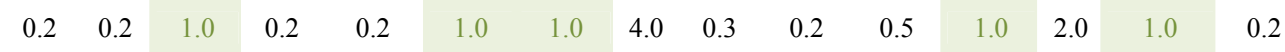

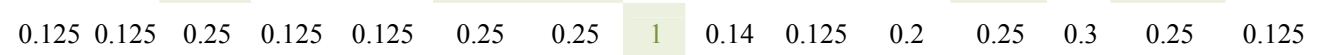

$\begin{array}{lllllllllllllll}0.5 & 0.5 & 4.0 & 0.5 & 0.5 & 4.0 & 4.0 & 7.0 & 1.0 & 0.5 & 3.0 & 4.0 & 5.0 & 4.0 & 0.5\end{array}$

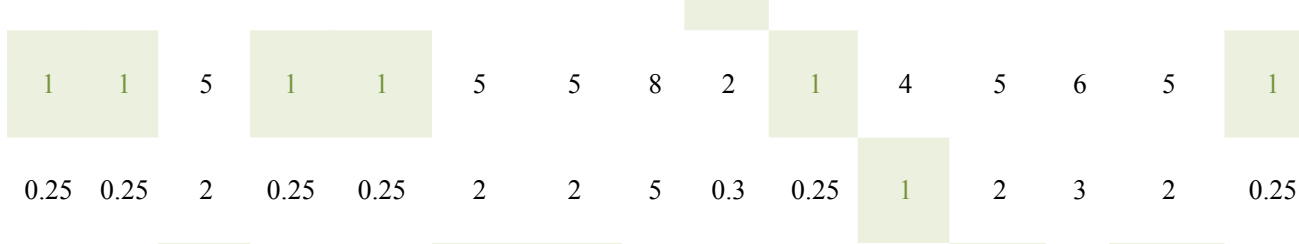

Structurally insulated timber panel system with OSB/3 each side, roofing underlay reclaimed clay tiles

Structurally insulated natural slate (temperate EN 636-2) decking each side] 


\begin{tabular}{|c|c|c|c|c|c|c|c|c|c|c|c|c|c|c|c|c|c|}
\hline 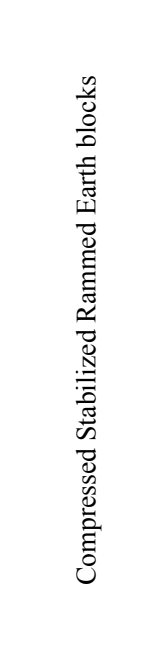 & 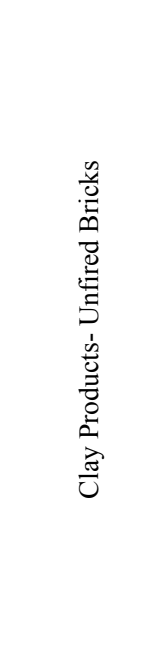 & 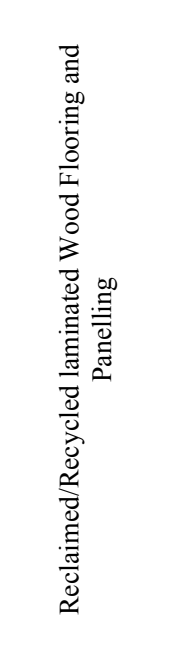 & 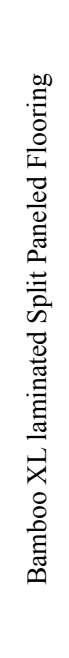 & 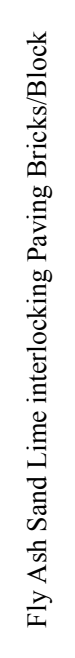 & 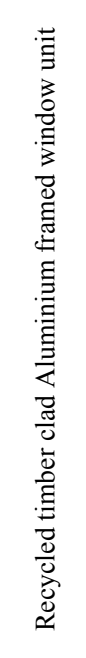 & 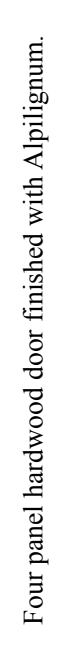 & 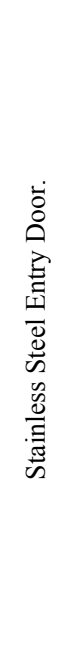 & 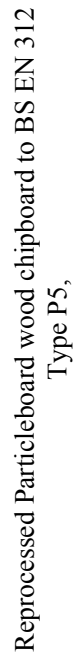 & 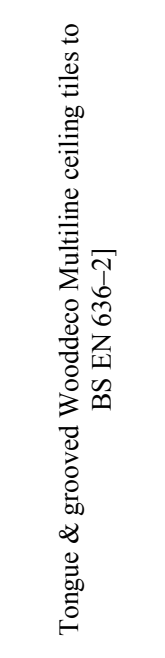 & 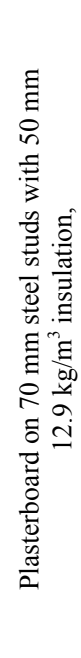 & 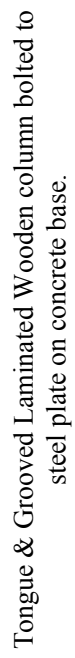 & 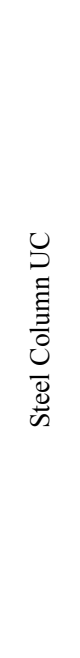 & 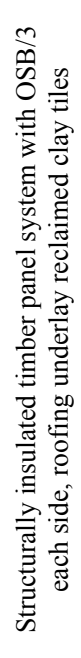 & 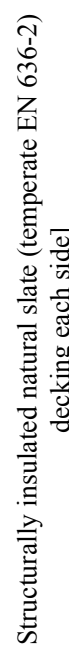 & U & $\stackrel{0}{0}$ & \\
\hline 0.12 & 0.12 & 0.12 & 0.1 & 0.12 & 0.1 & 0.1 & 0.1 & 0.12 & 0.12 & 0.13 & 0.12 & 0.11 & 0.12 & 0.12 & 0.12 & 120.97 & 7 RI 1.58 \\
\hline 0.1 & 0.1 & 0.1 & 0.1 & 0.1 & 0.1 & 0.1 & 0.1 & 0.1 & 0.12 & 0.13 & 0.12 & 0.11 & 0.12 & 0.12 & 0.12 & 120.97 & 7 CR 0.02 \\
\hline 0.0 & 0.0 & 0.0 & 0.0 & 0.0 & 0.0 & 0.0 & 0.05 & 0.01 & 0.02 & 0.02 & 0.02 & 0.04 & 0.02 & 0.02 & 0.03 & $\begin{array}{ll}03 & 1.07\end{array}$ & \\
\hline 0.1 & 0.1 & 0.1 & 0.1 & 0.1 & 0.1 & 0.1 & 0.1 & 0.12 & 0.12 & 0.13 & 0.12 & 0.11 & 0.12 & 0.12 & 0.12 & 120.97 & \\
\hline 0.1 & 0.1 & 0.1 & 0.1 & 0.12 & 0.1 & 0.12 & 0.1 & 0.12 & 0.12 & 0.13 & 0.12 & 0.11 & 0.12 & 0.12 & 0.12 & 120.97 & \\
\hline 0.0 & 0.0 & 0.0 & 0.0 & 0.02 & 0.0 & 0.02 & 0.05 & 0.01 & 0.02 & 0.02 & 0.02 & 0.04 & 0.02 & 0.02 & 0.03 & 031.07 & \\
\hline 0.0 & 0.0 & 0.0 & 0.0 & 0.02 & 0.0 & 0.02 & 0.05 & 0.01 & 0.02 & 0.02 & 0.02 & 0.04 & 0.02 & 0.02 & 0.03 & $\begin{array}{ll}3 & 1.07\end{array}$ & \\
\hline 0.015544041 & 0.015544041 & 0.005988024 & 0.01 & 0.02 & 0.004 & 0.01 & 0.01 & 0.009 & 0.015544041 & 0.03 & 0.005 & 0.006 & 0.005 & 0.015 & 50.0 & 010.88 & \\
\hline 0.1 & 0.1 & 0.1 & 0.1 & 0.06 & 0.1 & 0.10 & 0.1 & 0.06 & 0.06 & 0.10 & 0.10 & 0.09 & 0.10 & 0.06 & 0.08 & $08 \quad 1.18$ & \\
\hline 0.124352332 & 0.124352332 & 0.119760479 & 0.12 & 0.12 & 0.11 & 0.12 & 0.1 & 0.1 & 0.124352332 & 0.12 & 0.11 & 0.105 & 0.11 & 0.122 & 20.12 & 120.97 & \\
\hline 0.031088083 & 0.031088083 & 0.047904192 & 0.03 & 0.03 & 0.04 & 0.05 & 0.1 & 0.021 & 0.031088083 & 0.03 & 0.047 & 0.057 & 0.047 & 0.03 & 0.0 & 041.23 & \\
\hline 0.02 & 0.02 & 0.02 & 0.02 & 0.02 & 0.02 & 0.02 & 0.1 & 0.01 & 0.024870466 & 0.01 & 0.02 & 0.038 & 0.02 & 0.026 & 50.03 & $03 \quad 1.07$ & \\
\hline 0.0 & 0.0 & 0.0 & 0.0 & 0.02 & 0.0 & 0.01 & 0.01 & 0.01 & 0.02 & 0.01 & 0.01 & 0.02 & 0.01 & 0.02 & 0.02 & 020.97 & \\
\hline 0.0 & 0.0 & 0.0 & 0.0 & 0.0 & 0.0 & 0.0 & 0.05 & 0.01 & 0.02 & 0.02 & 0.02 & 0.04 & 0.02 & 0.02 & 0.0 & $03 \quad 1.07$ & \\
\hline 0.12 & 0.12 & 0.12 & 0.1 & 0.12 & 0.1 & 0.1 & 01 & 0.1 & 0.12 & 0.13 & 0.12 & 0.11 & 0.12 & 0.12 & 0.12 & $\begin{array}{ll}12 & 0.97\end{array}$ & \\
\hline 1.00 & 1.00 & 1.00 & 1.00 & 1.00 & 1.00 & 1.00 & 1.00 & 1.00 & 1.00 & 1.00 & 1.00 & 1.00 & 1.00 & 1.00 & 1.0 & 00 & \\
\hline
\end{tabular}

Figure 28. Normalised matrix: embodied $\mathrm{CO}_{2}$ emissions. 


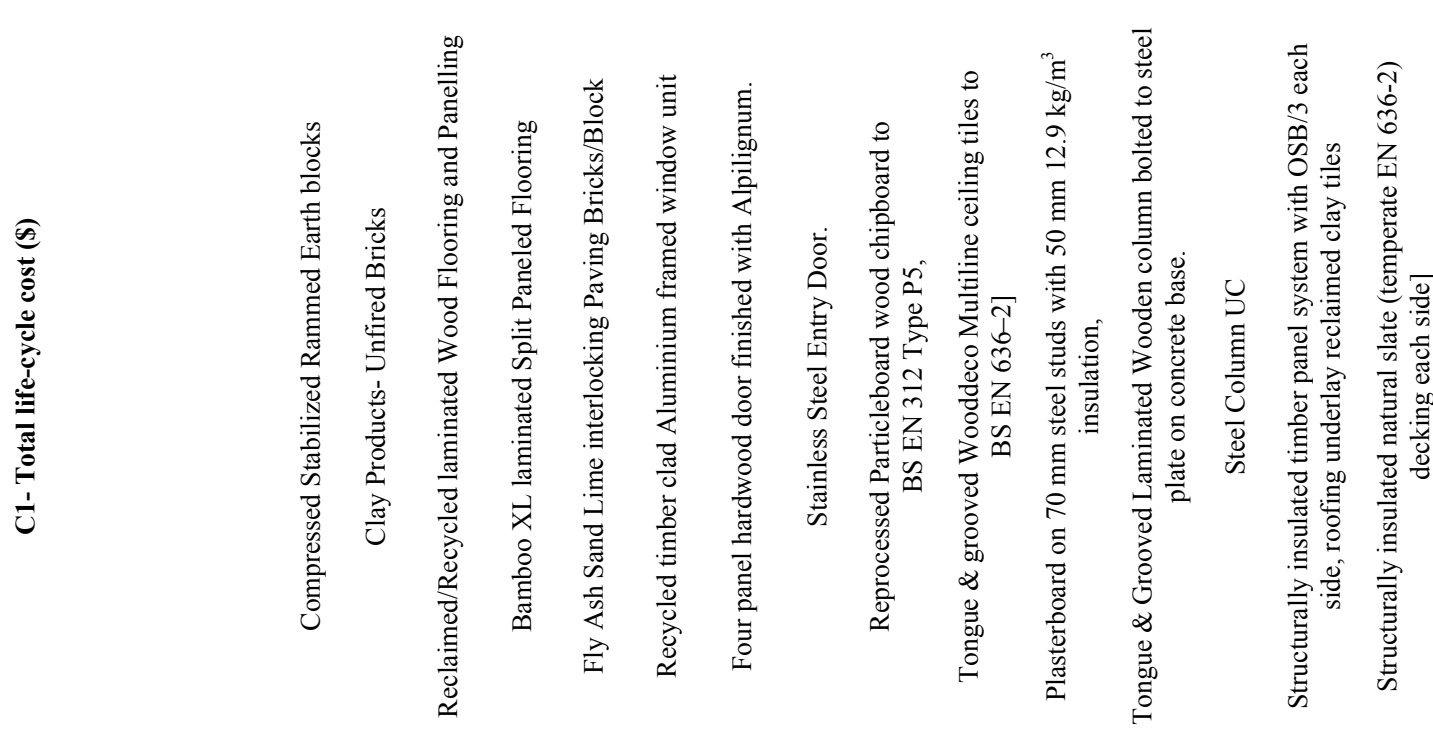

\begin{tabular}{|c|c|c|c|c|c|c|c|c|c|c|c|c|c|c|c|}
\hline $\begin{array}{l}\text { Compressed Stabilized Rammed Earth } \\
\text { blocks }\end{array}$ & 1.0 & 0.5 & 3.0 & 0.5 & 2.0 & 7.0 & 8.0 & 7.0 & 7.0 & 8.0 & 8.0 & 8.0 & 7.0 & 7.0 & 7.0 \\
\hline Clay Products- Unfired Bricks & 2 & 1 & 4 & 1 & 3 & 8 & 9 & 8 & 8 & 9 & 9 & 9 & 8 & 8 & 8 \\
\hline $\begin{array}{l}\text { Reclaimed/Recycled laminated Wood } \\
\text { Flooring and Panelling }\end{array}$ & 0.3 & 0.3 & 1.0 & 0.3 & 0.5 & 5.0 & 6.0 & 5.0 & 5.0 & 6.0 & 6.0 & 6.00 & 5.00 & 5.00 & 5.00 \\
\hline $\begin{array}{l}\text { Bamboo XL laminated Split Paneled } \\
\text { Flooring }\end{array}$ & 2 & 1 & 4 & 1 & 3 & 8 & 9 & 8 & 8 & 9 & 9 & 9 & 8 & 8 & 8 \\
\hline $\begin{array}{l}\text { Fly Ash Sand Lime interlocking Paving } \\
\text { Bricks/Block }\end{array}$ & 0.5 & 0.3 & 2 & 0.3 & 1 & 6 & 7 & 6 & 6 & 7 & 7 & 7 & 6 & 6 & 6 \\
\hline $\begin{array}{l}\text { Recycled timber clad Aluminium framed } \\
\text { window unit }\end{array}$ & 0.14 & 0.13 & 0.20 & 0.13 & 0.17 & 1.00 & 2.00 & 1.00 & 1.00 & 2.00 & 2.00 & 2.00 & 1.00 & 1.00 & 1.00 \\
\hline $\begin{array}{l}\text { Four panel hardwood door finished with } \\
\text { Alpilignum. }\end{array}$ & 0.1 & 0.1 & 0.2 & 0.1 & 0.1 & 0.5 & 1.0 & 0.5 & 0.5 & 1.0 & 1.0 & 1.0 & 0.5 & 0.5 & 0.5 \\
\hline Stainless Steel Entry Door. & 0.1 & 0.1 & 0.2 & 0.1 & 0.2 & 1.0 & 2.0 & 1.0 & 1.0 & 2.0 & 2.0 & 2.0 & 1.0 & 1.0 & 1.0 \\
\hline $\begin{array}{l}\text { Reprocessed Particleboard wood } \\
\text { chipboard to BS EN } 312 \text { Type P5, }\end{array}$ & 0.1 & 0.1 & 0.2 & 0.1 & 0.2 & 1.0 & 2.0 & 1.0 & 1.0 & 2.0 & 2.0 & 2.0 & 1.0 & 1.0 & 1.0 \\
\hline $\begin{array}{l}\text { Tongue \& grooved Wooddeco Multiline } \\
\text { ceiling tiles to BS EN 636-2] }\end{array}$ & 0.1 & 0.1 & 0.2 & 0.1 & 0.1 & 0.5 & 1.0 & 0.5 & 0.5 & 1.0 & 1.0 & 1.0 & 0.5 & 0.5 & 0.5 \\
\hline $\begin{array}{l}\text { Plasterboard on } 70 \mathrm{~mm} \text { steel studs with } \\
50 \mathrm{~mm} 12.9 \mathrm{~kg} / \mathrm{m}^{3} \text { insulation, }\end{array}$ & 0.1 & 0.1 & 0.2 & 0.1 & 0.1 & 0.5 & 1.0 & 0.5 & 0.5 & 1.0 & 1.0 & 1.0 & 0.5 & 0.5 & 0.5 \\
\hline $\begin{array}{l}\text { Tongue \& Grooved Laminated Wooden } \\
\text { column bolted to steel plate on concrete } \\
\text { base. }\end{array}$ & 0.1 & 0.1 & 0.2 & 0.1 & 0.1 & 0.5 & 1.0 & 0.5 & 0.5 & 1.0 & 1.0 & 1.0 & 0.5 & 0.5 & 0.5 \\
\hline Steel Column UC & 0.1 & 0.1 & 0.2 & 0.1 & 0.2 & 1.0 & 2.0 & 1.0 & 1.0 & 2.0 & 2.0 & 2.0 & 1.0 & 1.0 & 1.0 \\
\hline $\begin{array}{l}\text { Structurally insulated timber panel } \\
\text { system with OSB } / 3 \text { each side, roofing } \\
\text { underlay reclaimed clay tiles }\end{array}$ & 0.1 & 0.1 & 0.2 & 0.1 & 0.2 & 1.0 & 2.0 & 1.0 & 1.0 & 2.0 & 2.0 & 2.0 & 1.0 & 1.0 & 1.0 \\
\hline $\begin{array}{l}\text { Structurally insulated natural slate } \\
\text { (temperate EN 636-2) decking each side] }\end{array}$ & 0.1 & 0.1 & 0.2 & 0.1 & 0.2 & 1.0 & 2.0 & 1.0 & 1.0 & 2.0 & 2.0 & 2.0 & 1.0 & 1.0 & 1.0 \\
\hline Total & 7.2 & 4.3 & 15.9 & 4.3 & 11.1 & 42.0 & 55.0 & 42.0 & 42.0 & 55.0 & 55.0 & 55.0 & 42.0 & 42.0 & 42.0 \\
\hline
\end{tabular}

Figure 29. Pair-wise matrix: total life-cycle cost. 


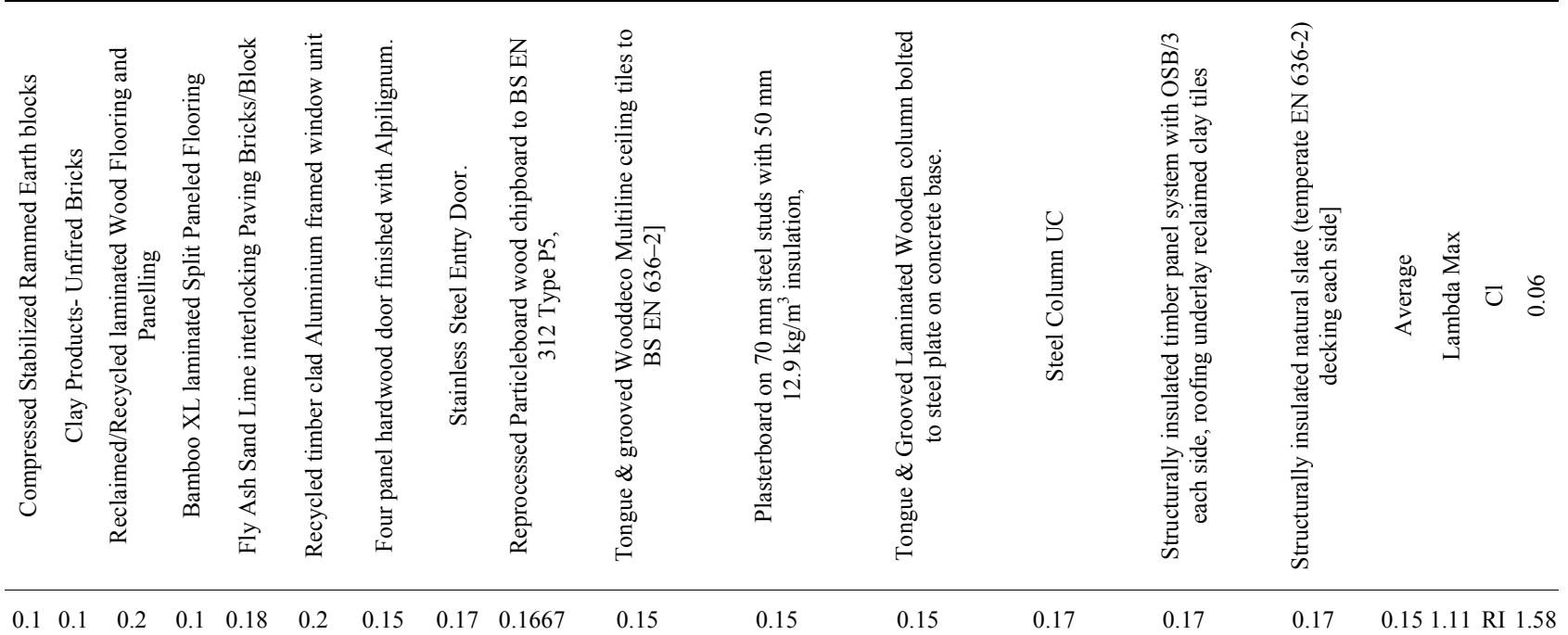

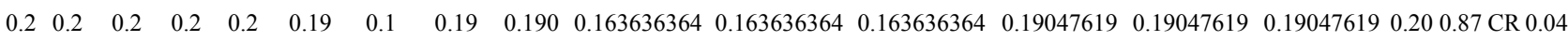

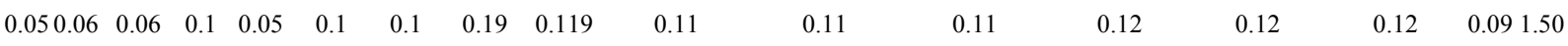

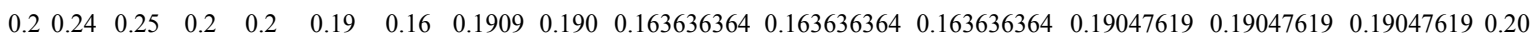

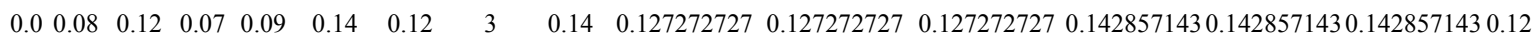

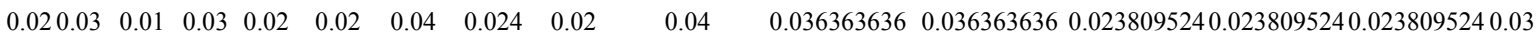
$\begin{array}{llllllllllllllll}0.0 & 0.0 & 0.0 & 0.0 & 0.01 & 0.0 & 0.02 & 0.0162 & 0.01 & 0.02 & 0.02 & 0.02 & 0.01 & 0.01 & 0.01 & 0.02\end{array}$

Figure 30. Normalised matrix: total life-cycle cost.

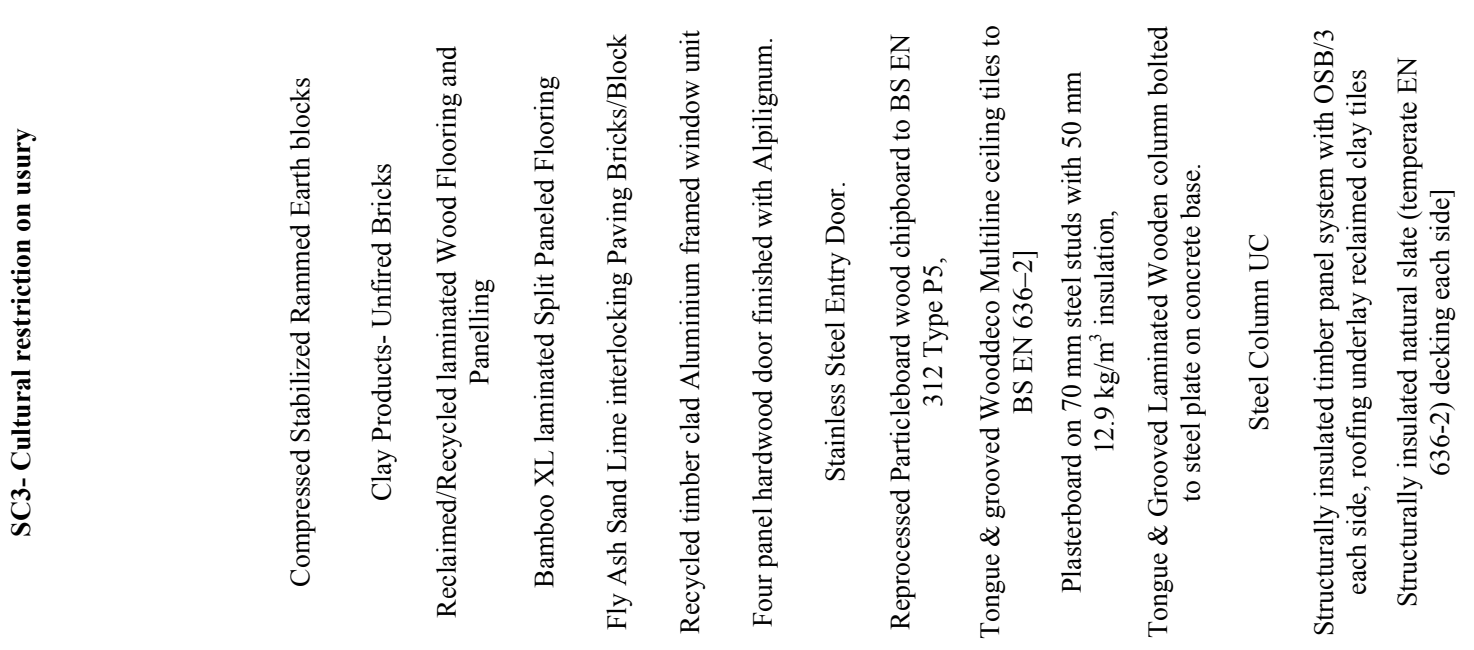

\begin{tabular}{|c|c|c|c|c|c|c|c|c|c|c|c|c|c|c|c|}
\hline $\begin{array}{l}\text { Compressed Stabilized Rammed } \\
\text { Earth blocks }\end{array}$ & 1.0 & 1.0 & 1.0 & 1.0 & 1.0 & 0.3 & 0.3 & 0.2 & 1.0 & 1.0 & 0.3 & 1.0 & 0.1 & 1.0 & 1.0 \\
\hline Clay Products-Unfired Bricks & 1.0 & 1.0 & 1.0 & 1.0 & 1.0 & 0.3 & 0.3 & 0.2 & 1.0 & 1.0 & 0.3 & 1.0 & 0.1 & 1.0 & 1.0 \\
\hline $\begin{array}{l}\text { Reclaimed/Recycled laminated Wood } \\
\text { Flooring and Panelling }\end{array}$ & 1.0 & 1.0 & 1.0 & 1.0 & 1.0 & 0.3 & 0.3 & 0.2 & 1.0 & 1.0 & 0.3 & 1.0 & 0.1 & 1.0 & 1.0 \\
\hline $\begin{array}{l}\text { Bamboo XL laminated Split Paneled } \\
\text { Flooring }\end{array}$ & 1.0 & 1.0 & 1.0 & 1.0 & 1.0 & 0.3 & 0.3 & 0.2 & 1.0 & 1.0 & 0.3 & 1.0 & 0.1 & 1.0 & 1.0 \\
\hline $\begin{array}{l}\text { Fly Ash Sand Lime interlocking } \\
\text { Paving Bricks/Block }\end{array}$ & 1.0 & 1.0 & 1.0 & 1.0 & 1.0 & 0.3 & 0.3 & 0.2 & 1.0 & 1.0 & 0.3 & 1.0 & 0.1 & 1.0 & 1.0 \\
\hline
\end{tabular}


Continued

\begin{tabular}{|c|c|c|c|c|c|c|c|c|c|c|c|c|c|c|c|}
\hline $\begin{array}{l}\text { Recycled timber clad Aluminium } \\
\text { framed window unit }\end{array}$ & 3.0 & 3.0 & 3.0 & 3.0 & 3.0 & 1.0 & 1.0 & 0.3 & 3.0 & 3.0 & 1.0 & 3.0 & 0.2 & 3.0 & 3.0 \\
\hline $\begin{array}{l}\text { Four panel hardwood door finished } \\
\text { with Alpilignum. }\end{array}$ & 3.0 & 3.0 & 3.0 & 3.0 & 3.0 & 1.0 & 1.0 & 0.3 & 3.0 & 3.0 & 1.0 & 3.0 & 0.2 & 3.0 & 3.0 \\
\hline Stainless Steel Entry Door. & 5.0 & 5.0 & 5.0 & 5.0 & 5.0 & 3.0 & 3.0 & 1.0 & 5.0 & 5.0 & 3.0 & 5.0 & 0.3 & 5.0 & 5.0 \\
\hline $\begin{array}{l}\text { Reprocessed Particleboard wood } \\
\text { chipboard to BS EN } 312 \text { Type P5, }\end{array}$ & 1.0 & 1.0 & 1.0 & 1.0 & 1.0 & 0.3 & 0.3 & 0.2 & 1.0 & 1.0 & 0.3 & 1.0 & 0.1 & 1.0 & 1.0 \\
\hline $\begin{array}{l}\text { Tongue \& grooved Wooddeco } \\
\text { Multiline ceiling tiles to BS EN 636-2] }\end{array}$ & 1.0 & 1.0 & 1.0 & 1.0 & 1.0 & 0.3 & 0.3 & 0.2 & 1.0 & 1.0 & 0.3 & 1.0 & 0.1 & 1.0 & 1.0 \\
\hline $\begin{array}{l}\text { Plasterboard on } 70 \mathrm{~mm} \text { steel studs } \\
\text { with } 50 \mathrm{~mm} 12.9 \mathrm{~kg} / \mathrm{m}^{3} \text { insulation, }\end{array}$ & 3.0 & 3.0 & 3.0 & 3.0 & 3.0 & 1.0 & 1.0 & 0.3 & 3.0 & 3.0 & 1.0 & 3.00 & 0.20 & 3.00 & 3.00 \\
\hline $\begin{array}{l}\text { Tongue \& Grooved Laminated } \\
\text { Wooden column bolted to steel plate } \\
\text { on concrete base. }\end{array}$ & 1.0 & 1.0 & 1.0 & 1.0 & 1.0 & 0.3 & 0.3 & 0.2 & 1.0 & 1.0 & 0.3 & 1.0 & 0.1 & 1.0 & 1.0 \\
\hline Steel Column UC & 7.0 & 7.0 & 7.0 & 7.0 & 7.0 & 5.0 & 5.0 & 3.0 & 7.0 & 7.0 & 5.0 & 7.0 & 1.0 & 7.0 & 7.0 \\
\hline $\begin{array}{l}\text { Structurally insulated timber panel } \\
\text { system with OSB } / 3 \text { each side, roofing } \\
\text { underlay reclaimed clay tiles }\end{array}$ & 1.0 & 1.0 & 1.0 & 1.0 & 1.0 & 0.3 & 0.3 & 0.2 & 1.0 & 1.0 & 0.3 & 1.0 & 0.1 & 1.0 & 1.0 \\
\hline $\begin{array}{l}\text { Structurally insulated natural slate } \\
\text { (temperate EN 636-2) decking each } \\
\text { side] }\end{array}$ & 1.0 & 1.0 & 1.0 & 1.0 & 1.0 & 0.3 & 0.3 & 0.2 & 1.0 & 1.0 & 0.3 & 1.0 & 0.1 & 1.0 & 1.0 \\
\hline Total & 31.0 & 31.0 & 31.0 & 31.0 & 31.0 & 14.3 & 14.3 & 7.0 & 31.0 & 31.0 & 14.3 & 31.0 & 3.4 & 31.0 & 31.0 \\
\hline
\end{tabular}

Figure 31. Pair-wise matrix: cultural restriction on usury.

\begin{tabular}{|c|c|c|c|c|c|c|c|c|c|c|c|c|c|c|c|c|c|c|}
\hline 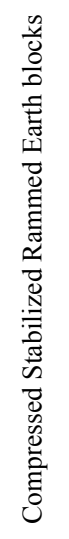 & 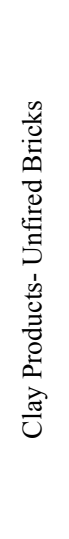 & 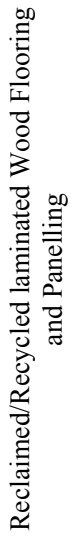 & 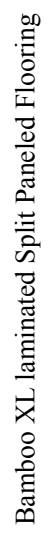 & 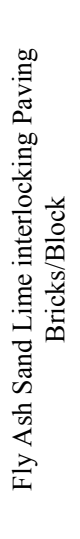 & 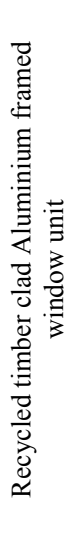 & 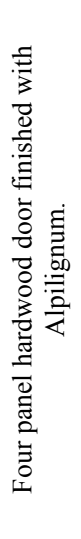 & 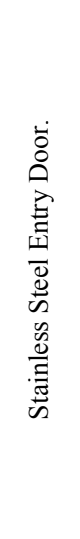 & 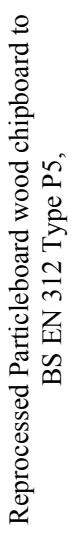 & 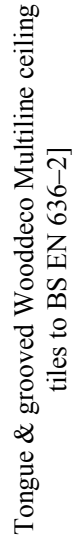 & 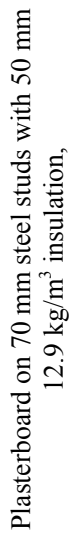 & 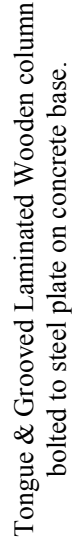 & 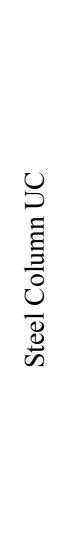 & 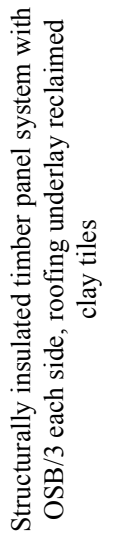 & 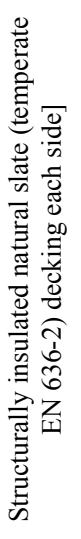 & $\begin{array}{l}\frac{8}{80} \\
\stackrel{\pi}{5} \\
\sum^{2}\end{array}$ & 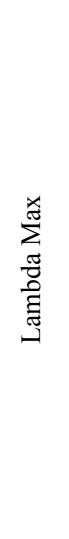 & 己 & 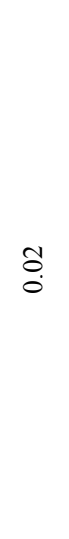 \\
\hline 0.0 & 0.0 & 0.0 & 0.0 & 0.03 & 0.0 & 0.02 & 0.02 & 0.03 & 0.03 & 0.02 & 0.03 & 0.04 & 0.03 & 0.03 & 0.03 & 0.96 & RI & 1.58 \\
\hline 0.0 & 0.0 & 0.0 & 0.0 & 0.03 & 0.0 & 0.02 & 0.02 & 0.03 & 0.03 & 0.02 & 0.03 & 0.04 & 0.03 & 0.03 & 0.03 & 0.96 & $\mathrm{CR}$ & 0.01 \\
\hline 0.0 & 0.0 & 0.0 & 0.0 & 0.03 & 0.0 & 0.02 & 0.02 & 0.03 & 0.03 & 0.02 & 0.03 & 0.04 & 0.03 & 0.03 & 0.03 & 0.96 & & \\
\hline 0.0 & 0.0 & 0.0 & 0.0 & 0.03 & 0.0 & 0.02 & 0.02 & 0.03 & 0.03 & 0.02 & 0.03 & 0.04 & 0.03 & 0.03 & 0.03 & 0.96 & & \\
\hline 0.0 & 0.0 & 0.0 & 0.0 & 0.03 & 0.0 & 0.02 & 0.02 & 0.03 & 0.03 & 0.02 & 0.03 & 0.04 & 0.03 & 0.03 & 0.03 & 0.96 & & \\
\hline 0.1 & 0.1 & 0.1 & 0.1 & 0.10 & 0.1 & 0.07 & 0.04 & 0.09 & 0.10 & 0.07 & 0.10 & 0.06 & 0.10 & 0.10 & 0.09 & 1.23 & & \\
\hline 0.1 & 0.1 & 0.1 & 0.1 & 0.10 & 0.1 & 0.07 & 0.04 & 0.09 & 0.10 & 0.07 & 0.10 & 0.06 & 0.10 & 0.10 & 0.09 & 1.23 & & \\
\hline 0.2 & 0.2 & 0.2 & 0.2 & 0.16 & 0.2 & 0.21 & 0.14 & 0.16 & 0.16 & 0.21 & 0.16 & 0.10 & 0.16 & 0.16 & 0.17 & 1.16 & & \\
\hline 0.0 & 0.0 & 0.0 & 0.0 & 0.03 & 0.0 & 0.02 & 0.02 & 0.03 & 0.03 & 0.02 & 0.03 & 0.04 & 0.03 & 0.03 & 0.03 & 0.96 & & \\
\hline 0.0 & 0.0 & 0.0 & 0.0 & 0.0 & 0.0 & 0.0 & 0.02 & 0.03 & 0.03 & 0.02 & 0.03 & 0.04 & 0.03 & 0.03 & 0.03 & 0.96 & & \\
\hline 0.10 & 0.10 & 0.10 & 0.1 & 0.10 & 0.1 & 0.1 & 0.04 & 0.09 & 0.10 & 0.07 & 0.10 & 0.06 & 0.10 & 0.10 & 0.09 & 1.23 & & \\
\hline 0.0 & 0.0 & 0.0 & 0.0 & 0.0 & 0.0 & 0.0 & 0.028 & 0.03 & 0.03 & 0.02 & 0.03 & 0.04 & 0.03 & 0.03 & 0.03 & 0.96 & & \\
\hline
\end{tabular}


Continued

\begin{tabular}{cccccccccccccccccc}
\hline 0.2 & 0.2 & 0.2 & 0.2 & 0.2 & 0.3 & 0.3 & 0.42 & 0.22 & 0.23 & 0.35 & 0.23 & 0.30 & 0.23 & 0.23 & 0.27 & 0.90 & \\
0.0 & 0.0 & 0.0 & 0.0 & 0.0 & 0.0 & 0.0 & 0.02 & 0.03 & 0.03 & 0.02 & 0.03 & 0.04 & 0.03 & 0.03 & 0.03 & 0.96 & \\
0.0 & 0.0 & 0.0 & 0.0 & 0.03 & 0.0 & 0.02 & 0.02 & 0.03 & 0.03 & 0.02 & 0.03 & 0.04 & 0.03 & 0.03 & 0.03 & 0.96 & \\
& & & & & & & & & & & & & & & & \\
1.00 & 1.00 & 1.00 & 1.00 & 1.00 & 1.00 & 1.00 & 1.00 & 1.00 & 1.00 & 1.00 & 1.00 & 1.00 & 1.00 & 1.00 & 1.00 & 15.3 & \\
\hline
\end{tabular}

Figure 32. Normalised matrix: cultural restriction on usury.

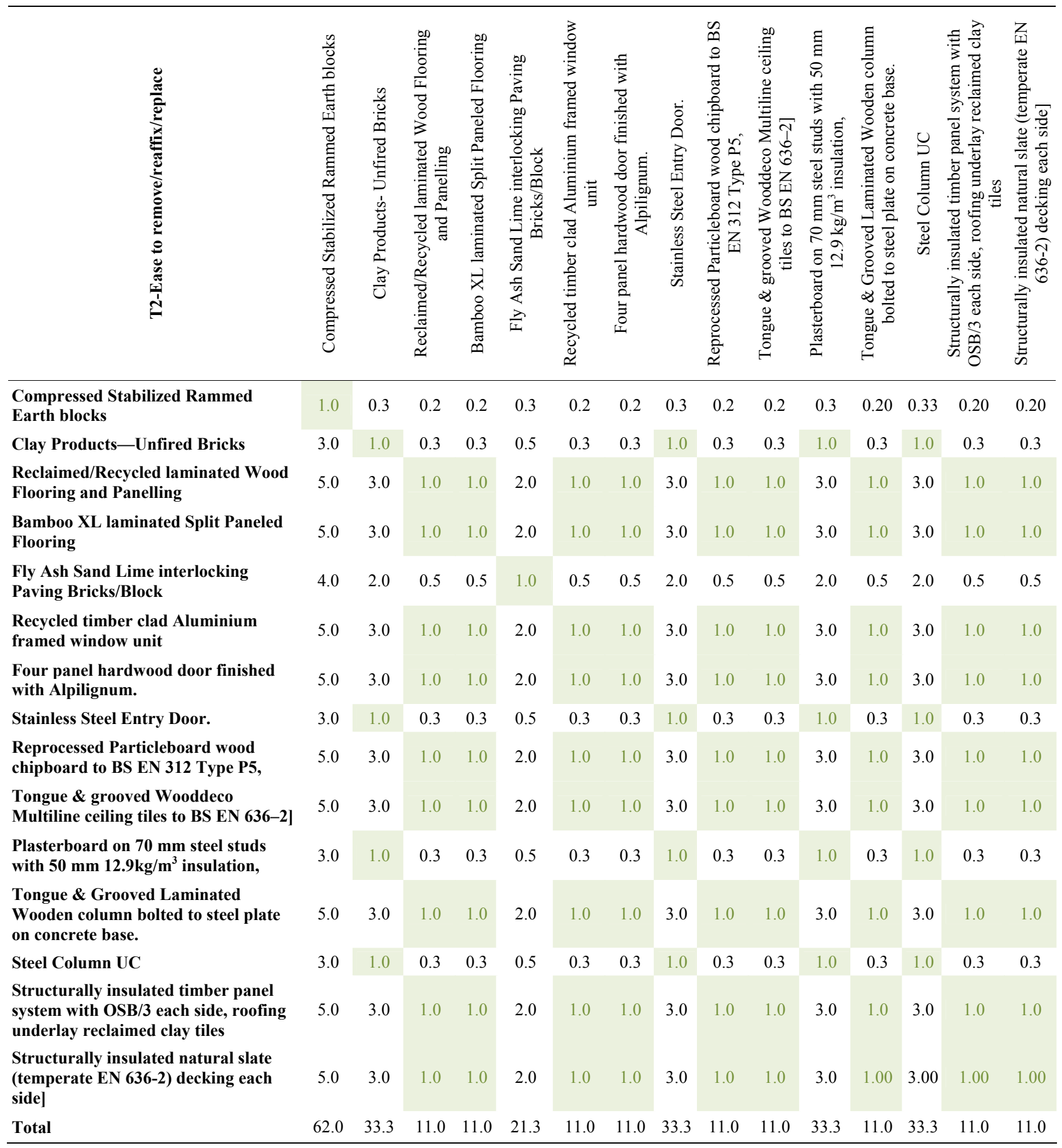

Figure 33. Pair-wise matrix: ease to remove/affix/replace. 


\begin{tabular}{|c|c|c|c|c|c|c|c|c|c|c|c|c|c|c|c|c|c|c|}
\hline 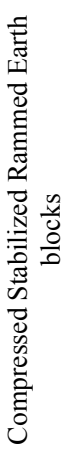 & 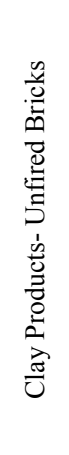 & 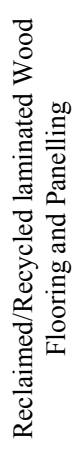 & 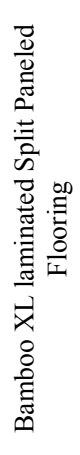 & 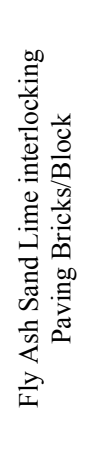 & 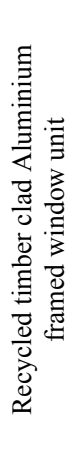 & 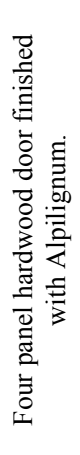 & 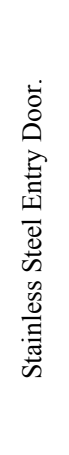 & 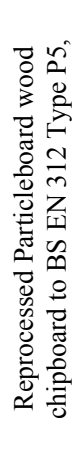 & 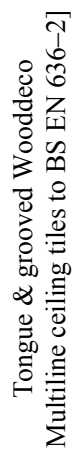 & 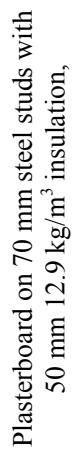 & 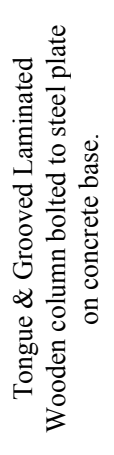 & 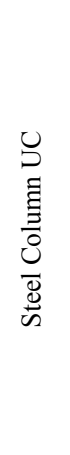 & 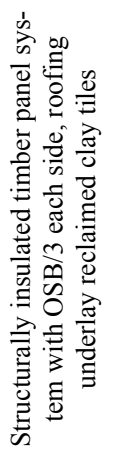 & 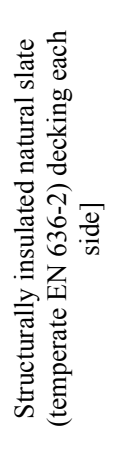 & 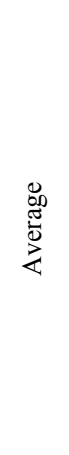 & 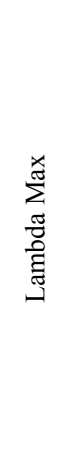 & $\nabla$ & $\stackrel{0}{0}$ \\
\hline 0.02 & 0.01 & 0.02 & 0.0 & 0.01 & 0.0 & 0.0 & 0.01 & 0.01 & 0.02 & 0.01 & 0.02 & 0.01 & 0.02 & 0.02 & 0.02 & 0.95 & & $\mathrm{RI}$ \\
\hline 0.0 & 0.0 & 0.0 & 0.0 & 0.0 & 0.0 & 0.0 & 0.03 & 0.03 & 0.03 & 0.03 & 0.03 & 0.03 & 0.03 & 0.03 & 0.03 & 1.03 & & $\mathrm{CR}$ \\
\hline 0.1 & 0.1 & 0.1 & 0.1 & 0.1 & 0.1 & 0.1 & 0.09 & 0.09 & 0.09 & 0.09 & 0.09 & 0.09 & 0.09 & 0.09 & 0.09 & 0.99 & & \\
\hline 0.1 & 0.1 & 0.1 & 0.1 & 0.1 & 0.1 & 0.1 & 0.09 & 0.09 & 0.09 & 0.09 & 0.09 & 0.09 & 0.09 & 0.09 & 0.09 & 0.99 & & \\
\hline 0.1 & 0.1 & 0.0 & 0.0 & 0.05 & 0.0 & 0.05 & 0.06 & 0.04 & 0.05 & 0.06 & 0.05 & 0.06 & 0.05 & 0.05 & 0.05 & 1.08 & & \\
\hline 0.1 & 0.1 & 0.1 & 0.1 & 0.09 & 0.1 & 0.09 & 0.09 & 0.09 & 0.09 & 0.09 & 0.09 & 0.09 & 0.09 & 0.09 & 0.09 & 0.99 & & \\
\hline 0.1 & 0.1 & 0.1 & 0.1 & 0.09 & 0.1 & 0.09 & 0.09 & 0.09 & 0.09 & 0.09 & 0.09 & 0.09 & 0.09 & 0.09 & 0.09 & 0.99 & & \\
\hline 0.0 & 0.0 & 0.0 & 0.0 & 0.02 & 0.0 & 0.03 & 0.03 & 0.03 & 0.03 & 0.03 & 0.03 & 0.03 & 0.03 & 0.03 & 0.03 & 1.03 & & \\
\hline 0.1 & 0.1 & 0.1 & 0.1 & 0.09 & 0.1 & 0.09 & 0.09 & 0.09 & 0.09 & 0.09 & 0.09 & 0.09 & 0.09 & 0.09 & 0.09 & 0.99 & & \\
\hline 0.1 & 0.1 & 0.1 & 0.1 & 0.09 & 0.1 & 0.09 & 0.09 & 0.09 & 0.09 & 0.09 & 0.09 & 0.09 & 0.09 & 0.09 & 0.09 & 0.99 & & \\
\hline 0.0 & 0.0 & 0.0 & 0.0 & 0.02 & 0.0 & 0.03 & 0.03 & 0.03 & 0.03 & 0.03 & 0.03 & 0.03 & 0.03 & 0.03 & 0.03 & 1.03 & & \\
\hline 0.1 & 0.1 & 0.1 & 0.1 & 0.09 & 0.1 & 0.09 & 0.09 & 0.09 & 0.09 & 0.09 & 0.09 & 0.09 & 0.09 & 0.09 & 0.09 & 0.99 & & \\
\hline 0.0 & 0.0 & 0.0 & 0.0 & 0.02 & 0.0 & 0.03 & 0.03 & 0.03 & 0.03 & 0.03 & 0.03 & 0.03 & 0.03 & 0.03 & 0.03 & 1.03 & & \\
\hline 0.1 & 0.1 & 0.1 & 0.1 & 0.1 & 0.1 & 0.1 & 0.09 & 0.09 & 0.09 & 0.09 & 0.09 & 0.09 & 0.09 & 0.09 & 0.09 & 0.99 & & \\
\hline 0.08 & 0.09 & 0.09 & 0.1 & 0.09 & 0.1 & 0.1 & 0.09 & 0.09 & 0.09 & 0.09 & 0.09 & 0.09 & 0.09 & 0.09 & 0.09 & 0.99 & & \\
\hline 1.00 & 1.00 & 1.00 & 1.00 & 1.00 & 1.00 & 1.00 & 1.00 & 1.00 & 1.00 & 1.00 & 1.00 & 1.00 & 1.00 & 1.00 & 1.00 & 15.1 & & \\
\hline
\end{tabular}

Figure 34. Normalised matrix: ease to remove/affix/replace.

\begin{tabular}{|c|c|c|c|c|c|c|c|c|c|c|c|c|c|c|c|}
\hline 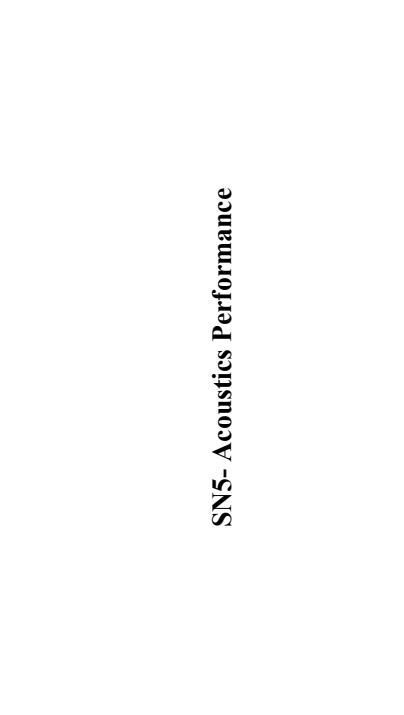 & 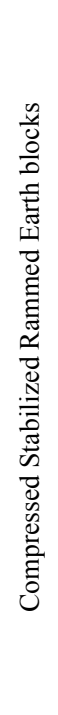 & 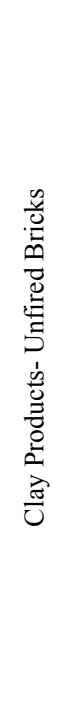 & 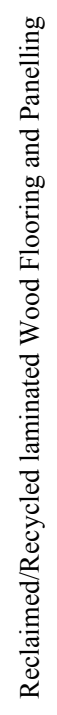 & 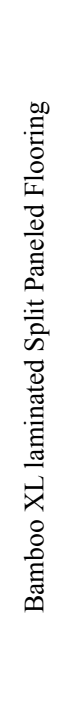 & 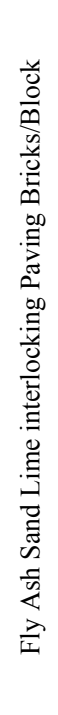 & 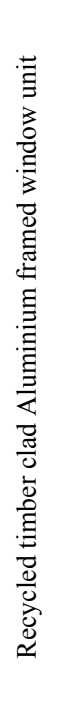 & 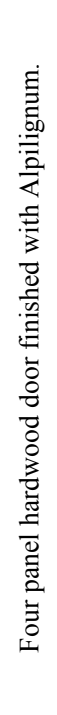 & 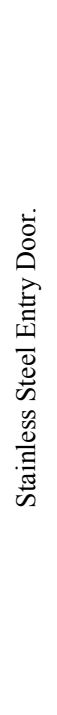 & \begin{tabular}{l} 
I \\
0 \\
$Z$ \\
\multicolumn{1}{|c}{} \\
0 \\
0 \\
0 \\
0 \\
0 \\
0 \\
0 \\
0 \\
0 \\
$\vdots$ \\
0 \\
0 \\
0 \\
0 \\
$\vdots$ \\
0 \\
0 \\
0 \\
0 \\
0 \\
0 \\
0 \\
0 \\
0 \\
0 \\
0 \\
0 \\
0 \\
0 \\
0 \\
0 \\
0
\end{tabular} & 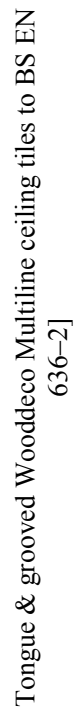 & 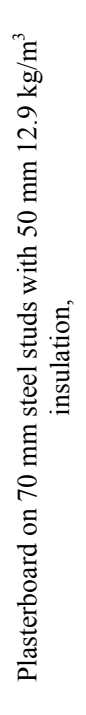 & 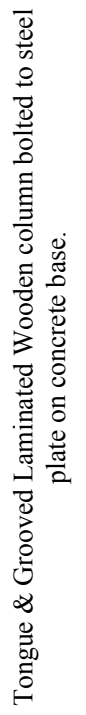 & 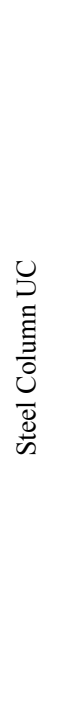 & 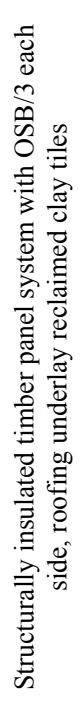 & 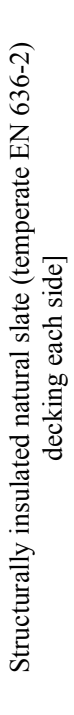 \\
\hline $\begin{array}{l}\text { Compressed Stabilized Rammed } \\
\text { Earth blocks }\end{array}$ & 1.0 & 0.2 & 0.3 & 0.2 & 0.2 & 0.3 & 0.2 & 1.0 & 0.3 & 0.3 & 0.3 & 0.3 & 0.3 & 0.3 & 1.0 \\
\hline Clay Products-Unfired Bricks & 5.0 & 1.0 & 2.0 & 1.0 & 1.0 & 3.0 & 1.0 & 5.0 & 2.0 & 2.0 & 2.0 & 2.0 & 2.0 & 2.0 & 5.0 \\
\hline
\end{tabular}




\section{Continued}

\begin{tabular}{|c|c|c|c|c|c|c|c|c|c|c|c|c|c|c|c|}
\hline $\begin{array}{l}\text { Reclaimed/Recycled laminated Wood } \\
\text { Flooring and Panelling }\end{array}$ & 4.0 & 0.5 & 1.0 & 0.5 & 0.5 & 2.0 & 0.5 & 4.0 & 1.0 & 1.0 & 1.0 & 1.0 & 1.0 & 1.0 & 4.0 \\
\hline $\begin{array}{l}\text { Bamboo XL laminated Split Paneled } \\
\text { Flooring }\end{array}$ & 5.0 & 1.0 & 2.0 & 1.0 & 1.0 & 3.0 & 1.0 & 5.0 & 2.0 & 2.0 & 2.0 & 2.0 & 2.0 & 2.0 & 5.0 \\
\hline $\begin{array}{l}\text { Fly Ash Sand Lime interlocking } \\
\text { Paving Bricks/Block }\end{array}$ & 5.0 & 1.0 & 2.0 & 1.0 & 1.0 & 3.0 & 1.0 & 5.0 & 2.0 & 2.0 & 2.0 & 2.0 & 2.0 & 2.0 & 5.0 \\
\hline $\begin{array}{l}\text { Recycled timber clad Aluminium } \\
\text { framed window unit }\end{array}$ & 3.0 & 0.3 & 0.5 & 0.3 & 0.3 & 1.0 & 0.3 & 3.0 & 0.5 & 0.5 & 0.5 & 0.5 & 0.5 & 0.5 & 3.0 \\
\hline $\begin{array}{l}\text { Four panel hardwood door finished } \\
\text { with Alpilignum. }\end{array}$ & 5.0 & 1.0 & 2.0 & 1.0 & 1.0 & 3.0 & 1.0 & 5.0 & 2.0 & 2.0 & 2.0 & 2.0 & 2.0 & 2.0 & 5.0 \\
\hline Stainless Steel Entry Door. & 1.0 & 0.2 & 0.3 & 0.2 & 0.2 & 0.3 & 0.2 & 1.0 & 0.3 & 0.3 & 0.3 & 0.3 & 0.3 & 0.3 & 1.0 \\
\hline $\begin{array}{l}\text { Reprocessed Particleboard wood } \\
\text { chipboard to BS EN } 312 \text { Type P5, }\end{array}$ & 4 & 0.5 & 1 & 0.5 & 0.5 & 2 & 0.5 & 4 & 1 & 1 & 1 & 1 & 1 & 1 & 4 \\
\hline $\begin{array}{l}\text { Tongue \& grooved Wooddeco } \\
\text { Multiline ceiling tiles to BS EN 636-2] }\end{array}$ & 4.0 & 0.5 & 1.0 & 0.5 & 0.5 & 2.0 & 0.5 & 4.0 & 1.0 & 1.0 & 1.0 & 1.0 & 1.0 & 1.0 & 4.0 \\
\hline $\begin{array}{l}\text { Plasterboard on } 70 \mathrm{~mm} \text { steel studs } \\
\text { with } 50 \mathrm{~mm} 12.9 \mathrm{~kg} / \mathrm{m}^{3} \text { insulation, }\end{array}$ & 4 & 0.5 & 1 & 0.5 & 0.5 & 2 & 0.5 & 4 & 1 & 1 & 1 & 1 & 1 & 1 & 4 \\
\hline $\begin{array}{l}\text { Tongue \& Grooved Laminated } \\
\text { Wooden column bolted to steel plate } \\
\text { on concrete base. }\end{array}$ & 4 & 0.5 & 1 & 0.5 & 0.5 & 2 & 0.5 & 4 & 1 & 1 & 1 & 1 & 1 & 1 & 4 \\
\hline Steel Column UC & 4.00 & 0.50 & 1.00 & 0.50 & 0.50 & 2.00 & 0.50 & 4.00 & 1.00 & 1.00 & 1.00 & 1.00 & 1.00 & 1.00 & 4.00 \\
\hline $\begin{array}{l}\text { Structurally insulated timber panel } \\
\text { system with OSB/3 each side, roofing } \\
\text { underlay reclaimed clay tiles }\end{array}$ & 4.0 & 0.5 & 1.0 & 0.5 & 0.5 & 2.0 & 0.5 & 4.0 & 1.0 & 1.0 & 1.0 & 1.0 & 1.0 & 1.0 & 4.0 \\
\hline $\begin{array}{l}\text { Structurally insulated natural slate } \\
\text { (temperate EN 636-2) decking each } \\
\text { side] }\end{array}$ & 1.0 & 0.2 & 0.3 & 0.2 & 0.2 & 0.3 & 0.2 & 1.0 & 0.3 & 0.3 & 0.3 & 0.3 & 0.3 & 0.3 & 1.0 \\
\hline Total & 54.0 & 8.4 & 16.3 & 8.4 & 8.4 & 28.0 & 8.4 & 54.0 & 16.3 & 16.3 & 16.3 & 16.3 & 16.3 & 16.3 & 54.0 \\
\hline
\end{tabular}

Figure 35. Pair-wise matrix: acoustics performance.

\begin{tabular}{|c|c|c|c|c|c|c|c|c|c|c|c|c|c|c|c|c|c|c|}
\hline 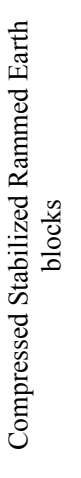 & 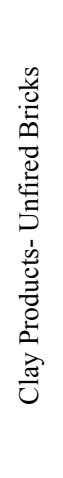 & 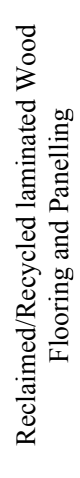 & 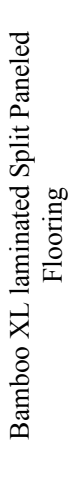 & 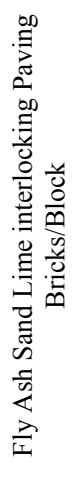 & 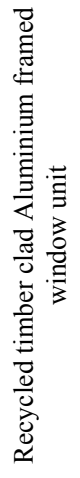 & 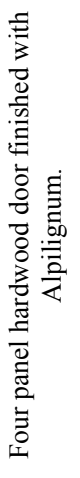 & 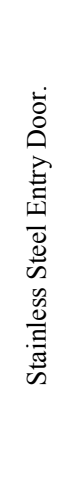 & 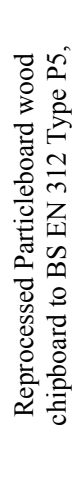 & 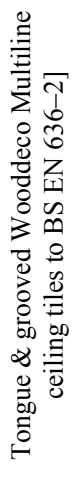 & 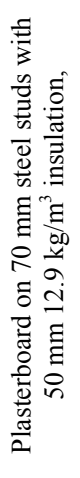 & 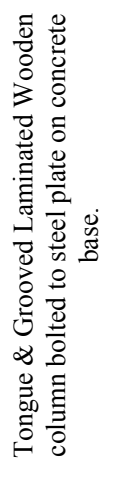 & 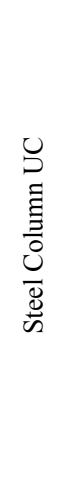 & 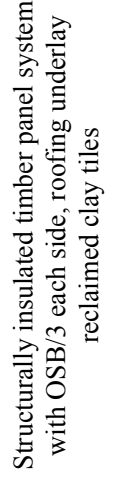 & 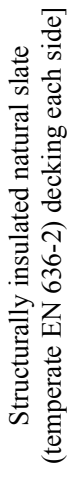 & 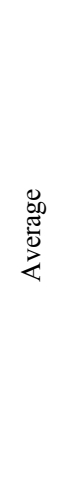 & 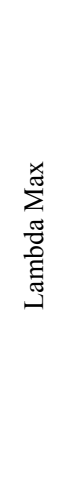 & U & $\stackrel{\overrightarrow{0}}{0}$ \\
\hline 0.0 & 0.0 & 0.0 & 0.0 & 0.0 & 0.0 & 0.0 & 0.01 & 0.01 & 0.02 & 0.02 & 0.02 & 0.02 & 0.02 & 0.02 & 0.02 & 0.97 & RI & 1.58 \\
\hline 0.1 & 0.1 & 0.1 & 0.1 & 0.1 & 0.1 & 0.1 & 0.09 & 0.12 & 0.12 & 0.12 & 0.12 & 0.12 & 0.12 & 0.09 & 0.11 & 0.97 & $\mathrm{CR}$ & 0.01 \\
\hline 0.1 & 0.1 & 0.1 & 0.1 & 0.1 & 0.1 & 0.1 & 0.07 & 0.061 & 0.06 & 0.06 & 0.06 & 0.06 & 0.06 & 0.07 & 0.06 & 1.04 & & \\
\hline 0.1 & 0.1 & 0.1 & 0.1 & 0.1 & 0.1 & 0.1 & 0.09 & 0.123 & 0.12 & 0.12 & 0.12 & 0.12 & 0.12 & 0.09 & 0.11 & 0.97 & & \\
\hline 0.1 & 0.1 & 0.1 & 0.1 & 0.1 & 0.1 & 0.1 & 0.09 & 0.123 & 0.12 & 0.12 & 0.12 & 0.12 & 0.12 & 0.09 & 0.11 & 0.97 & & \\
\hline 0.1 & 0.0 & 0.0 & 0.0 & 0.0 & 0.0 & 0.0 & 0.05 & 0.030 & 0.03 & 0.03 & 0.03 & 0.03 & 0.03 & 0.06 & 0.04 & 1.07 & & \\
\hline 0.1 & 0.1 & 0.1 & 0.1 & 0.1 & 0.1 & 0.1 & 0.09 & 0.123 & 0.12 & 0.12 & 0.12 & 0.12 & 0.12 & 0.09 & 0.11 & 0.97 & & \\
\hline 0.0 & 0.0 & 0.0 & 0.0 & 0.0 & 0.0 & 0.0 & 0.018 & 0.01 & 0.02 & 0.02 & 0.02 & 0.02 & 0.02 & 0.02 & 0.02 & 0.97 & & \\
\hline
\end{tabular}




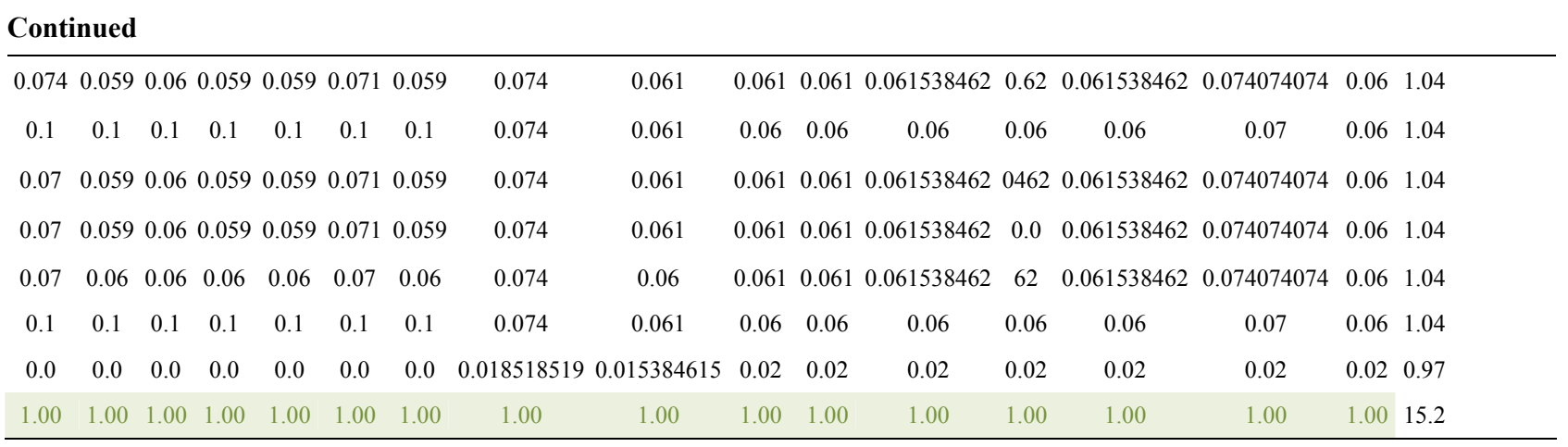

Figure 36. Normalised matrix: acoustics performance.

Pesults
Previous

\section{GREEN UTILITY INDEX}

\begin{tabular}{rrrrrrrrr} 
Score & Rank & \multicolumn{3}{c}{ Gener Enviro Econo } & Socio- Techni Sensorial \\
0.07 & 8.00 & 0.00 & 0.00 & 0.01 & 0.02 & 0.02 & 0.02 \\
0.07 & 6.00 & 0.00 & 0.01 & 0.01 & 0.02 & 0.02 & 0.01 \\
0.07 & 10.00 & 0.00 & 0.00 & 0.01 & 0.01 & 0.03 & 0.02 \\
0.07 & 7.00 & 0.00 & 0.00 & 0.01 & 0.02 & 0.02 & 0.01 \\
0.06 & 14 & 0.00 & 0.00 & 0.01 & 0.01 & 0.02 & 0.02 \\
0.07 & 5 & 0.00 & 0.00 & 0.01 & 0.02 & 0.02 & 0.01 \\
0.09 & 1 & 0.00 & 0.01 & 0.01 & 0.03 & 0.02 & 0.02 \\
0.07 & 4 & 0.00 & 0.00 & 0.01 & 0.02 & 0.03 & 0.01 \\
0.07 & 2 & 0.00 & 0.00 & 0.01 & 0.02 & 0.03 & 0.02 \\
0.07 & 3 & 0.00 & 0.01 & 0.01 & 0.02 & 0.02 & 0.01 \\
0.06 & 15 & 0.00 & 0.00 & 0.01 & 0.01 & 0.02 & 0.01 \\
0.07 & 11 & 0.00 & 0.00 & 0.01 & 0.02 & 0.02 & 0.01 \\
0.06 & 13 & 0.00 & 0.01 & 0.01 & 0.02 & 0.02 & 0.01 \\
0.07 & 9 & 0.00 & 0.00 & 0.01 & 0.02 & 0.02 & 0.01 \\
0.07 & 12 & 0.00 & 0.01 & 0.01 & 0.01 & 0.02 & 0.01
\end{tabular}

Figure 37. Green utility indices of the selected materials.

\section{Potential Benefits of the MSDSS Model}

The following are the benefits expected from the application of the MSDSS Model. However the model developed for this research differs from that of the previous works in the following ways:

- The main point of difference from the off-the-shelf assessment tools is that they only trade-off numerical values based on the single-attributes. These singleattribute claims ignore the possibility of what other variables can yield. MSDSS supports trade-off with and without tangible variables, such as a client's preference, environmental statutory compliance, and cultural restriction on usury. This feature is important as decision making in reality engages with solid, verbal and subjective elements.
- In terms of cost, it provides an opportunity for designers to be able to advise their clients as to what the probable financial estimate of the project may be. This helps clients to decide how much they are prepared to spend on different variables of construction.

- A separate set of contextual considerations was included as a heuristics base to facilitate site-specific feasibility and appropriateness testing of each material choice. Boundaries of sustainability inform of knowledge base rules as contained in the MSDSS model could help reduce bias that is often associated with the material selection process.

- Available material assessment tools are particularity ill-adapted for the early stages of the design process and are generally labour intensive. The MSDSS model consists of a resource for relatively small 


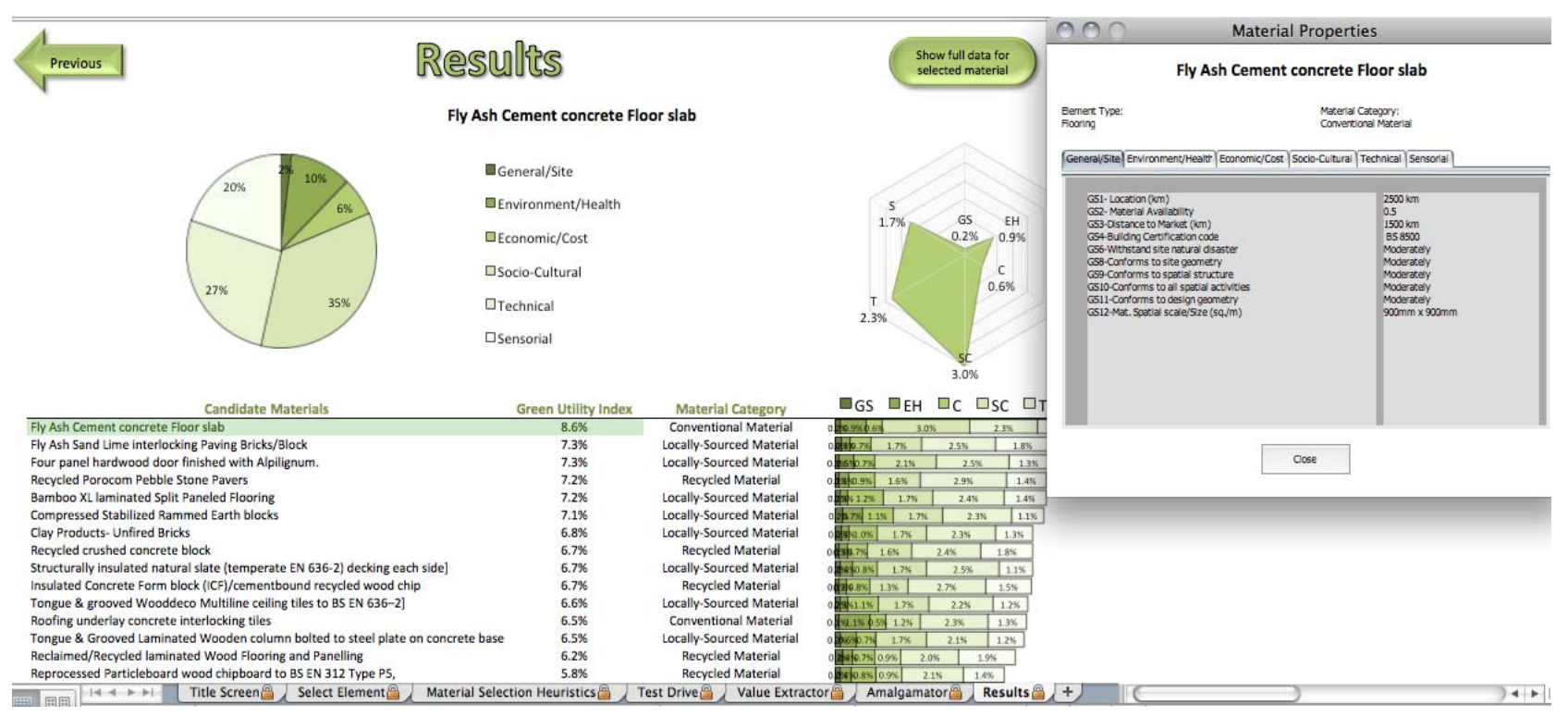

Figure 38. Corresponding indices of the ranked materials.

information input to produce quick and fairly accurate or approximate output of results with little or no training on the part of experienced users. This means that users that may require little training are inexperienced users but not as extensive as obtainable in previous tools.

- There are still significant numbers of smaller firms who cannot afford most material assessment tools because they are extremely expensive. This tool is more or less open source software recommended to provide solution to this challenge.

- Context is a critical consideration for all project decision-making, since even projects located on neighbouring sites will have different end users, and different specific site characteristics. This tool could be applied to other regions with minimal or no changes, and therefore has the ability to adapt to any situation, or change in design according to users' needs or different material alternatives.

- Unlike in the previous models, this tool contains tutorials and help menu as well as video guidance on how to use the software. This provides adequate help to beginners or inexperienced designers.

- For the visual aspect, the MSDSS model has the ability to produce a picture representative of data input rather than abstract. It is able to transfer data from it to other software, applicable to building material selection, and present the properties of each material in a successive window.

- User weightings have been included in the selection methodology to supplement, and not supplant human judgment in the decision-making process. By incorporating user weightings into the selection process, the methodology gains greater acceptability to the user who supplies the weightings.

- Materials change in their innovation, composition, price and availability and most tools find it challenging to update information relating to products. In this MSDSS model, the materials and the corresponding performance of the selected products is updated through a link to the manufacturers web page on the internet, and the users may access more information regarding the selected material or technology through internet from the supplier's web pages.

- The system has been designed to produce an artistic output, accurate, detailed representation and close to reality as much as it can be, without attempt to conceal any feature whether attractive or not;

- Provision of only a limited set of operations or criteria restricts the techniques and solutions that can be applied and consequently restricts the decision-making process. On the other hand, the inclusion of many objectives and the permitting of user specification of input data, system parameters and models, generally increases system flexibility and increases decision support freedom;

- In most tools, AHP technique at the pare-wise comparison stage, tend to be quite cumbersome and often takes a lot of time to maintain the consistency of the response. To eliminate this challenge MSDSS automatically debugs the system at every stage of the evaluation and selection process.

- The system has been thoroughly debugged to be less error prone, so that practitioners can integrate the decisions made by the tools more smoothly into practice, and that it takes less than few seconds to respond to users inputs;

- Responses/feedback from system programmers and 
accredited green building experts have also been included in the study to prove the ease of use, applicability and usability of the MSDSS model (see appendix A). As a result, some features have been adjusted based on expert feedbacks to support more reliable and expedient, timelier feedback to different design alternatives or changes.

\section{Reflective Summary}

This paper discussed the process of developing a decision-support system to support choices in low-cost green building materials. The research presented in this paper acknowledged the lack of a reliable database model that decision makers can readily use to aid informed decision-making when selecting low-cost green materials for low-cost green residential housing development. The findings from the reviewed literature and the results of the surveyed questionnaire further underscored the need for improving understanding of relevant data associated with the use of such building materials and components, with the goal to change and positively influence the current mental models, attitudes and priorities of multiple stakeholders involved in the production of the built environment, so as to encourage their wider-scale use in mainstream housing.

Based on the data obtained from selected expert builder/developer companies, a prototype MSDSS model was developed to aid designers in making informed decisions regarding their choice of materials for low-cost green residential housing projects. This model was consolidated in to an excel-based decision tool that allows designers to select low-cost green building products from a range of possibilities, and view the resulting impacts and difference in the cost, durability and performance of a range of alternatives. An analysis using the Analytical Hierarchy Process (AHP), based on the results of the participants was performed to show how optimal choices could change with changing user weightings and variables. The participants gained views from participating in the evaluation exercise for a real-life project, including the difficulties in choosing preference scores.

This study thus, indicates that perhaps the development of a DSS model associated with the impacts of lowcost green building materials is useful in that it gives designers a new approach of going through the process of value elicitation, which allows them to explicitly and transparently test the impacts of their elicited values. Providing a visual representation, allowing designers or specifiers to compare multiple alternatives across multiple criteria, was a particularly useful aspect of this study.

\section{Conclusions}

This report has demonstrated how a DSS model can be used to support multi-stakeholder involvement in the selection of low-cost green construction materials in ways that enable building energy performance and lifecycle cost to be considered at the early stage of residential housing design. The study further reinforced the significance in taking a multi-attribute approach to assessing a building product's sustainable performance. To achieve this goal, the AHP model of decision-making [57-60] was adopted to deal with the ambiguities involved in the assessment of material alternatives and relative importance weightings of multiple factors, given its ability to solve multi-criteria decision-making (MCDM) between finite alternatives.

To prove the validity of the model and the feasibility of the proposed selection methodology, a real-life but hypothetical application scenario was used to further illustrate the application of the MSDSS model in selecting the most appropriate floor material for a single 5-bedroom residential housing project located in the Sutton County of London. The results demonstrated the capabilities of the system, and exposed the way in which the system transparently demonstrates the implications of each step of the analysis. It also proved the practicality of using the MSDSS model, as it combines multiple factors into a single performance value that is easily interpreted.

Since the purpose of this research study was to develop an innovative concept to demonstrate a step-bystep methodology for selecting low-cost green materials with reasonable accuracy and in real time, as opposed to developing a fully-equipped commercial software, macro-in-excel database management technique was used in the back-end of the system to integrate the large volumes of data obtained from multiple sources. Excel was adopted as the database management system since it has the capabilities to perform all necessary calculations and is common enough that most people are familiar with it.

The process followed to develop the prototype MSDSS model in this research demonstrates that, depending on the domain and scope of the problem at hand, a DSS can be built fairly quickly and can be used effectively to help designers quantify how they compare materials that are yet to be certified under the standard specifications and codes of practice, and that which are already permitted under existing codes.

However further work is required to fully validate the MSDSS and the methodology presented. To do so, this research intends to run further case studies ideally using "live" building design projects, by comparing the outputs from the algorithms of the MSDSS system to monitored data from the completed case study building, in order to review the potential savings of the new materials or components proposed by the MSDSS model. 


\subsection{Contributions to Research and Industry}

Insights identified from addressing the research objectives in Section 3 represent part of the original contribution to knowledge made by this study. The following are itemised as key contributions of the study to research and practice:

- The contribution of this research includes the consideration of a holistic approach to low-cost green building product selection based on socio-cultural, technical, emotive, site, cost and environmental performance. Pre-design estimators and pre-construction managers could improve their estimating and product selection practices using the proposed MSDSS tool.

- Material suppliers can also benefit from this approach, as they can use it to enhance their pricing strategies, marketing plans, and overall product competitiveness.

- Decision problems about a product's choice are usually unstructured and ill-defined. By suggesting an alternative means of integrating the available resources associated with the informed selection of low-cost green building materials, it is hoped that the model will help decision makers to further refine their material selection criteria thus, encourage effective decision-making.

- The material selection process is characterized by competitive objectives, involving multiple stakeholders and key actors, dynamic and uncertain procedures and limited timeframes to make significant decisions. The decision makers within this domain: the designers, specifiers and other stakeholders are often confronted with conflicting subjective preferences and fragmented expertise; hence resulting in decision-making failures. The capacity of the system to compare materials using multiple factors with user-specified weightings, will therefore, encourage decision-makers to explicitly consider the effects of their previously-implicit judgments on the outcome of the project, and thus make choices that are timely, and result in more sustainable residential housing project design and implementation.

- The ability to quickly quantify and qualify the suitability outcomes of alternative materials may encourage greater industry acceptance of innovative technology for materials that are yet to be certified under the standard specifications and codes of practice.

- The overall approach used here could be tested in other contexts to determine its generalizability and applicability. In other words, the system could be extended to select materials for commercial development or for any other purpose.

- The material selection factors identified in the prototype model of the MSDSS, provides a unique insight into sustainability and environmental design informa- tion requirements for low-cost green housing.

- The adopted research methodology (see Table 1) employed to address the research objectives in Section 3 represents part of the original contribution to knowledge made by this study.

- The number of academic publications on the impacts of low-cost green materials was found to be low; hence makes a crucial contribution.

- In the short term, the model could be used in the housing sector as a catalogue of materials to support decision-making in low-cost green housing designs.

- As low-cost green building materials and components become well understood by design and building professionals, there is a likelihood of reducing over-dependency on conventional construction materials in the housing industry.

- The outcome of this study could aid top executives within the housing sector to consider low-cost green materials as part of existing regulatory frameworks and building codes of the Construction Standards Institute (CSI) in capital projects. By doing so, such an approach may create a potential market for local manufacturing and processing of such materials.

\subsection{Setbacks, Challenges and Probable Solutions}

There were few possible limitations that this research faced during the cause of the study. The limitations are hereby listed for future consideration.

- The process of developing the selection methodology was faced with critical issues that led to several changes in the research methodology and its objectives so many times, in order to achieve the aim of this research.

- Citing prior research studies formed the basis of the literature review and helped lay the foundation for understanding the research problem investigated in this study. However, there were reservations regarding the currency and scope of the research topic, as there was no compelling evidence of prior research on the topic. As literature on DSS for low-cost green housing design is still relatively low, the study therefore had to rely on the most current reports, interviews, and observations from the different and various organisations, and building professionals for its information.

- It remains true that sample sizes that are too small cannot adequately support claims of having achieved valid conclusions and sample sizes that are too large do not permit the deep, naturalistic, and inductive analysis that defines qualitative inquiry [47]. Yin [47] noted that determining adequate sample size in qualitative research is ultimately a matter of judgment and experience in evaluating the quality. Hair et al. [61] warned that it is important to consider not only the 
statistical significance, but also the quality and practical significance of the results for managerial applications, when analysing data. They noted that unequal or uneven sample sizes amongst different professional groups could also bias or influence the results as getting equal sample sizes from different groups of respondents was unrealistic and demanding. To address this issue the study adopted a sampling strategy using the stratified random sampling approach where each group of the sample population had reasonable number of randomly selected participants, which helped to achieve sampling equivalence between the researcher and professionals of the various building professions both in higher institutions and practicing building design and housing construction firms.

- Giving that most respondents were practicing professionals, getting a list of the sample population for the study was very discouraging. Having access to people, and organizations, was otherwise limited, giving the time differences and tight-scheduled activities. However the use of progressive approach of reminding the subjects using any available means either through e-mails, LinkedIn, Facebook, Twitter or through phone calls helped to address this problem.

- Very few of the participants had little exposure to AHP quantitative-based decision-making process. Though they found the process a bit daunting, they were somewhat comfortable with the idea of ranking preferences, as they were used to considering the choice for alternatives based on unquantified methods, but without assigning personal values to criteria. Prior help manual sent to participants before embarking on expert evaluation survey helped to reduce the complexities associated with the MCDM technique adopted.

\subsection{Potential Areas for Further Studies}

Several areas were identified as potential areas for further research as itemised below:

- Although not demonstrated in this system but it is also possible that potential researchers can redesign or customize the database to best fit the needs of any particular region or could be extended to select materials for commercial development;

- While the findings of this research focused specifically on a subset of design and building professionals involved with public residential housing sector projects, the overall approach used here could be tested in other contexts to determine its generalizability and applicability.

\section{Acknowledgements}

This work was made possible through private funding, and was partially supported by a discount from the Journal of Building Construction and Planning Research Doctoral Research Student Discount Scheme program.

\section{REFERENCES}

[1] IEA (International Energy Agency), "Energy Efficiency Requirements in Building Codes, Energy Efficiency Policies for New Buildings," OECD/IEA, Paris, 2008.

[2] IEA (International Energy Agency), "IEA Net Zero Energy," Montreal, 2009.

[3] World Bank, "Nigeria: State Building, Sustaining Growth, and Reducing Poverty. A Country Economic Report," Report 29551-NG, Poverty Reduction and Economic Management Sector Unit, West Africa Region, Washington DC, 2010

[4] UN-HABITAT, "Global Campaign on Urban Governance," Oxford University Press, New York, 2011.

http://www.unhabitat.org.

[5] United Nations Development Plan (UNDP), "African Economic Outlook 2011: Africa and Its Emerging Partners," African Development Bank, OECD, UNDP and UNECA, 2011.

[6] United States Department of Energy (USDOE), "Energy Efficiency and Renewable Energy," Federal Energy Management Program, 2010, pp. 1-34.

[7] United States Department of Energy, "About the Weatherization Assistance Program," Washington DC, 2010. http://www1.eere.energy. gov/wip/wap.html

[8] J. Kennedy, "Building without Borders: Sustainable Construction for the Global Village," New Society Publishers, Gabriola, 2004.

[9] M. Shuman, "The Small-Mart Revolution: How Local Businesses Are Beating the Global Competition," BerrettKoehler Publishers, San Francisco, 2008.

[10] Y. Oruwari, M. Jev and P. Owei, "Acquisition of Technological Capability in Africa: A Case Study of Indigenous Building Materials Firms in Nigeria," ATPS Working Paper Series No. 33, African Technology Policy Studies Network, Nairobi, 2002.

[11] K. K. Ashraf, "This Is Not a Building! Hand-Making a School in a Bangladeshi Village," Architectural Design, Vol. 77, No. 6, 2007, pp. 114-117. http://dx.doi.org/10.1002/ad.575

[12] C. C. Zhou, G. F. Yin and X. B. Hu, "Multi-Objective Optimization of Material Selection for Sustainable Products: Artificial Neural Networks and Genetic Algorithm Approach," Materials \& Design, Vol. 30, No. 4, 2009, pp. 1209-1215.

http://dx.doi.org/10.1016/j.matdes.2008.06.006

[13] P. Zhou, B. W. Ang and D. Q. Zhou, "Weighting and Aggregation in Composite Indicator Construction: A Multiplicative Optimization Approach," Social Indicator Research, Vol. 96, No. 1, 2010, pp. 169-181. http://dx.doi.org/10.1007/s11205-009-9472-3

[14] G. Seyfang, "Community Action for Sustainable Housing: Building a Low Carbon Future," Energy Policy, Vol. 38, No. 12, 2010, pp. 7624-7633. 
http://dx.doi.org/10.1016/j.enpol.2009.10.027

[15] M. Malanca, "Green Building Rating Tools in Africa," In: Conference on Promoting Green Building Rating in Africa, Green Building Africa, Nairobi, 4-6 May 2010, pp. 16-25.

[16] L. Wastiels, I. Wouters and J. Lindekens, "Material Knowledge for Design: The Architect's Vocabulary, Emerging Trends in Design Research," International Association of Societies of Design Research (IASDR) Conference, Hong Kong, 16-19 July 2007.

[17] M. C. Quinones, "Decision Support System For Building Construction Product Selection Using Life-Cycle Management," A Thesis Presented to the Academic Faculty in Partial Fulfillment of the Requirements for the Degree Master of Science in Building Construction and Facility Management, Georgia Institute of Technology, Atlanta, 2011.

[18] W. B. Trusty, "Incorporating LCA in Green Building Rating Systems," Air \& Waste Management Association, Ottawa, 2009.

[19] W. B. Trusty, "Sustainable Building: A Materials Perspective," Prepared for Canada Mortgage and Housing Corporation Continuing Education Series for Architects, 2003.

[20] W. B. Trusty, "Understanding the Green Building Toolkit: Picking the Right Tool for the Job," Proceedings of the USGBC Greenbuild Conference \& Expo, Pittsburgh, 2003.

[21] W. B. Trusty, J. K. Meril and G. A. Norris, "ATHENA: A LCA Decision Support Tool for the Building Community," Proceedings: Green Building Challenge '98-An International Conference on the Performance Assessment of Buildings, Vancouver, 26-28 October 1998, p. 8.

[22] T. Woolley, "Natural Building: A Guide to Materials and Techniques," The Crowood Press Ltd, Ramsbury, Marlborough, Wiltshire, 2006.

[23] United States Green Building Council (USGBC), "LEEDLeadership in Energy and Environmental Design: Pilot Credit Library: Pilot Credit 1-Life Cycle Assessment of Building Assemblies and Materials," US Green Building Council, 2010.

[24] L. Florez, D. Castro and J. Irizarry, "Impact of Sustainability Perceptions on Optimal Material Selection in Construction Projects," Proceedings of the Second International Conference on Sustainable Construction Materials and Technologies, University Politecnica delle Marche, Ancona, Italy, Coventry University and The University of Wisconsin Milwaukee Centre for By-products Utilization, 28-30 June 2010, pp. 719-727.

http://www.claisse.info/Proceedings.htm,

[25] L. Florez, D. Castro-Lacouture and J. Irizarry, "Impact of Sustainability Perceptions on the Purchasability of Materials in Construction Projects," Proceedings of the 2009 ASCE Construction Research Congress, Banff, 8-10 May 2010, pp. 226-235

[26] D. Castro-Lacouture, J. A. Sefair, L. Florez and A. L. Medaglia, "Optimization Model for the Selection of Materials Using the LEED Green Building Rating System," Proceedings of the 2009 ASCE Construction Research Congress, Seattle, Washington, 5-7 April 2009, pp. 608617.
[27] E. Keysar and A. Pearce, "Decision Support Tools for Green Building: Facilitating Selection among New Adopters on Public Sector-Projects," Journal of Green Building, Vol. 2, No. 3, 2007, pp. 153-171. http://dx.doi.org/10.3992/igb.2.3.153

[28] C. Bayer, M. Gamble, R. Gentry and S. Joshi, "AIA Guide to Building Life Cycle Assessment in Practice," The American Institute of Architects, Washington DC, 2010.

[29] ATHENA Institute, "The Impact Estimator for Buildings," 2011. http://athenasmi.org/tools/impactEstimator/

[30] ATHENA Institute, "The EcoCalculator for Buildings," 2011. http://athenasmi.org/tools/ecoCalculator/index.html

[31] Z. Kapelan, D. Savic and G. Walters, "Decision-Suppport Tools for Sustainable Urban Development," Proceedings of the Institution of Civil Engineers, Engineering Sustainability, Vol. 158, No. 3, 2005, pp. 135-142.

[32] S. Rahman, S. Perera, H. Odeyinka and Y. Bi, "A Knowledge-Based Decision Support System for Roofing Materials selection and Cost Estimating: A Conceptual Framework and Catamodelling," 25th Annual ARCOM Conference, Nottingham, 7-9 September 2009, pp. 1-10.

[33] S. Rahman, S. Perera, H. Odeyinka and Y. Bi, "A Conceptual Knowledge-Based Cost Model for Optimising the Selection of Material and Technology for Building Design," In: A. R. J. Dainty, Ed, 24th Annual ARCOM Conference, Association of Researchers in Construction Management, University of Glamorgan, 1-3 September 2008, pp. 217-225.

[34] E. Loh, T. Crosbie, N. Dawood and J. Dean, "A Framework and Decision Support System to Increase Building Life Cycle Energy Performance," Journal of Information Technology in Construction, Vol. 15, No. 2, 2010, pp. 337-353.

[35] G. K. C. Ding, "Sustainable Construction: The Role of Environmental Assessment Tools," Journal of Environmental Management, Vol. 86, No. 3, 2008, pp. 451-464. http://dx.doi.org/10.1016/j.jenvman.2006.12.025

[36] C. Hopfe, C. Struck, et al., "Exploration of Using Building Performance Simulation Tools for Conceptual Building Design," IBPSA-NVL Conference, Delft, 20 October 2005, pp. 1-8.

[37] R. S. Perera and U. Fernando, "Cost Modelling for Roofing Material Selection," Built Environment: Srilanka, Vol. 3, No. 1, 2002, pp. 11-24.

[38] A. Mohamed and T. Celik, "An Integrated KnowledgeBased System for Alternative Design and Materials Selection and Cost Estimating," Expert Systems with Applications, Vol. 14, No. 3, 1998, pp. 329-339. http://dx.doi.org/10.1016/S0957-4174(97)00086-9

[39] M. A. A. Mahmoud, M. Aref and A. Al-Hammad, "An Expert System for Evaluation and Selection of Floor Finishing Materials," Expert Systems with Applications, Vol. 10, No. 2, 1996, pp. 281-303. http://dx.doi.org/10.1016/0957-4174(95)00054-2

[40] K. Lam and N. Wong, "A study of the Use of Performance Based Simulation Tools for Building Design and Evaluation in Singapore," IBPSA, Kyoto, 1999.

[41] J. L. Chen, S. H. Sun and W. C. Hwang, "An Intelligent 
Data Base System for Composite Material Selection in Structural Design," Engineering Fracture Mechanics, Vol. 50, No. 5-6, 1995, pp. 935-946. http://dx.doi.org/10.1016/0013-7944(94)E0068-R

[42] G. Soronis, "An Approach to the Selection of Roofing Materials for Durability," Construction and Building Materials, Vol. 6, No. 1, 1992, pp. 9-14.

[43] I. Giorgetti and A. Lovell, "Sustainable Building Practices for Low Cost Housing: Implications for Climate Change Mitigation and Adaptation in Developing Countries," Giorgetti and Lovell, South Africa, 2010.

[44] R. Ellis, "Who Pays for Green Buildings? The Economics of Sustainable Buildings," CB Richard Ellis and EMEA Research, New York, 2009.

[45] R. J. Cole, "Building Environmental Assessment Methods: Redefining Intentions and Roles," Building Research and Information, Vol. 35, No. 5, 2005, pp. 455-467.

[46] R. J. Cole, G. Lidnsey and J. A. Todd, "Assessing Life Cycles: Shifting from Green to Sustainable Design," Proceedings: International Conference Sustainable Building, Rotterdam, 22-25 October 2000, pp. 22-24.

[47] R. K. Yin, "Case Study Research: Design and Methods," 4th Edition, Sage Publications, Los Angeles, 2009.

[48] B. Reza, R. Sadiq and K. Hewage, "Sustainability Assessment of Flooring Systems in the City of Tehran: An AHPBased Life Cycle Analysis," Construction and Building Materials, Vol. 25, No. 4, 2011, pp. 2053-2066.

[49] D. K. H. Chua, Y. C. Kog and P. K. Loh, "Critical Success Factors for Different Project Objectives," Journal of Construction Engineering and Management, Vol. 125, No. 3, 1999, pp. 142-150. http://dx.doi.org/10.1061/(ASCE)0733-9364(1999)125:3( $\underline{142)}$

[50] T. L. Saaty, "Relative Measurement and Its Generalization in Decision Making Why Pairwise Comparisons Are Central in Mathematics for the Measurement of Intangible Factors the Analytic Hierarchy/Network Process," RACSAMRevista de la Real Academia de Ciencias Exactas, Fisicas y Naturales. Serie A. Matematicas, Vol. 102, No. 2, 2008,

\section{APPENDIX A: Feedbacks from Evaluators}

The following are feedbacks and suggestions retrieved from users on the MSDS tool. The names of the participants were undisclosed to respect their anonymity.

"The system relates to issues concerned with local knowledge, local materials data, local climate know-how, local experts needed to operate system, which are hardly considered in other systems". I think it shows great promise and the mechanics are very well-developed and user-friendly,

"Material costs vary from location to location (especially in the USA where material costs vary not just from state to state but also from city to city". Perhaps when the material selection is sorted by the element choice, pp. 251-318.

[51] T. L. Saaty, "Time Dependent Decision-Making; Dynamic Priorities in the AHP/ANP: Generalizing From Points to Functions and from Real to Complex Variables," Mathematical and Computer Modelling, Vol. 46, No. 7-8, 2007, pp. 860-891

[52] T. L. Saaty, "Decision Making for Leaders: The Analytic Hierarchy Process for Decisions in a Complex World," RWS Publications, Pittsburgh, 2001.

[53] T. L. Saaty, "Fundamentals of the Analytic Hierarchy Process," RWS Publications, Pittsburgh, 2000.

[54] T. L. Saaty, "Fundamentals of Decision Making and Priority Theory with the Analytic Hierarchy Process," RWS Publishers, Pittsburgh, 1994.

[55] T. L. Saaty, "The Analytic Hierarchy Process," McGrawHill, New York, 1980.

[56] J. A. Alonso and M. T. Lamata, "Consistency in the Analytic Hierarchy Process: A New Approach," International Journal of Uncertainty, Fuzziness and KnowledgeBased Systems, Vol. 14, No. 4, 2006, pp. 445-459. http://dx.doi.org/10.1142/S0218488506004114

[57] P. Gluch and H. Baumann, "The Life Cycle Costing (LCC) Approach: A Conceptual Discussion of its Usefulness for Environmental Decision Making," Building and Environment, Vol. 39, No. 5, 2004, pp. 571-580. http://dx.doi.org/10.1016/j.buildenv.2003.10.008

[58] C. J. Kibert, "Sustainable Construction: Green Building Design and Delivery," 2nd Edition, John Wiley and Sons, Inc., Hoboken, 2008.

[59] R. Spiegel and D. Meadows, "Green Building Materials: A Guide to Product Selection and Specification," John Wiley \& Sons, Inc., New York, 2010, pp. 1-7.

[60] M. F. Ashby and K. Johnson, "Materials and Design: The Art and Science of Material Selection in Product Design," Butterworth-Heinemann, Oxford, Boston, 2002.

[61] J. F. Hair, R. E. Anderson, R. L. Tatham and W. C. Black, "Multivariate Data Analysis," Prentice Hall, Upper Saddle River, 1998.

this will seem more useful".

"It depends on what resources you are referring to; if referring to the underlying database, those are considerable. If referring to the resource needs of the organization that would use the model, not too costly to operate".

"The interface is very well-designed and easy to navigate. However, there is a need for more explanatory material to allow the user to understand what s/he is actually doing, and how to operate some parts of the model appropriately".

"In terms of its operation, interoperability, flexibility, usability and applicability, per se, it is very clear and straightforward; it's the underlying premise and data that needs little clarification in order for the user to operate the model effectively. 